\title{
NONLINEAR RESPONSE OF CONCRETE GRAVITY DAMS TO STRONG EARTHQUAKE-INDUCED GROUND MOTION
}

\author{
by \\ Paul F. Mlakar \\ JAYCOR \\ 2732 Washington Street \\ Vicksburg, Mississippi 39180
}

BOOKS ARE ACCOUNTABLE PROPERTY CHARGED

TO AN IRDIVIDUAL BY NAME. PLEASE DO

NOT LEND TO OTHERS WITHOUT CLEARING YOURSELF.

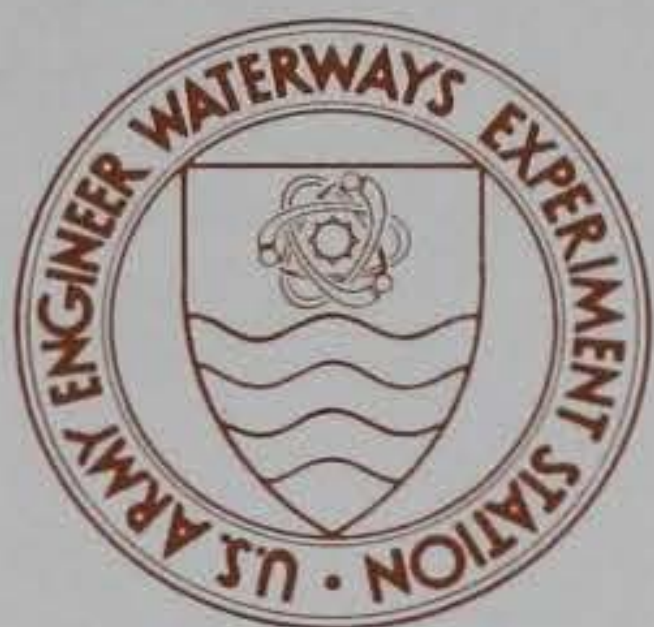

March 1987

Final Report

Approved For Public Release; Distribution Unlimited

\section{Library Branch Technical Information Center
U.S. Army Engineer Waterways Exporiment Station Vicksburg, Mississippi}

Monitored by Structures Laboratory

US Army Engineer Waterways Experiment Station PO Box 631, Vicksburg, Mississippi 39180-0631

Under Contract No. DACW39-85-M-4964

Prepared for DEPARTMENT OF THE ARMY

US Army Corps of Engineers

Washington, DC 20314-1000
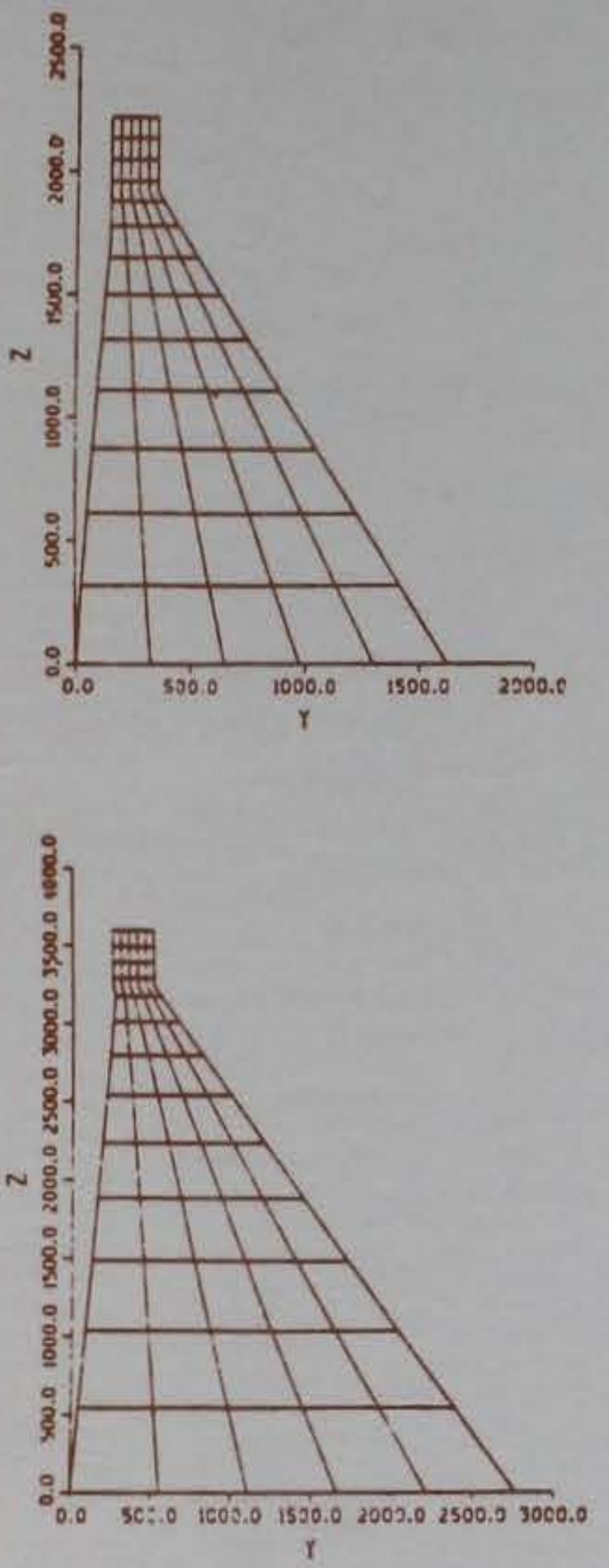

की एᄄㅐㅈㅔ LABORATORY 


\section{REPORT DOCUMENTATION PAGE}

\begin{tabular}{|c|c|c|c|c|}
\hline \multicolumn{2}{|l|}{$\begin{array}{l}\text { 1a. REPORT SECURITY CLASSIFICATION } \\
\text { Unclassified }\end{array}$} & \multicolumn{3}{|l|}{ 16. RESTRICTIVẸ MARKINGS } \\
\hline \multicolumn{2}{|l|}{ 2a. SECURITY CLASSIFICATION AUTHORITY } & \multirow{2}{*}{\multicolumn{3}{|c|}{ 3. DISTRIBUTIONIAVAILABILITY OF REPORT }} \\
\hline \multicolumn{2}{|c|}{ 2b. DECLASSIFICATIONIDOWNGRADING SCHEDULE } & & & \\
\hline \multicolumn{2}{|c|}{ 4. PERFORMING ORGANIZATION REPORT NUMBER(S) } & \multicolumn{3}{|c|}{$\begin{array}{l}\text { 5. MONITORING ORGANIZATION REPORT NUMBER(S) } \\
\text { Technical Report SL-87-7 }\end{array}$} \\
\hline \multicolumn{2}{|c|}{$\begin{array}{l}\begin{array}{l}\text { 6. NAME OF PERFORMING ORGANIZATION } \\
\text { JAYCOR }\end{array} \\
\begin{array}{c}\text { 6b. OFFICE SYMBOL } \\
\text { (If apolicabla) }\end{array}\end{array}$} & \multicolumn{3}{|c|}{$\begin{array}{l}\text { 7a. NAME OF MONITORING ORGANIZATION } \\
\text { USAEWES } \\
\text { Structures Laboratory }\end{array}$} \\
\hline \multicolumn{2}{|l|}{$\begin{array}{l}2732 \text { Washington Street } \\
\text { Vicksburg, MS } 39180\end{array}$} & \multicolumn{3}{|c|}{$\begin{array}{l}\text { P0 Box } 631 \\
\text { Vicksburg, MS } 39180-0631\end{array}$} \\
\hline $\begin{array}{l}\text { 8a. NAME OF FUNDING/SPONSORING } \\
\text { ORGANIZATION } \\
\text { US Army COrps of Engineers }\end{array}$ & $\begin{array}{l}\text { 8b. OFFICE SYMBOL } \\
\text { (if applicable) }\end{array}$ & \multicolumn{3}{|c|}{ 9. PROCUREMENT INSTRUMENT IDENTIFICATION NUMBER } \\
\hline \multicolumn{2}{|l|}{ 8c. ADDRESS (City, State, and ZIP Cook) } & \multicolumn{3}{|c|}{ 10. SOURCE OF FUNDING NUMBERS See reverse. } \\
\hline Washington, DC 20314-1000 & & \begin{tabular}{l|l} 
PROGRAM & PROJECT \\
ELEMENT NO. & NO.
\end{tabular} & $\begin{array}{l}\text { TASK } \\
\text { NO. }\end{array}$ & $\begin{array}{l}\text { WORK UNIT } \\
\text { ACCESSION NO. }\end{array}$ \\
\hline \multicolumn{5}{|l|}{$\begin{array}{l}\text { 11. TITLE (Include Security Classification) } \\
\text { Nonlinear Response of Concr }\end{array}$} \\
\hline \multicolumn{5}{|l|}{$\begin{array}{l}\text { 12. PERSONAL AUTHOR(S) } \\
\text { M1akar, Pau1 F. }\end{array}$} \\
\hline $\begin{array}{l}\text { 13a. TYPE OF REPORT } \\
\text { Final report }\end{array}$ & OVERED & $\begin{array}{l}\text { 14. DATE OF REPORT (Year, } \\
\text { March } 1987\end{array}$ & Day) & COUNT \\
\hline
\end{tabular}

\section{SUPPLEMENTARY NOTATION}

Available from National Technical Information Service, 5285 Port Royal Road, Springfield, VA 22161.

\begin{tabular}{|c|c|c|}
\hline 17. & \multicolumn{3}{|c|}{ COSATI CODES } \\
\hline FIELD & GROUP & SUB-GROUP \\
\hline & & \\
\hline & & \\
\hline
\end{tabular}

18. SUBJECT TERMS (Continue on reverse if necessary and identify by block number) Concrete dams (LC) Dams--Earthquake effects Finite element method (LC)

\section{ABSTRACT (Continue on reverse if necessary and identify by block number)}

This report documents an investigation of the behavior of concrete gravity dams subjected to earthquake motions of sufficient strength to induce cracking. Nonlinear, dynamic, finite element analyses of three dams subjected to the Parkfield earthquake motion are conducted with the ADINA84 code. In the analyses the essential characteristics of static preloading, bidirectional seismic motion, dynamic concrete cracking, and hydrodynamic interaction are modeled. The results show that cracked zones can propogate through the cross sections at various elevations. The US Army Corps of Engineers' guidance for seismic evaluation of gravity dams compares conservatively to these results but incorrectly locates the elevation of cracking through the section in some cases. A procedure to estimate the relative permanent displacement across such cracked sections is developed using the sliding block analysis. Recommendations for further research to improve the guidance for seismic safety evaluation of concrete gravity dams are made.

\section{DISTRIBUTION/AVAILABILITY OF ABSTRACT DUNCLASSIFIEDNNLIMITED $\square$ SAME AS RPT. 22a. NAME OF RESPONSIBLE INDIVIDUAL}

\section{ABSTRACT SECURITY CLASSIFICATION} Unclassified \begin{tabular}{l|l} 
22b. TELEPHONE (Include Area Code) & 22c. OFFICE SYMBOL
\end{tabular}
DD FORM 1473,84 MAR
83 APR edition may be used until exhausted. All other editions are obsolete.
SECURITY CLASSIFICATION OF THIS PAGE

Unclassified 
Inclassified

STCUNITY CLAREIPICA TION OP THIS PAES

10. SOURCE OF FUNDING NUMBERS (Continued).

Contract No. DACW39-85-M-4964.

Unclassified 


\section{PREFACE}

The study reported herein was conducted by JAYCOR for the Structural Mechanics Division (SMD), Structures Laboratory (SL), US Army Engineer Waterways Experiment Station (WES), under Contract No. DACW39-85-M-4964. Mr. Vincent P. Chiarito, SMD, was the WES Technical Monitor. Valuable discussions were also held with Messrs. Robert E. Walker, Robert A. Cole, R. Stephen Wright, C. Dean Norman, and Richard L. Stowe, SL, and Mr. Lucian Guthrie, Headquarters, US Army Corps of Engineers.

During the conduct of this work, Dr. Jimmy P. Balsara was Chief, SMD, and Mr. Bryant Mather was Chief, SL.

COL Allen F. Grum, USA, was the previous Director of WES. The present Commander and Director is COL Dwayne G. Lee, CE. The Technical Director is Dr. Robert W. Whalin. 
PREFACE . . . . . . . . . . . . . . . . . . . . . . . . . . . . 1

CONVERSION FACTORS, NON-SI TO SI (METRIC) UNITS OF MEASUREMENT • • • • 3

PART I: INTRODUCTION . . . . . . . . . . . . . . . . . 4

PART II: ADINA ANALYSES .................... . . . 6

PART III: EVALUATION OF ETL 1110-2-303................ 11

Russe11 Dam .......................... 11

Russell Dam with Tripled Parkfield Loading . . . . . . . . . 12

Standard Dam ........................ . 12

Dworshak Dam ........................ 13

Discussion ........................ 13

Summary . . . . . . . . . . . . . . . . . . 14

PART IV: PERMANENT DISPLACEMENTS . . . . . . . . . . . . . . . 15

PART V: CONCLUDING REMARKS . . . . . . . . . . . . . . . . . 20

PART VI: RECOMMENDATIONS FOR FURTHER STUDY . . . . . . . . . . . . . 21

REFERENCES . . . . . . . . . . . . . . . . . . . . . . 22

TABLES $1-6$

FIGURES $1-24$ 


\section{CONVERSION FACTORS, NON-SI TO SI (METRIC) \\ UNITS OF MEASUREMENT}

Non-SI units of measurement used in this report can be converted to SI (metric) units as follows:

\section{Multiply}

degrees (angle)

feet

gallons (US 1iquid)

inches

kips (force)

kips (force) per square inch

megatons (nuclear equivalent of TNT)

pounds (force) per square inch

pounds (mass)

pounds (mass) per cubic foot
By

$$
0.01745329
$$

0.3048

3.785412

25.4

4.448222

6.894757

4.184

6.894757

0.4535924

16.01846
To Obtain

radians

metres

cubic decimetres

(1itres)

millimetres

kilonewtons

megapascals

petajoules

kilopascals

kilograms

kilograms per cubic metre 


\section{PART I: INTRODUCTION}

1. The Corps of Engineers (CE) has recently published (Department of the Army (DA) 1985) criteria and guidance for assessing the seismic resistance of concrete gravity dams. This publication reflects the products of research conducted by the $\mathrm{CE}$ and others during the last decade and thus represents the most up-to-date information now avallable. In contrast to the static selsmic coefficient method of analysis previously used (DA 1960) the new guidance considers the dynamic properties of the dam, the local seismicity of the site and, to some extent, the interaction among the dam, reservoir and foundation. However, the procedure reproduced in Figure 1 to estimate the extent and significance of cracking experienced during extreme ground shaking is admittedly interim and lacking in extensive justification.

2. The objective of the research described herein is to confirm or appropriately modify the sequence of analysis in Figure 1. It specifically encompassed the following contractual tasks:

a. Perform nonlinear analyses on three (3) given nonoverflow gravity dam cross sections, using a sufficient number of strong earthquake ground motion records to bracket the frequency range of significant dynamic response for the gravity dam sections. The results from these analyses will be used to estimate the extent of cracking possible and any permanent displacements likely to occur along weak planes in the foundation, at the dam-foundation interface or within the dam cross section in areas of maximum cracking.

b. Evaluate the interim procedure contained in ETL 1110-2-303, paragraphs 6 and 7 , pages 1-8 through 1-11, for analyzing the response of a gravity dam to a maximum credible earthquake and evaluating the results of the analysis, and recommend improvements based upon the nonlinear analyses performed, as described in a above.

c. Develop a simplified method of analysis to estimate upper bounds for permanent displacements due to vibratory ground motion in the foundation, at the dam-foundation interface, and within the dam cross section without resorting to multiple acceleration time-history analyses. 
3. The remainder of this report confirms and modifies the evaluation procedure of Figure 1. Sections 2 through 4 describe our work in accordance with the foregoing tasks. In Section 5 we summarize our conclusions and we present our recommendations in Section 6 . 
4. The nonlinear analyses of gravity dam response to seismic motion were performed using the general-purpose finite element code ADINA (ADINA Engineering 1984). The cross section of each structure was modeled using 9-node, isoparametric, quadrilateral, plane stress elements of unit thickness. The discretization of the finite element meshes corresponded to SUBROUTINE INPUTG of Cole and Cheek (1985) wherein this degree of resolution was found to adequately reproduce the stress distributions within gravity dams.

5. The constitutive behavior of the concrete of the dams was described with the ADINA concrete material model (Bathe and Ramaswamy 1979). For the static and the seismic loadings imposed, this description provided an essentially linear behavior in compression and a linear behavior in tension up to the stress level at which cracking occurred as seen in Figure 2 . When this level of stress was reached, spatial zones of cracked material were defined. In these zones the tensile stiffness across the cracked surface was reduced to zero and the shear stiffness was reduced to half the uncracked value. The effects of strain rate on material behavior were approximated as follows. First, the static stiffness and strength were related through (American Concrete Institute 1977):

$$
E_{c}=33 w^{1.5} \sqrt{f_{c}^{\prime}}
$$

in which:

$E_{c}=$ Initial modulus of elasticity, psi.

$f_{c}^{\prime}=$ Uniaxial compressive strength, psi.

$\mathrm{w}=$ Unit weight, $150 \mathrm{pcf}$.

Next, the static uniaxial tensile strength in psi, $f_{t}$, was found from (Raphael 1982):

$$
\mathrm{f}_{\mathrm{t}}=1.7 \mathrm{f}_{\mathrm{c}}^{\prime 2 / 3}
$$


Static uniaxial ultimate compressive stresses $f_{u}$ were estimated from typical stress-strain curves corresponding to $f_{c}^{\prime}$ (Winter and Nilson 1979). In accordance with recent dynamic biaxial test (Mlakar, Vitaya-Udom, and Cole 1984), a dynamic strength amplification was estimated from:

$$
A=1-0.02503 \ln \frac{t_{r}}{600000}
$$

in which one fourth of the dam's fundamental period was substituted for the rise time of loading in $\mathrm{msec}, t_{r}$. The constant strength parameters used in the ADINA calculations were then:

$$
\begin{aligned}
& \tilde{\sigma}_{t}=A f_{t} \\
& \tilde{\sigma}_{c}=A f_{c}^{\prime} \\
& \tilde{\sigma}_{u}=A f_{u}
\end{aligned}
$$

in which:

$$
\begin{aligned}
& \tilde{\sigma}_{t}=\text { Uniaxial cut off tensile stress. } \\
& \tilde{\sigma}_{c}=\text { Uniaxial maximum compressive stress. } \\
& \tilde{\sigma}_{u}=\text { Uniaxial ultimate compressive stress. }
\end{aligned}
$$

The uniaxial compressive strain $\tilde{e}_{c}$ corresponding to $\tilde{\sigma}_{c}$ and the uniaxial ultimate compressive strain $\tilde{e}_{u}$ were estimated from the static stress-strain curves corresponding to $f_{c}^{\prime}$ (Winter and Nilson 1979). This is supported by the finding of Mlakar, Vitaya-Udom, and Cole (1984) that the strain at concrete failure is independent of rate effects. Finally, the tangent modulus at zero strain $\tilde{\mathrm{E}}_{\mathrm{O}}$ was approximated to be

$$
\tilde{E}_{0}=\sqrt{A} E_{c}
$$

for consistency with the foregoing. The numerical values of these material parameters input to ADINA are listed for each dam in Table 1. In each case, a Poisson's ratio of 0.2 was used. 
6. In the nonlinear analysis, both static and seismic loadings were considered. The self-weight of the cross section was applied as a mass proportional body force. The hydrostatic loading of the reservoir was accomplished through a set of pressure loadings along the upstream surface of the structure. Both of these loadings were linearly increased from zero initially to their full static value in a rise time of $2 \mathrm{sec}$. This rise time was selected to achieve equilibrium under the static loading prior to the arrival of the strong earthquake motion. The horizontal and the vertical earthquake loading were applied as uniformly prescribed displacements along the base of the dams. Finally, the hydrodynamic loading of the reservoir was approximated by adding concentrated nodal masses on the upstream face corresponding to the distribution (Chopra 1978)

$$
\mathrm{m}_{\mathrm{a}}(\mathrm{z})=\frac{\overline{\mathrm{p}}_{1}\left(\mathrm{z}, \tilde{\omega}_{\mathrm{s}}\right)}{\psi(\mathrm{z})}
$$

in which:

$z$ = Vertical coordinate.

$\mathbf{g} \overline{\mathrm{p}}_{1}=$ Hydrodynamic pressure in fundamental mode.

$\tilde{\omega}_{s}=$ Fundamental frequency including hydrodynamic effects.

$\psi=$ Fundamental mode shape.

$g$ = Acceleration of gravity.

7. The foregoing constitutes a problem which is both materially nonlinear and dynamic. It was solved through implicit integration with respect to time using the trapezoidal rule with a step of $0.02 \mathrm{sec}$. This value was the sampling interval of the recorded earthquake loadings and is thus presumably small enough to describe the energy of the ground motion. Consequently, the response of structures to this excitation is also adequately represented with this step. The BFGS matrix update method (Bathe 1982 ) was employed to iteratively solve the equilibrium equations with an energy convergence criteria. Stiffness reformation and equilibrium iteration were performed in each time step.

8. Three dams were analyzed in this study. They were selected to characterize that segment of the Corps' population of such structures which is of the greatest seismic interest. Two actual projects and a standard 
cross section representative of other structures are included. The three structures considered are a subset of those linearly analyzed in Cole and Cheek (1985) so as to facilitate direct comparisons with this work. The geometric parameters describing these structures are compared in Table 2 .

9. The shortest structure is the Richard B. Russell Dam of the Savannah District. This project is $185 \mathrm{ft}$ tall and has a modulus of elasticity equal to $3 \mathrm{million}$ psi. This dam was included because a number of previous studies have been conducted on it (Norman 1979) (Norman and Stone 1979) (Chiarito and Mlakar 1983). The finite element grid used in the analysis is shown in Figure 3. It contains 65 elements and 297 nodes having 594 degrees of freedom in all.

10. The second structure is a "standard" dam having a horizontal foundation, a near vertical upstream face, a rectangular crown and a downstream face with a slope of 10 on 12 as seen in Figure 4 . The structural height is $300 \mathrm{ft}$ which is approximately the ninetieth percentile of the Corps' population. Computations were made using a modulus of concrete of 3 million psi which is representative of Corps' construction practice. The finite element mesh of this structure has 594 degress of freedom in all.

11. The tallest dam considered is the Dworshack Dam on the Clearwater River in Idaho. This structure is $638 \mathrm{ft} \mathrm{high,} \mathrm{and} \mathrm{is} \mathrm{made} \mathrm{of} \mathrm{concrete} \mathrm{with}$ an estimated 5 million psi modulus. It is included to be representative of the very tallest concrete dams owned by the CE. The finite element discretization of this dam has 80 elements, 363 nodes, 726 degress of freedom and is shown in Figure 5.

12. Preliminarily to the nonlinear analyses, the first four periods and mode shapes of each structure without reservoir effects were found. The results in Table 3 and Figures 6,7 and 8 are consistent with previous studies of gravity dam dynamics (Chopra and Chakrabarti 1971) (Norman 1979) (Norman and Stone 1979).

13. The earthquake loading, Figure 9, used in the analyses was the N65W and vertical components of the 1966 Parkfield, California earthquake recorded at Temblor No. 2 Station, CIT File Nos. B037-1 and B037-3. This loading is representative of strong earthquake motions likely to be encountered at rock sites upon which all CE concrete dams are founded. Table 4 lists three pertinent parameters of 22 earthquake recordings at such sites as 
tabulated by Lai (1980). Note that the peak ground acceleration $A_{m}$ of the selected loading is one of the greatest in Table 4, and thus most likely to significantly excite the nonlinear response of concrete dams. The parameter $\omega_{g}$ characterizes the ground frequency of the power spectral density function (Kanai 1961) (Tajimi 1960). Note in Figure 10 that this parameter is independent of the peak ground acceleration and that the value for the selected earthquake is representative of the entire set of records. The equivalent strong motion duration $S_{0}$, as defined by Vanmarcke and Lai (1980) is also listed in Table 4. In Figure 11, note that this parameter tends to decrease with increasing peak ground acceleration. The record selected is seen to be representative of the stronger recordings in this important respect. It should also be noted that the Parkfield loading chosen for this study is one of those used by Cole and Cheek (1985), and thereby facilitates direct comparison with their work.

14. In this section the structural geometry, material behavior, loading conditions and nonlinear solution scheme of the ADINA analyses have been described. The results of these calculations are presented in the following section. Therein, these results are also used to judge the structural evaluation procedure advocated in DA (1985). 
PART III: EVALUATION OF ETL 1110-2-303

15. In the previous section, we described the manner in which the ADINA finite element code was used to model the nonlinear response of concrete gravity dams to strong earthquake-induced ground motion. Herein, the results of these analyses are discussed and used to evaluate the Corps' criteria and guidance for assessing the seismic resistance of such structures (DA 1985). The remainder of this section is organized by each of the four dam-earthquake combinations which were analyzed.

\section{Russe11 Dam}

16. The first dam to be discussed is the Russell Dam. When it was subjected to the Parkfield motion with the ADINA mode1, no cracked zones propagated through any portion of the cross section. This case was thus of trivial nonlinear interest. It does, however, provide an interesting instance for the evaluation of ETL 1110-2-303.

17. The results of all four dam-earthquake analyses with the guidance of this ETL are summarized in Table 5 . Therein, $f_{0.05}, f_{0.07}$, and $f_{0.10}$ are the maximum stresses calculated with the simplified procedure (Cole and Cheek 1985) for 5, 7, and 10 percent of critical damping, respectively. The guidance, Figure 1, first prescribes an analysis with 5 percent damping. The combined maximum stress for Russell Dam is 640 ps 1 at the upstream edge of the base. As this exceeds $0.20 \mathrm{f}_{c}^{\prime}$, a reanalysis with 10 percent damping is performed. The maximum stress is reduced to $530 \mathrm{ps} 1$ at the upstream edge of the base. Since this value exceeds $0.10 \mathrm{f}_{c}^{\prime}$, a sliding stability analysis on the base plane is required.

18. In this case, the ETL guidance is conservative when judged by the ADINA results. The ETL requires a sliding stability analysis along a hypothetical cracked plane while the ADINA analyses indicates no propagation of cracked zones through the dam. There are two reasons for this difference. First, the response of this dam to the equivalent static loading of the ETL overestimates the dynamic response for this earthquake (Cole and Cheek 1985). Secondly, the tensile strength modeled in ADINA, $\tilde{\sigma}_{t}=380$ ps 1 in Table 1, accounts for some dynamic increase above the $0.15 \mathrm{f}_{c}^{\prime}$ of the ETL. 


\section{$\underline{\text { Russe11 Dam with Tripled Parkfield Loading }}$}

19. To obtain a significant nonlinear response in this structure, it was also subjected to a base motion of three times the amplitude of the recorded Parkfield Earthquake. In the ADINA analysis of this case, a cracked zone does propagate through the cross section. An indication of this propagation is obtained from Figure 12 which shows the total number of elemental integration points at which cracking has occurred as a function of time. Figure 13 shows the extent of the cracked zones at the key instants of time identified in Figure 12. No cracking occurs prior to the arrival of the strong ground shaking as one would expect. Cracking initiates near the upstream edge of the base and temporarily stabilizes until $3.84 \mathrm{sec}$. Thereafter, it propagates toward the downstream edge. Simultaneously, a cracked zone initiates near the change in upstream slope. This zone stabilizes while the one at the base propagates through the downstream face.

20. The analysis of this situation prescribed by the ETL is reported in the third column of Table 5. In this case, the ETL guidance leads to results which are consistent with the ADINA analysis in the essential features. The maximum stresses computed by the simplified method occur at the upstream edge of the base and the criteria require a sliding stability analysis along this horizontal plane. The more comprehensive ADINA analysis indicates cracking from the upstream face to the downstream face at this same elevation.

\section{Standard Dam}

21. The second structure to be considered is the $300-\mathrm{ft}-\mathrm{tall}$ Standard Dam. In the ADINA analysis with the recorded Parkfield motion, two cracked zones propagate through the cross section. The progression of cracking with time is shown in Figure 14 and the zones of cracking at critical times are presented in Figure 15. Note that a cracked zone initiates at the upstream edge of the base, propagates toward the downstream edge, but stabilizes before transecting the cross section. Subsequently, two cracked zones form on the downstream surface at the elevation of slope change and at a slightly lower elevation. These then quickly propagate to the upstream surface. 
22. The ETL analysis of the corresponding case is summarized in the fourth column of Table 5. In this case, the ETL guidance is in partial agreement with the ADINA mode1. The ETL procedure does indicate that this structure will crack through the cross section. However, the ETL procedure predicts this cracking to occur at the base while the ADINA model shows it to occur in the upper portion of the dam.

\section{Dworshak Dam}

23. The final dam considered is the 638-ft-tall Dworshak structure. In the ADINA analysis, a cracked zone transects the cross section at the elevation of change in downstream slope. The progression of cracking in time and space is shown in Figures 16 and 17. Cracking initiates at the upstream edge of the base and soon stabilizes. Later, a cracked zone propagates from the downstream face at the elevation of slope change and another propagates from a lower elevation on this face. The latter propagates toward a fourth zone which subsequently forms on the upstream face. However, the transection of the cross section occurs in the zone at the elevation of downstream slope change.

24. The ETL analysis of Dworshak Dam is summarized in the last column of Table 5. These results are partially consistent with those of the ADINA calculation. The ETL procedure indicates that cracking is expected through the base of the structure. The ADINA model also indicates cracking through the structure but near the elevation of change in downstream slope.

\section{Discussion}

25. When excited by an earthquake motion strong enough to initiate cracking, the dams considered cracked completely through their cross sections. This is consistent with limited scale model tests (Niwa and Clough 1980). It is noted here that in some cases the cracked zones grew through stable stages. In other cases, the cracking was virtually instantaneous once it began. The practical implication of this may be that dams which crack during an earthquake do crack completely through their cross section. 
However, further analytical and experimental study is required to support this conclusion in general.

26. The three dams considered cracked completely at various elevations. It is noted that the shortest structure cracked through its base while the taller ones cracked through the upper elevations. The elevation of complete cracking may be sensitive to the flexibility of the foundation which was not considered in this nonlinear analysis. However, a state-of-the-art linear analysis which included this feature (Fenves and Chopra 1984) Indicates that the maximum total stress occurs at the upstream edge of the base. This is the same location at which cracking initiated in each of the nonlinear analyses conducted herein.

27. The simple procedure of ETL 1110-2-303 conservatively evaluated the safety of each of the four dam-earthquake combinations considered comprehensively in this work. But in two cases, the simple linear procedure was misleading in that the elevation of cracking through the cross section differed from that observed in the nonlinear analysis. It is important that this elevation be correctly predicted so that a subsequent estimate of permanent displacement along the cracked plane is meaningful. This prediction requires that the inelastic behavior following initial cracking be incorporated in the evaluation procedure. This might be simply achieved with a static nonlinear resistance function and an inelastic response spectrum. Further study is suggested to revise the procedure in this way.

\section{Summary}

28. In this section we have discussed the results of ADINA analyses of four dam-earthquake combinations. The location and extent of cracking calculated by ADINA have further been used to evaluate the procedures recommended in ETL 1110-2-303. In the following section, a procedure is developed to estimate the permanent relative displacement likely to occur along cracks in these zones. 


\section{PART IV: PERMANENT DISPLACEMENTS}

29. In the foregoing section it was seen that extremely strong ground shaking can cause cracking through the cross section of a concrete gravity dam. In fact, this may have occurred at the Koyna Dam during the December 1967 earthquake (Chopra and Chakrabart1 1971). The Corps' analytical procedure for the maximum credible earthquake (Figure 1), requires an estimate of permanent displacement in such a case. A simple procedure for this estimation is developed and illustrated in this section.

30. In the proposed procedure, the cracked dam is idealized, as shown in Figure 18. The cracked surface is assumed to be planar and inclined at angle $\theta$ to the horizontal. The portion of the monolith above this crack is assumed to be a rigid body subject to sliding along the crack plane as the portion of the monolith below the crack moves horizontally due to the ground motion. This idealization resembles the sliding block analysis widely employed for earth embankments (Newmark 1965) (Sarma 1975) (Franklin and Chang 1977) (Hynes-Griffin and Franklin 1984) and should be no less applicable to the problem at hand.

31. The general application of the sliding block analyses has been facilitated by a recent probabilistic treatment (Lin and Whitman 1986). In Figure 19, the expected permanent displacement $D$ is presented as a function of peak base acceleration $A_{\max }$ and the limiting acceleration $A_{c} \cdot$ The result for rock sites is applicable as all CE gravity dams are so founded. Observe that no permanent displacement is expected if $A_{c}>A_{\max } \cdot$ For $A_{c}<A_{\max }$, the probability, $P$, of exceeding various displacement thresholds, $D_{0}$, can subsequently be obtained from Figure 20.

32. For the cracked gravity dam, the limiting acceleration $A_{c}$ at which sliding impends follows from equilibrium of Figure 18, wherein:

$\mathrm{W}=$ Welght of dam above crack.

$\mathrm{H}=$ Hydrostatic force on dam above crack.

$\mathrm{N}=$ Normal force across crack.

$\mathrm{F}=$ Frictional force along crack.

$A=$ Base horizontal acceleration. 
For a coefficient of friction $\mu$ and a gravitational acceleration $g$, the limiting value for downstream sliding is:

$$
\frac{A_{c}}{g}=\frac{\mu \cos \theta-\sin \theta}{\mu \sin \theta+\cos \theta}-\frac{H}{W}
$$

The limiting value corresponding to upstream sliding is given by:

$$
\frac{A_{c}}{g}=\frac{\mu \cos \theta+\sin \theta}{\cos \theta-\mu \sin \theta}+\frac{H}{W}
$$

and this may be more critical for small hydrostatic forces and cracks whose normal is inclined upstream (negative values of $\theta$ ). This is seen in the plot of limiting acceleration as a function of crack inclination in Figure 21 for $\mu=1.0$ and $H / W=0.1$. Observe that $A_{c}$ decreases for sharply inclined cracks. As $\mathrm{H} / \mathrm{W}$ increases, the upstream critical acceleration increases while the downstream value decreases from that shown. For increasing $\mu$, both upstream and downstream $A_{c}$ increase.

33. Some indication of an appropriate value of the frictional coefficient $\mu$ is obtained from direct shear tests of concrete and rock specimens which are summarized in Table 6. The values for the precut specimens undoubtedly underestimate the resistance provided by naturally cracked concrete. However, the consistency between precut concrete and rock frictional coefficients suggests that the coefficients for natural rock joints may also represent those for natural concrete cracks. From model tests on concrete gravity dams (Niwa and Clough 1980), we anticipate any earthquake-induced cracked surfaces to be relatively rough. From the limited information available, a value of $\mu=1.0$ is thus preliminarily proposed for use in the sliding block analysis. However, a further investigation of this important parameter may be desirable.

34. The peak base acceleration $A_{\max }$ should be chosen to reflect the amplification of ground motion at the level of cracking in the structure. The absolute acceleration $a$ at elevation $z$ and time $t$ is (Biggs 1964):

$$
a(z, t)=a_{g}(t)+\sum_{n=1}^{\infty} \Gamma_{n} \ddot{u}_{n}^{o}(t) \psi_{n}(z)
$$


wherein:

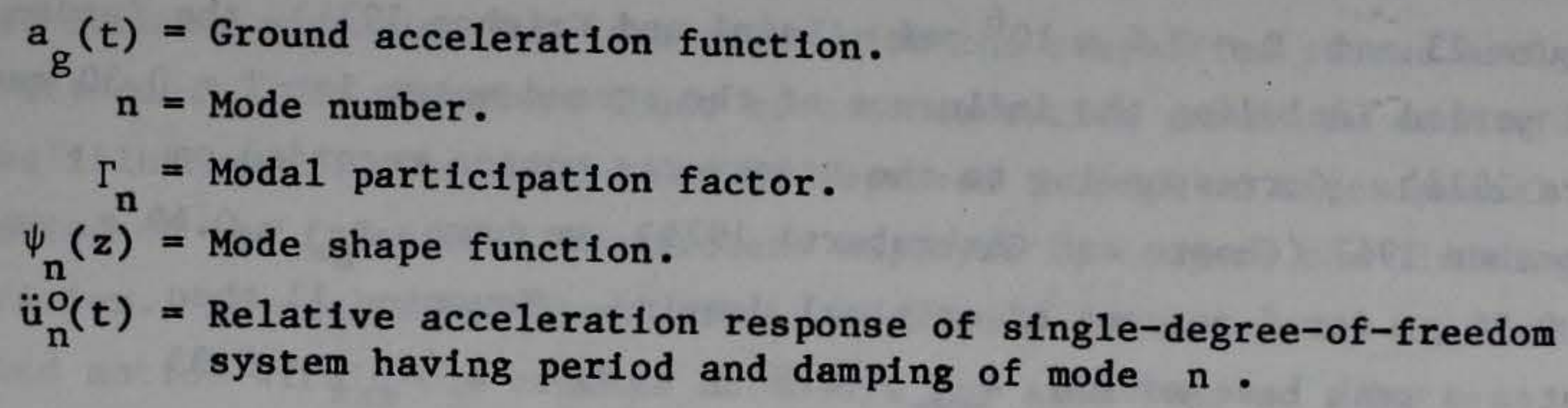

If only the first mode of vibration is considered, a reasonable root mean square estimate of peak base acceleration at the elevation of cracking is (Newmark and Rosenbleuth 1971):

$$
A_{\max }=\left[a_{g m}^{2}+\left(\Gamma_{1} s_{a 1} \psi_{1}(z)\right)^{2}\right]^{1 / 2}
$$

In which $a_{g m}$ is the maximum ground acceleration and $s_{a 1}$ is the ordinate of the psuedoacceleration response spectrum at the fundamental period corresponding to $a_{g}(t)$. Consistency with the simplified stress analysis of gravity dams (Chopra 1978) is achieved by taking $\Gamma_{1}=4$ and

$$
\begin{aligned}
\psi_{1}(\mathrm{z})= & -0.0002+0.1427\left(\frac{\mathrm{z}}{\mathrm{H}_{\mathrm{s}}}\right)+0.6683\left(\frac{\mathrm{z}}{\mathrm{H}_{\mathrm{S}}}\right)^{2} \\
& -0.8508\left(\frac{\mathrm{z}}{\mathrm{H}_{\mathrm{s}}}\right)^{3}+1.0399\left(\frac{\mathrm{z}}{\mathrm{H}_{\mathrm{s}}}\right)^{4}
\end{aligned}
$$

where $H_{s}$ is the structural height of the dam. The amplification of ground motion implied by Equation 12 is shown in Figure 22. Note that $A_{\max }$ increases with the elevation of cracking and with the spectral acceleration as one would expect.

35. To 1llustrate this procedure, let us examine the experience of the Koyna Dam during the strong 1967 earthquake. From the evidence of upstream and downstream surficial cracking (Chopra and Chakrabarti 1971), we assume a horizontal crack, as shown in Figure 23, where elevations are referenced in feet to the Koyna Reduced Level (KRL). For a concrete density of $1651 \mathrm{~b} / \mathrm{ft}^{3}$ 
(Saini and Krishna 1974), $\mathrm{H} / \mathrm{W}=0.19$. With $\mu=1.0$, Equation 9 then indicates the limiting acceleration to be $A_{c}=0.81 \mathrm{~g}$. For the geometry of Figure 23 and $E=3.6 \times 10^{6} \mathrm{psi}$ (Saini and Krishna 1974), the fundamental period including the influence of the stored water is $T=0.30 \mathrm{sec}$ (Chopra i978). Corresponding to the transverse motion recorded on

11 December 1967 (Chopra and Chakrabart1 1971), we have $a_{g m}=0.49 \mathrm{~g}$ and $\mathrm{S}_{\mathrm{a} 1}=0.56 \mathrm{~g}$ for 5 percent of critical damping. Equation 12 then estimates a peak base motion $A_{\max }=0.87 \mathrm{~g}$. For $A_{c} / A_{\max }=0.93$, Figure 19 implies an expected permanent displacement $D<0.1 \times 0.87=$ $0.087 \mathrm{~cm}$. As no offset in the cracked monoliths was observed following the 1967 earthquake, we gain confidence in the procedure developed herein. It is also noted that $A_{\max }=0.87 \mathrm{~g}$ estimated with Equation 12 compares favorably with $0.8 \mathrm{~g}$ calculated through numerical integration of the equations governing transverse vibration (Saini and Krishna 1974).

36. As a further application of the method, consider the Russell Dam subjected to the Parkfield Earthquake motion. As shown in Figure 24, we hypothetically assume that a horizontal crack occurs at the elevation of change in downstream slope where the stress is a local maximum in the simplified linear analysis (Cole and Cheek 1985). For the conditions shown, the limiting acceleration $A_{c}=0.95 \mathrm{~g}$ follows from Equation 8. Equation 12 indicates a peak acceleration $A_{\max }=1.77 \mathrm{~g}$. The expected permanent displacement $D=4.4 \mathrm{~cm}$ then follows from Figure 19. Figure 20 may be used to quantify the uncertainty in this estimate due to the randomness of ground motion. For example, an exceedance probability of $P=0.1$ corresponds to the permanent displacement $D_{0}=2.2 \times 4.4=9.8 \mathrm{~cm}$. This is a conditional probability given the values of limiting and peak accelerations. As considerable uncertainties exist with respect to $A_{c}$ and $A_{\max }$, the permanent displacement corresponding to an unconditional probability of exceedance may differ from that given by Figure 20. It should be noted that these displacements are conservative as the nonlinear analyses of the previous section did not indicate any cracking in the upper portion of this dam for the Parkfield motion.

37. The sliding block analysis can thus be applied to simply estimate the permanent displacements of gravity dams cracked by strong ground motion. 
In the analysis, the limiting acceleration is calculated from equilibrium of the monolith above the crack and the amplification of ground motion is computed from an approximation consistent with the simplified stress analysis of gravity dams. The procedure leads to a conservative result in each of the examples 11lustrated. The method may be improved through an experimental examination of the frictional coefficient employed to compute the limiting acceleration. An analytical study of the amplitude and frequency modulation of ground motion within the cracked structure may also lead to a better procedure. 
38. The funding for this contract permitted the investigation of a rather limited number of cases. Thus, broadly applicable conclusions are not supported by this study alone. However, the following observations can be made :

a. When excited by an earthquake motion of sufficient strength to initiate cracking, the three dams considered cracked completely through their cross sections. In some cases, this cracking progressed through stable stages and in others, it was virtually instantaneous.

b. The cracking through the dam cross sections occurred at the base, at the elevation of downstream slope change, and at a lower elevation. The shortest structure considered cracked through its base while the taller ones cracked through the upper elevations.

c. The recently published procedure of ETL 1110-2-303 conservatively evaluated the safety of the four cases considered. However, in two cases the simplified analysis procedure incorrectly located the elevation at which cracking occurs through the cross section.

d. The sliding block analysis is a rational basis to estimate the permanent relative displacements along cracked planes through a dam cross section. 


\section{PART VI: RECOMMENDATIONS FOR FURTHER STUDY}

39. The scope of this investigation was limited to first learn what might be achieved before undertaking a more comprehensive examination of the nonlinear response of concrete gravity dams to strong earthquake-induced ground motion. Based on the observations of the preceding section, the following specific recommendations for further investigation are offered:

a. Further dynamic, nonlinear, finite element analyses should be conducted of earthquake-loaded gravity dams to genralize the tentative observations about the location and the extent of cracking. In these analyses, additional earthquake motions recorded on rock should be used to excite the structure. Also, a simple model of the most essential effects of foundation flexibility should be incorporated.

b. The simplified method of analysis should be revised so that it correctly locates the elevation at which cracking occurs through the cross section of gravity dams. This can probably be achieved by including the most essential features of foundation compliance and nonlinear postcracking behavior.

c. The frictional resistance along naturally cracked concrete surfaces should be experimentally studied to obtain appropriate frictional coefficients for the sliding block analysis. 


\section{REFERENCES}

ADINA Engineering, 1984, "Automatic Dynamic Incremental Nonlinear Analysis Users Manual," Report AE 84-1, ADINA Engineering, Watertown, MA.

American Concrete Institute, 1977, "Building Code Requirements for Reinforced Concrete," ACI Committee 318, Detro1t, MI, 103 pp.

K.-J. Bathe, 1982, Finite Element Procedures in Engineering Analysis, Prentice-Hall, Inc., Englewood Cliffs, NJ.

K. -J. Bathe and S. Ramaswamy, 1979, "On Three-Dimensional Nonlinear Anaysis of Concrete Structures," Journal of Nuclear Engineering and Design, Vol 52, pp 385-409.

J. M. Biggs, 1964, Introduction to Structural Dynamics, McGraw-Hill Book Company, New York, NY.

V. P. Chiarito and P. F. Mlakar, 1983, "Vibration Test of Richard B. Russell Dam Before Reservoir Impoundment," Technical Report SL-83-2, US Army Engineer Waterways Experiment Station, CE, Vicksburg, MS.

A. K. Chopra, 1978, "Earthquake Resistant Design of Concrete Gravity Dams," Journal of the Structural Division, American Society of Civil Engineers, Vol 104, No. ST6, pp 953-971.

R. A. Cole and J. B. Cheek, 1985, "Seismic Analysis of Gravity Dams," Technical Report (in publication), US Army Engineer Waterways Experiment Station, CE, Vicksburg, MS.

Department of the Army, US Army Corps of Engineers, 1985, "Engineering and Design Earthquake Analysis and Design of Concrete Gravity Dams," Engineer Technica1 Letter 1110-2-303, Washington, DC.

Department of the Army, US Army Corps of Engineers, 1960, "Gravity Dam Design," Engineer Manual 1110-2-2200, Washington, DC.

G. Fenves and A. K. Chopra, 1984, "Earthquake Analysis and Response of Concrete Gravity Dams," Report No. UCB/EERC-84/10, Earthquake Engineering Research Center, College of Engineering, University of California, Berkeley, CA.

A. G. Frank1in and F. K. Chang, 1977, "Earthquake Resistance of Earth and Rock-Fill Dams: Permanent Displacement of Earth Embankments by Newmark Sliding Block Analysis," Miscellaneous Paper S-71-17, Report 5, US Army Engineer Waterways Experiment Station, CE, Vicksburg, MS.

M. E. Hynes-Griffin and A. G. Franklin, 1984, "Rationalizing the Seismic Coefficient Method," Miscellaneous Paper GL-84-13, US Army Engineer Waterways Experiment Station, CE, Vicksburg, MS. 
K. Kana1, 1961, "An Empirical Formula for the Spectrum of Strong Earthquake Motions," Bulletin of the Earthquake Research Institute, University of Tokyo, Vol 39.

S. P. La1, 1980, "Overall Safety Assessment of Multistory Steel Buildings Subjected to Earthquake Loads," MIT Department of Civil Engineering Research Report R80-26.

J.-S. Lin and R. V. Whitman, 1986, "Earthquake Induced Displacements of Sliding Blocks," Journal of Geotechnical Engineering, American Society of Civil Engineers, Vol 112, No. 1, pp 44-59.

P. F. Mlakar, K. P. Vitaya-Udom, and R. A. Cole, 1984, "Concrete Behavior Under Dynamic Tensile-Compressive Load," Technical Report SL-84-1, US Army Engineer Waterways Experiment Station, CE, Vicksburg, MS.

N. M. Newmark, 1965, "Effect of Earthquakes on Dams and Embankments," Geotechnique, Vol 15, No. 2, pp 139-160.

N. M. Newmark and E. Rosenblueth, 1971, Fundamentals of Earthquake Engineering, Prentice-Ha11, Inc., Englewood Cliffs, NJ.

A. Niwa and R. W. Clough, 1980, "Shaking Table Research on Concrete Dam Models," Report UCB/EERC-80/05, Earthquake Engineering Research Center, University of California, Berkeley, CA.

C. D. Norman, 1979, "Earthquake Analysis of the Modified Geometry of the Concrete Nonoverflow Section Richard B. Russell Dam," Technical Report SL-79-14, US Army Engineer Waterways Experiment Station, CE, Vicksburg, MS.

C. D. Norman and H. E. Stone, 1979, "Earthquake Analysis of the Gravity Dam Monoliths of the Richard B. Russell Dam," Technical Report SL-79-8, US Army Engineer Waterways Experiment Station, CE, Vicksburg, MS.

J. M. Raphael, 1982, "The Tensile Strength of Concrete," Paper Submitted to the American Concrete Institute.

S. S. Saini and J. Krishna, 1974, "Overturning of Top Profile of the Koyna Dam During Severe Ground Motion," International Journal of Earthquake Engineering and Structural Dynamics, Vol 2, pp 207-217.

S. K. Sarma, 1975, "Seismic Stability of Earth Dams and Embankments," Geotechnique, London, England, Vol 25, No. 4, pp 743-761.

R. L. Stowe, 1978, "Concrete and Rock Tests, Rehabilitation Work, Brandon Rock Dam, Illinois Waterway, Chicago District," Miscellaneous Paper, US Army Engineer Waterways Experiment Station, Vicksburg, MS.

R. L. Stowe, et al., 1980, "Concrete and Rock Tests, Major Rehabilitation and Compliance, Lockport Lock, Illinois Waterway, Chicago District," Miscellaneous Paper SL-80-4, US Army Engineer Waterways Experiment Station, Vicksburg, MS. 
H. Tajimi, 1960, "A Statistical Method of Determining the Maximum Response of a Building Structure During an Earthquake," Proceedings of the 2nd World Conference on Earthquake Engineering, Vol II, Tokyo.

H. T. Thornton, Jr., et a1., 1981, "Evaluation of Condition of Lake Superior Regulatory Structure, Sault Ste. Marie, Michigan," Miscellaneous Paper SL-8114, US Army Engineer Waterways Experiment Station, Vicksburg, MS.

E. H. Vanmarcke and S. P. LaI, 1980, "Strong-Motion Duration and RMS Amplitude of Earthquake Records," Bulletin of the Selsmological Society of America.

G. Winter and A. H. Nilson, 1979, Design of Concrete Structures, 9th ed., McGraw-Hil1 Book Company, New York, NY, p. 16. 
Table 1

Parameter Values Used in ADINA Concrete Model

\begin{tabular}{|c|c|c|c|}
\hline Parameter & Russe11 Dam & Standard Dam & Dworshak Dam \\
\hline$\tilde{\mathrm{E}}_{0}, 10^{6} \mathrm{ps} 1$ & 3.34 & 3.33 & 5.52 \\
\hline$\tilde{\sigma}_{t}, p s i$ & 380 & 380 & 740 \\
\hline$\tilde{\sigma}_{c}, p s 1$ & -3040 & -3010 & -8300 \\
\hline$\tilde{\mathbf{e}}_{c}$ & -0.002 & -0.002 & -0.002 \\
\hline$\tilde{\sigma}_{u}, p s i$ & -2230 & -2220 & -3050 \\
\hline$\tilde{\mathbf{e}}_{\mathbf{u}}$ & -0.004 & -0.004 & -0.003 \\
\hline
\end{tabular}


Table 2

Geometric Parameter Values for Dams Analyzed

\begin{tabular}{|c|c|c|c|}
\hline Parameter & Russe11 Dam & Standard Dam & Dworshak Dam \\
\hline Dam he1ght, ft & 185 & 300 & 638 \\
\hline Upstream slope & $1 / 12$ & $1 / 12$ & 0 \\
\hline Upstream slope he1ght, ft & 143 & 250 & - \\
\hline Crest width, ft & 17 & 21 & 27 \\
\hline Downstream slope & $2 / 3$ & $7 / 10$ & $4 / 5$ \\
\hline Downstream slope height, ft & 160 & 270 & 585 \\
\hline Base width, ft & 136 & 231 & 495 \\
\hline Reservolr height, ft & 170 & 285 & 570 \\
\hline
\end{tabular}


Table 3

Natural Periods in Seconds of Dams Analyzed

\begin{tabular}{cccc}
\hline Mode & Russe11 Dam & Standard Dam & Dworshak Dam \\
\cline { 2 - 4 } 1 & 0.1581 & 0.2375 & 0.3676 \\
2 & 0.0743 & 0.1129 & 0.1849 \\
3 & 0.0549 & 0.0879 & 0.1446 \\
4 & 0.0428 & 0.0686 & 0.1173
\end{tabular}


Table 4

Parameters of Earthquakes Recorded at Rock Sites (La1 1980)

\begin{tabular}{|c|c|c|c|}
\hline CIT No. & $\begin{array}{l}\mathrm{A}_{\mathrm{m}} \\
\mathrm{g} \\
\end{array}$ & $\begin{array}{c}\omega_{\mathrm{g}} \\
\mathrm{rad} / \mathrm{sec} \\
\end{array}$ & $\begin{array}{l}\mathrm{S} \\
\mathrm{sec} \\
\end{array}$ \\
\hline A015-1 & 0.083 & 33.50 & 1.34 \\
\hline A015-2 & 0.105 & 37.45 & 2.02 \\
\hline В037-1* & 0.269 & 24.61 & 1.39 \\
\hline В037-2 & 0.347 & 21.21 & 0.65 \\
\hline В038-1 & 0.014 & 25.11 & 8.27 \\
\hline В038-2 & 0.012 & 29.73 & 8.07 \\
\hline В040-1 & 0.041 & 20.47 & 7.01 \\
\hline В040-2 & 0.046 & 21.22 & 5.65 \\
\hline D056-1 & 0.315 & 23.96 & 2.71 \\
\hline D056-2 & 0.271 & 17.29 & 7.07 \\
\hline V314-1 & 0.064 & 7.88 & 21.62 \\
\hline V314-2 & 0.097 & 6.54 & 13.48 \\
\hline V319-1 & 0.054 & 21.49 & 3.40 \\
\hline V319-2 & 0.036 & 17.11 & 7.05 \\
\hline V331-1 & 0.041 & 33.06 & 1.63 \\
\hline V331-2 & 0.037 & 45.80 & 1.27 \\
\hline W334-1 & 0.142 & 18.12 & 2.42 \\
\hline W334-2 & 0.198 & 25.02 & 1.26 \\
\hline W335-1 & 0.071 & 42.21 & 2.98 \\
\hline W335-2 & 0.056 & 45.99 & 2.26 \\
\hline W336-1 & 0.057 & 35.99 & 3.36 \\
\hline W336-2 & 0.071 & 32.96 & 1.90 \\
\hline Mean & 0.110 & 26.67 & 4.86 \\
\hline
\end{tabular}

Horizontal motion used in analyses. 
Table 5

Analysis of Dams by ETL 1110-2-303

\begin{tabular}{|c|c|c|c|c|}
\hline & Russe11 Dam & $\begin{array}{c}\text { Russell Dam } \\
\text { with Tripled Load }\end{array}$ & Standard Dam & Dworshak Dam \\
\hline$f_{c}^{\prime}, p s i$ & 2450 & 2450 & 2450 & 6800 \\
\hline$f_{0.05}, p s i$ & 640 & 2000 & 1290 & 1300 \\
\hline Location & Base upstream & Base upstream & Base upstream & Base upstream \\
\hline $\begin{array}{l}f_{0.07}, p s i \\
\text { Location }\end{array}$ & $\mathrm{NA}$ & $\mathrm{NA}$ & NA & $\begin{array}{c}786 \\
\text { Base upstream }\end{array}$ \\
\hline $\begin{array}{l}f_{0.10} \text {, psi } \\
\text { Location }\end{array}$ & $\begin{array}{l}\quad 530 \\
\text { Base upstream }\end{array}$ & $\begin{array}{l}\quad 1420 \\
\text { Base upstream }\end{array}$ & $\begin{array}{l}890 \\
\text { Base upstream }\end{array}$ & $\mathrm{NA}$ \\
\hline $\begin{array}{l}\text { Required Evaluation of } \\
\text { Cracking Severity }\end{array}$ & $\begin{array}{l}\text { Sliding stability } \\
\text { along base }\end{array}$ & $\begin{array}{l}\text { Sliding stability } \\
\text { along base }\end{array}$ & $\begin{array}{l}\text { Sliding stability } \\
\text { along base }\end{array}$ & $\begin{array}{l}\text { Sliding stability } \\
\text { along base }\end{array}$ \\
\hline
\end{tabular}


Table 6

Direct Shear Tests of Precut Concrete and Rock Specimens

\begin{tabular}{|c|c|c|}
\hline Condition & Res1dual & Reference \\
\hline Concrete on dolomite, precut & 0.49 & Stowe 1978 \\
\hline Dolomite on dolomite, precut & 0.40 & Stowe 1978 \\
\hline Natural, smooth dolomite joint & 0.42 & Stowe 1978 \\
\hline Concrete on dolomite, precut & 0.49 & Stowe et a1. 1980 \\
\hline Dolomite on dolomite, precut & 0.40 & Stowe et al. 1980 \\
\hline Natural, medium rough dolomite joint & 1.04 & Stowe et al. 1980 \\
\hline Concrete on very hard sandstone, precut & 0.63 & Thornton et al. 1981 \\
\hline Very hard sandstone on sandstone, precut & 0.65 & Thornton et al. 1981 \\
\hline Natural very hard sandstone joint & 0.62 & Thornton et al. 1981 \\
\hline Hard sandstone on sandstone, precut & 0.50 & Thornton et al. 1981 \\
\hline Natural hard sandstone joint & 1.17 & Thornton et al. 1981 \\
\hline Shaley sandstone on sandstone, precut & 0.62 & Thornton et al. 1981 \\
\hline
\end{tabular}




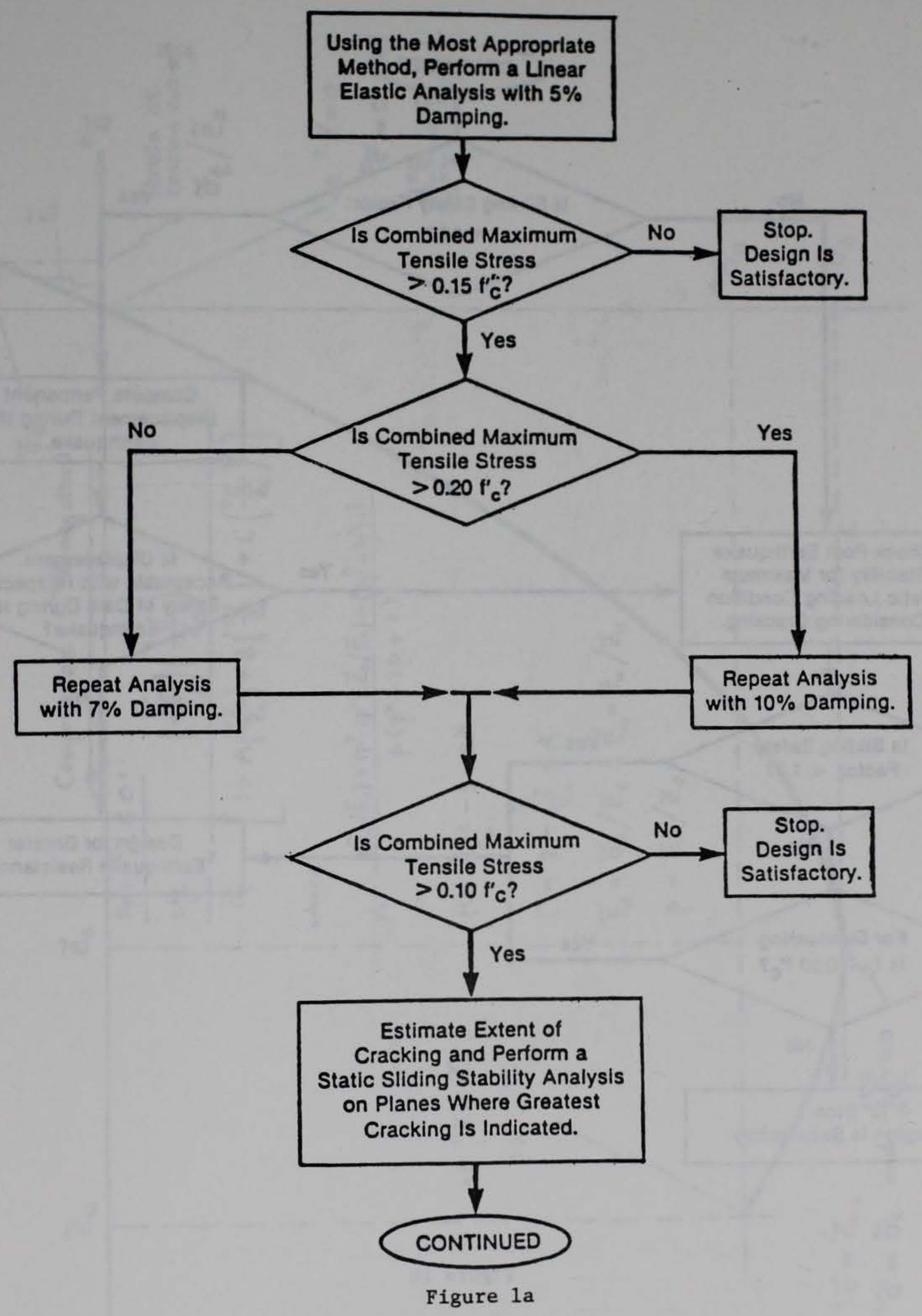

Figure 1. Sequence of analysis for the maximum credible earthquake (DA 1985) (Sheet 1 of 2) 


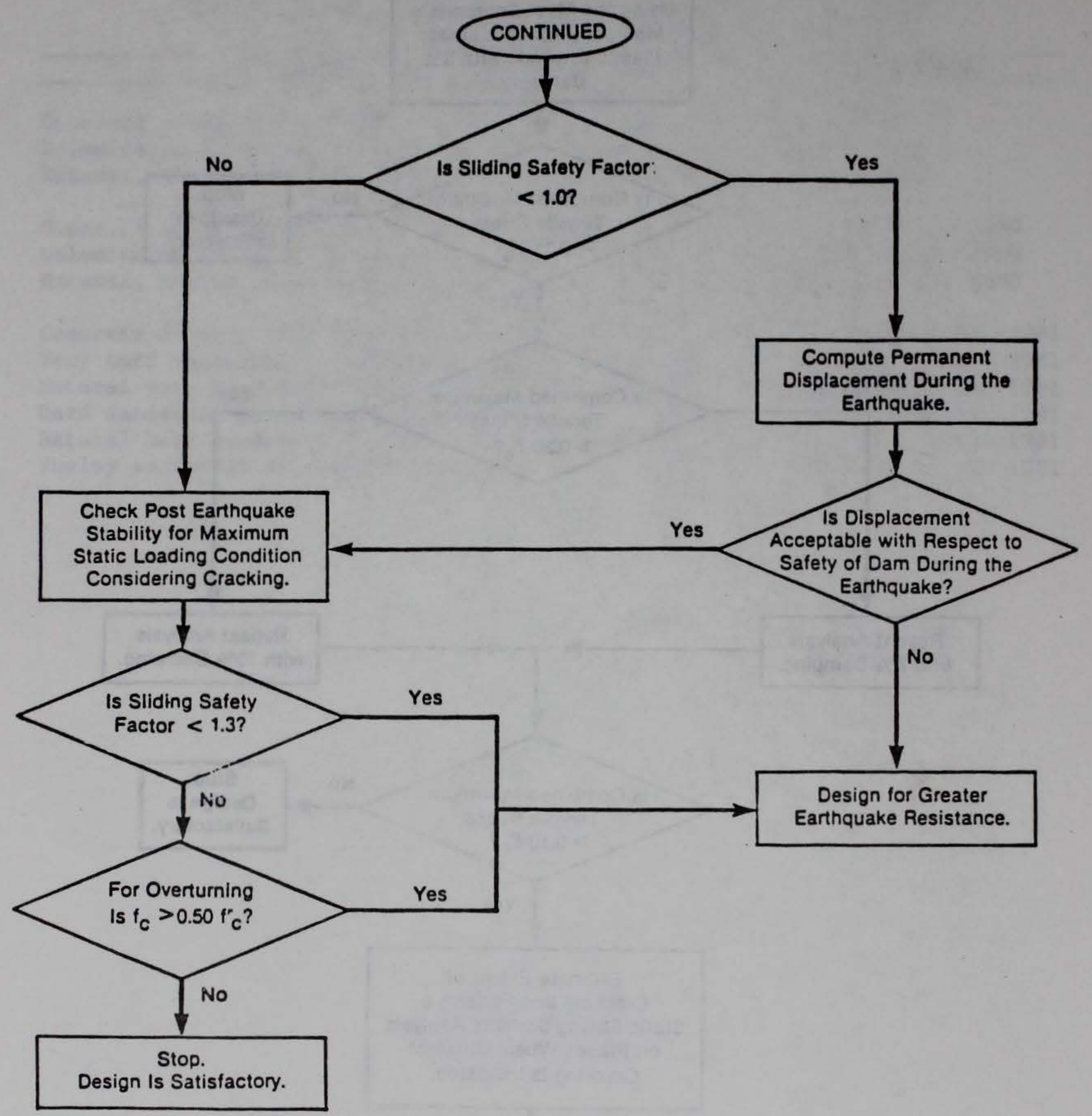

Figure 1b

Figure 1. (Sheet 2 of 2) 


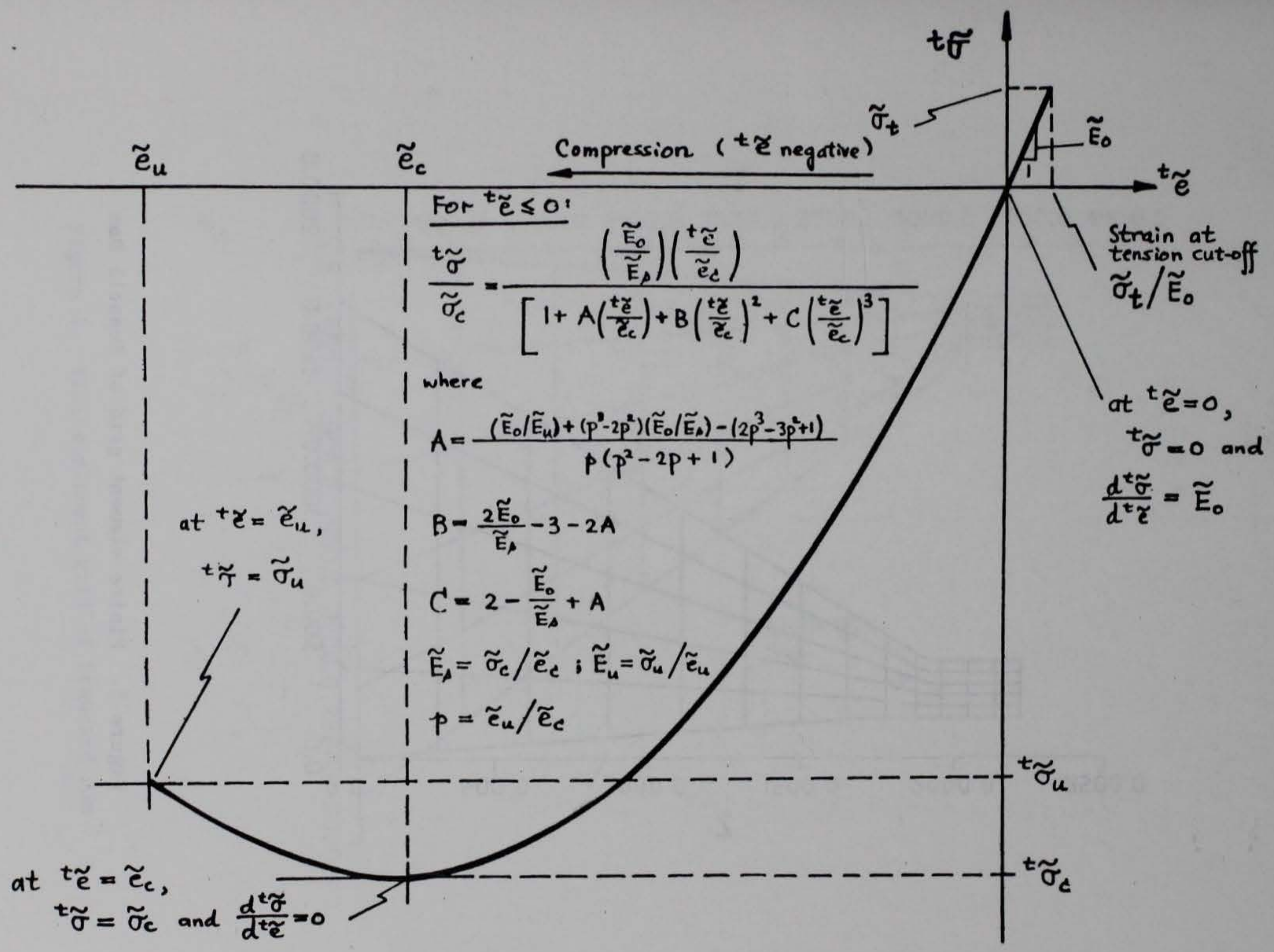

Figure 2. Uniaxial stress-strain relation used in concrete model (Bathe and Ramaswamy 1979) 


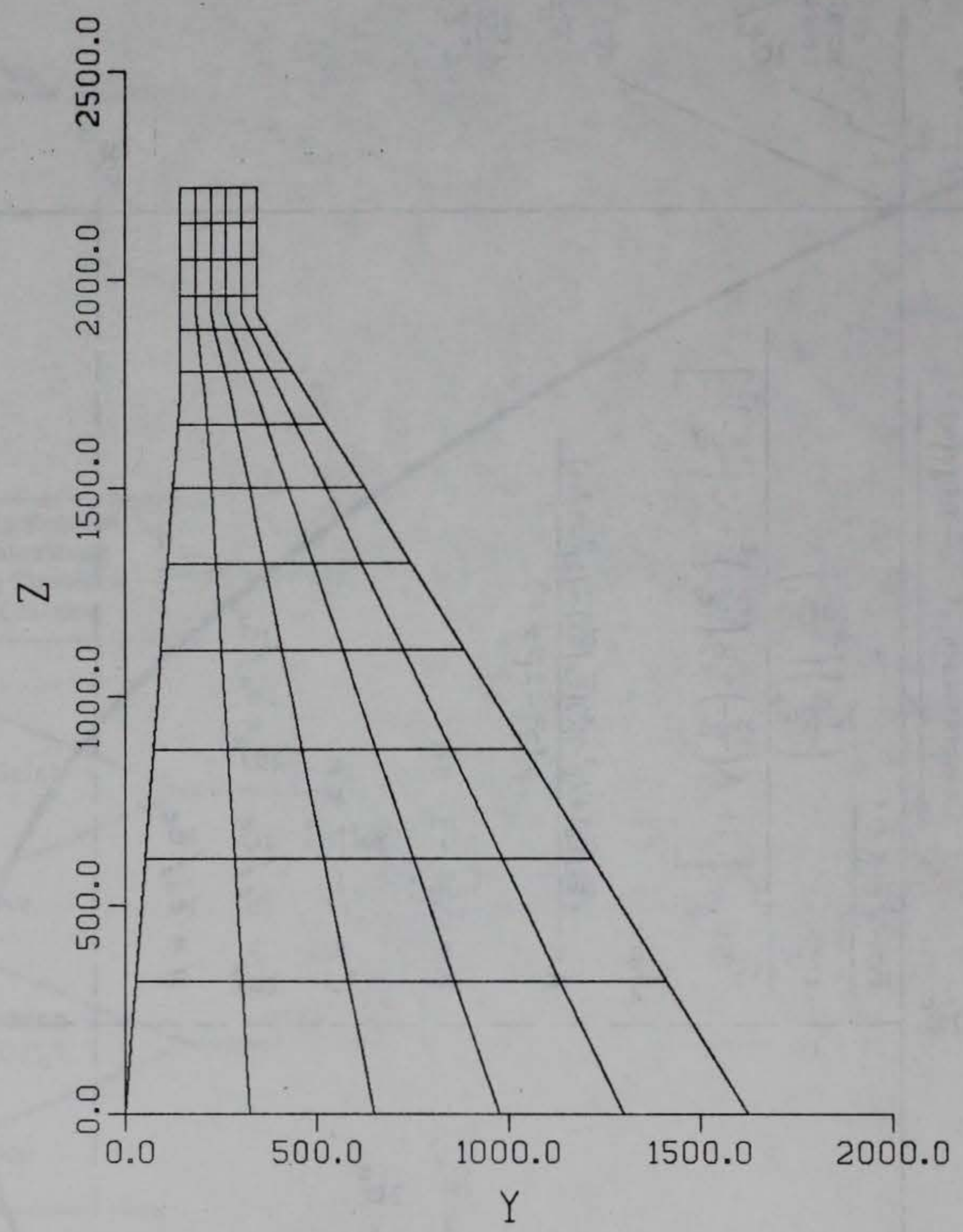

Figure 3. Finite element grid of Russell Dam 


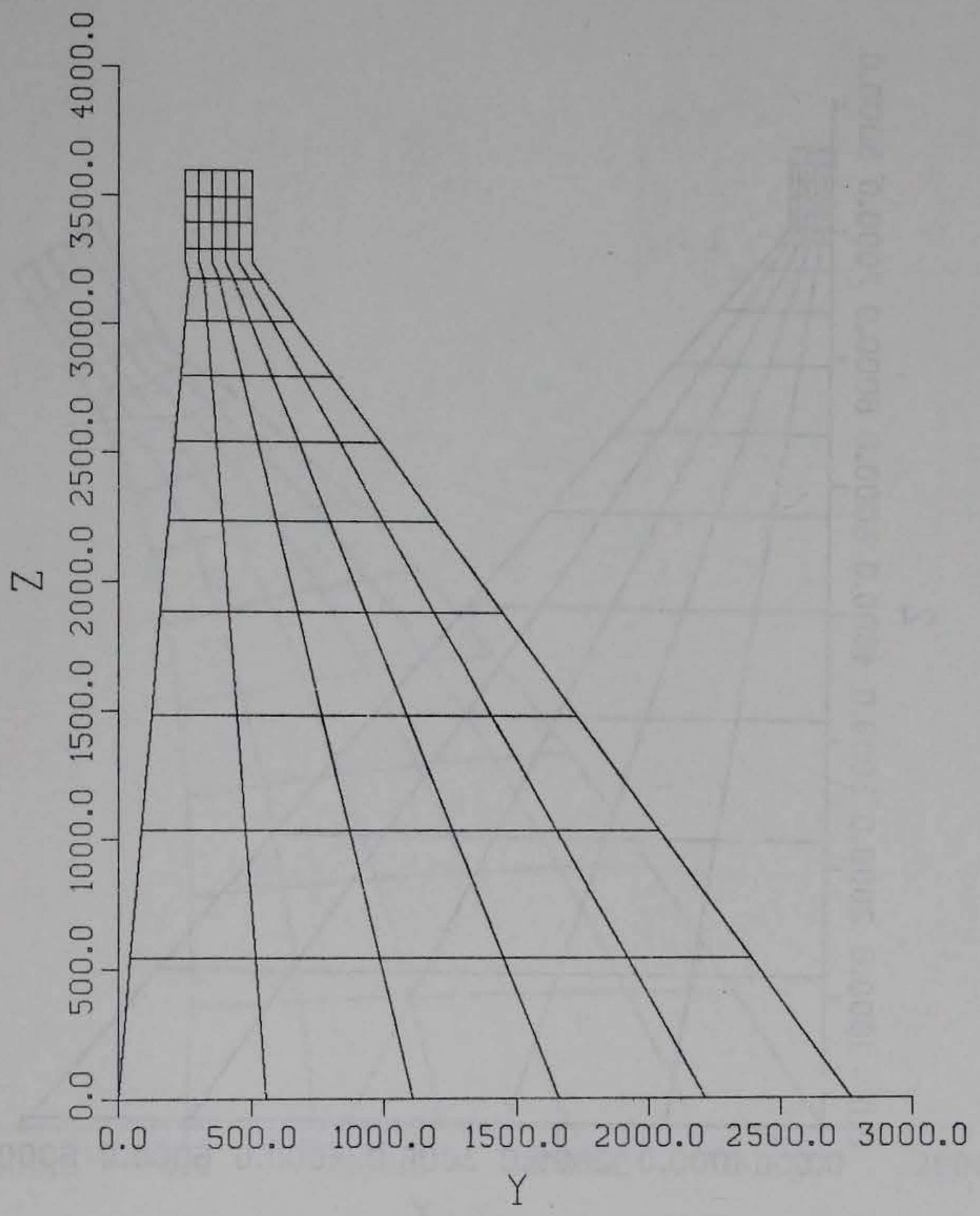

Figure 4. Finite element grid of Standard Dam 


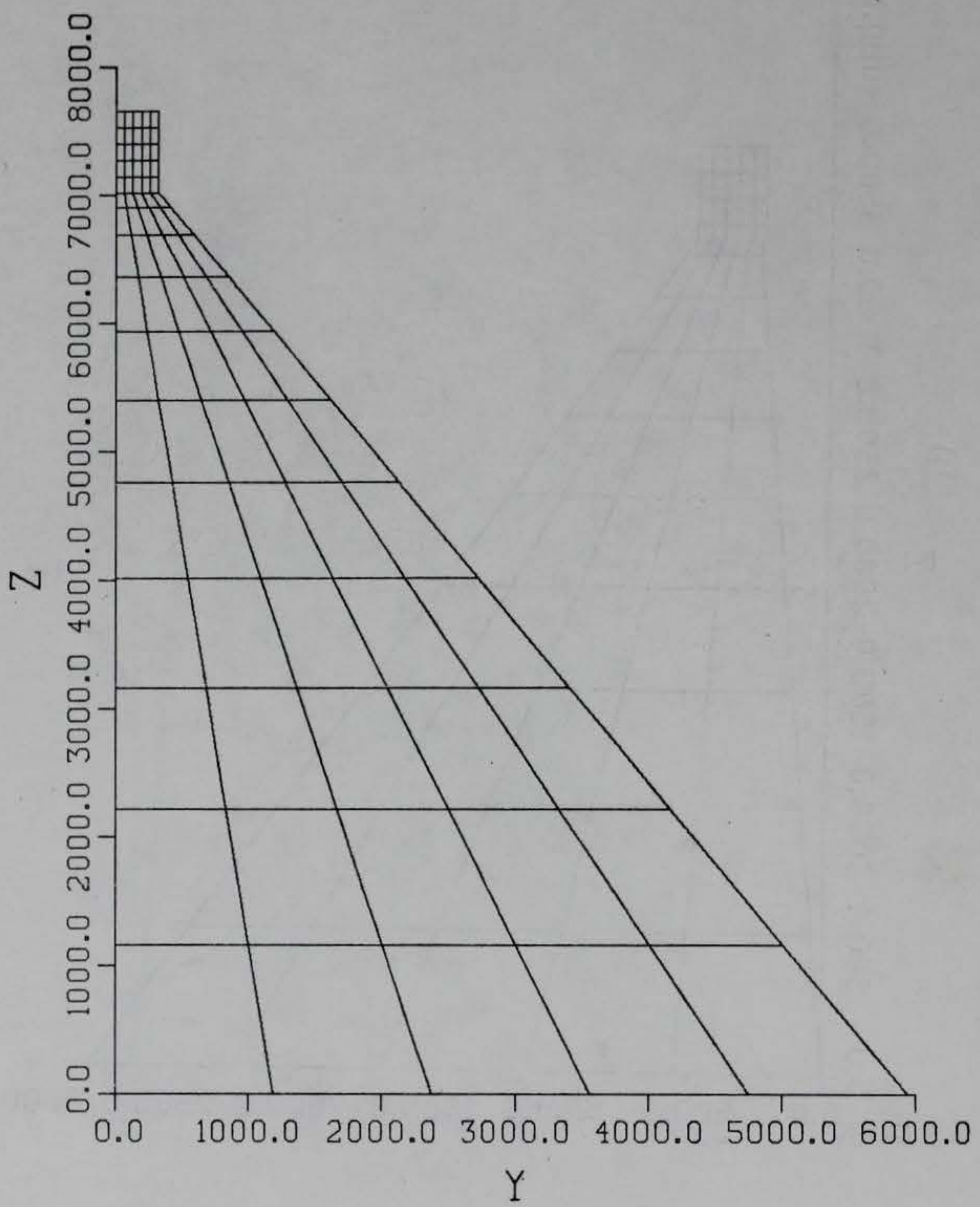

Figure 5. Finite element grid of Dworshak Dam 


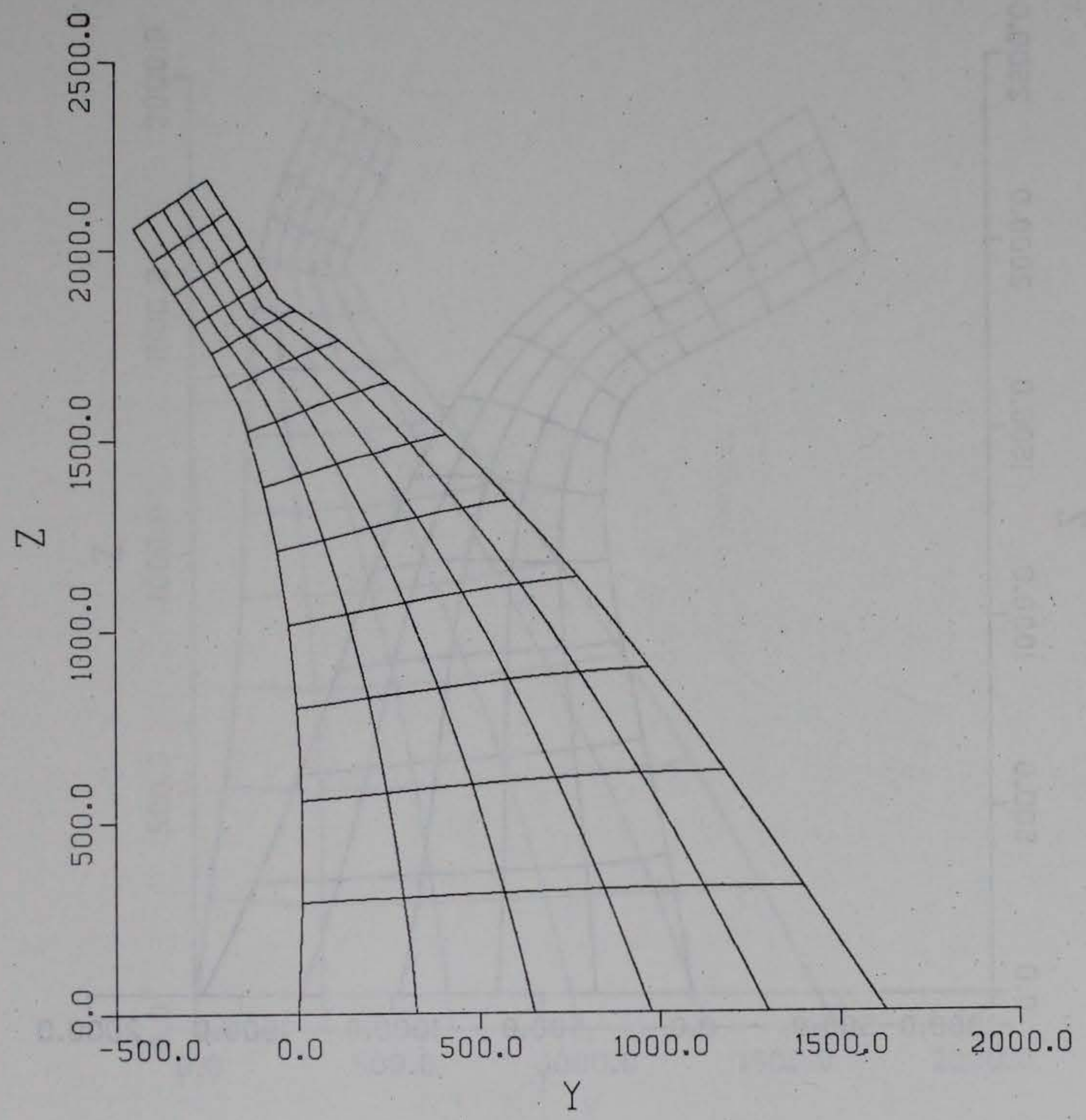

a. Mode 1

Figure 6. Characteristic shapes of Russell Dam (Sheet 1 of 4) 


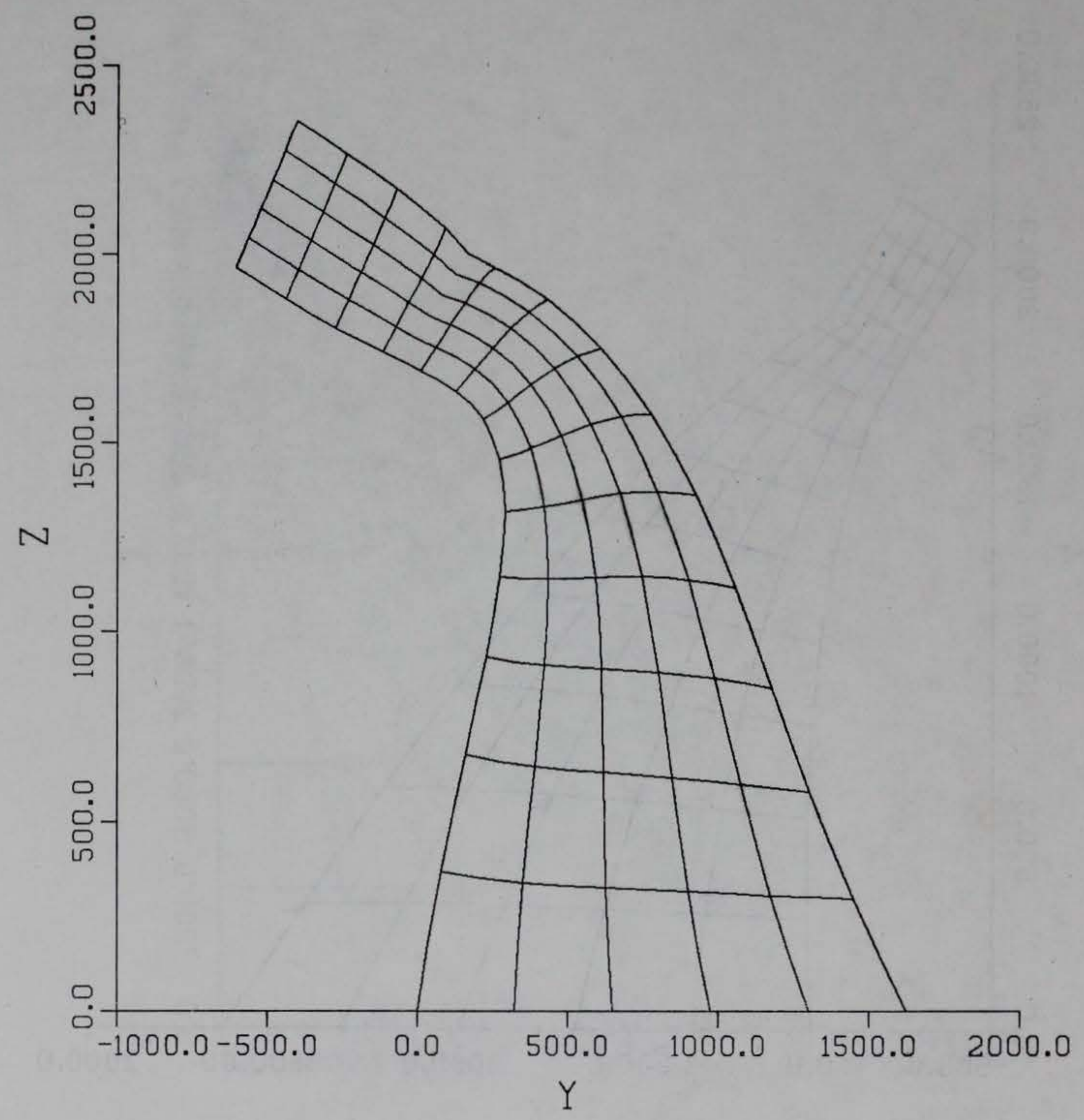

b. Mode 2

Figure 6. (Sheet 2 of 4) 


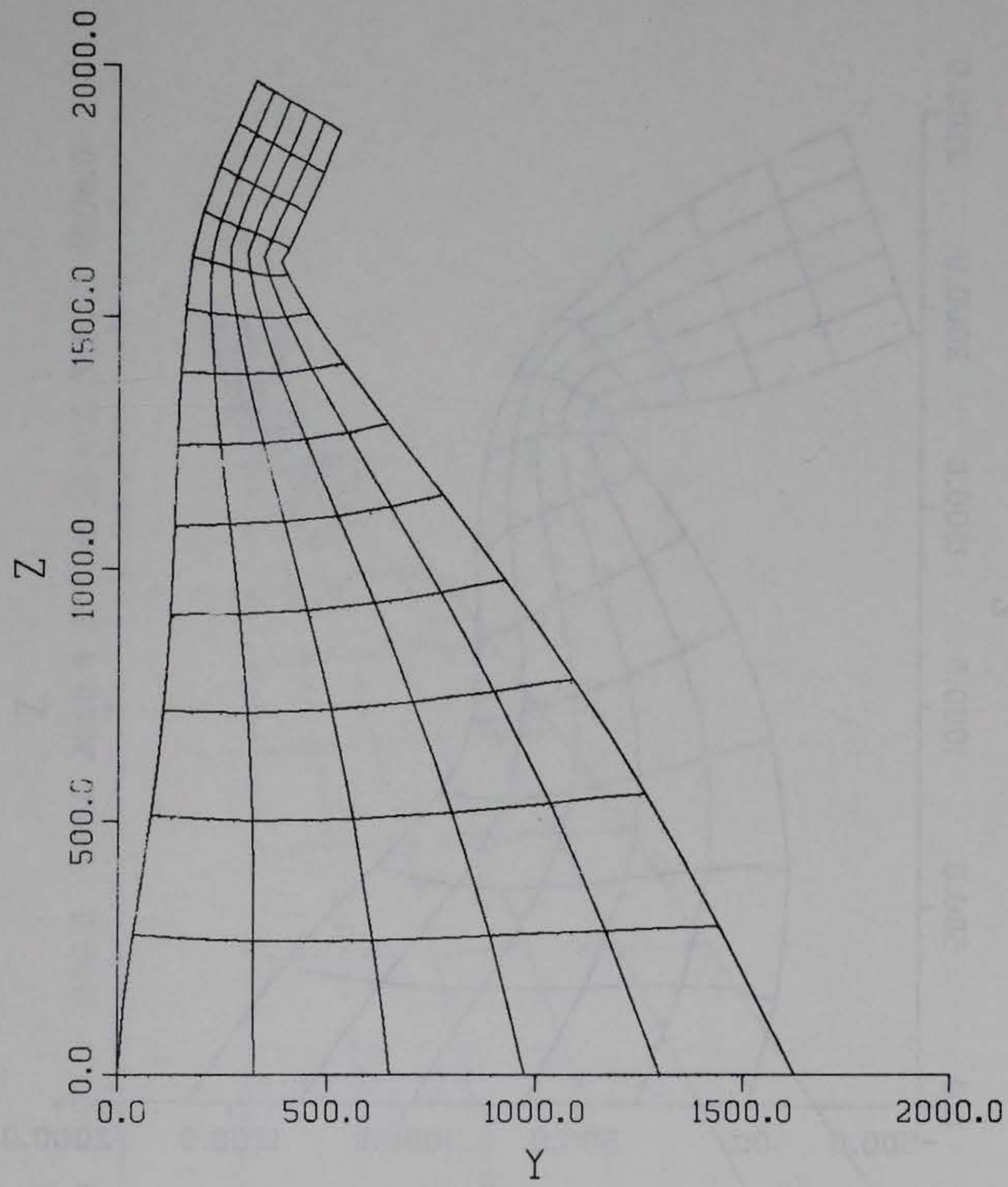

c. Mode 3

Figure 6. (Sheet 3 of 4) 


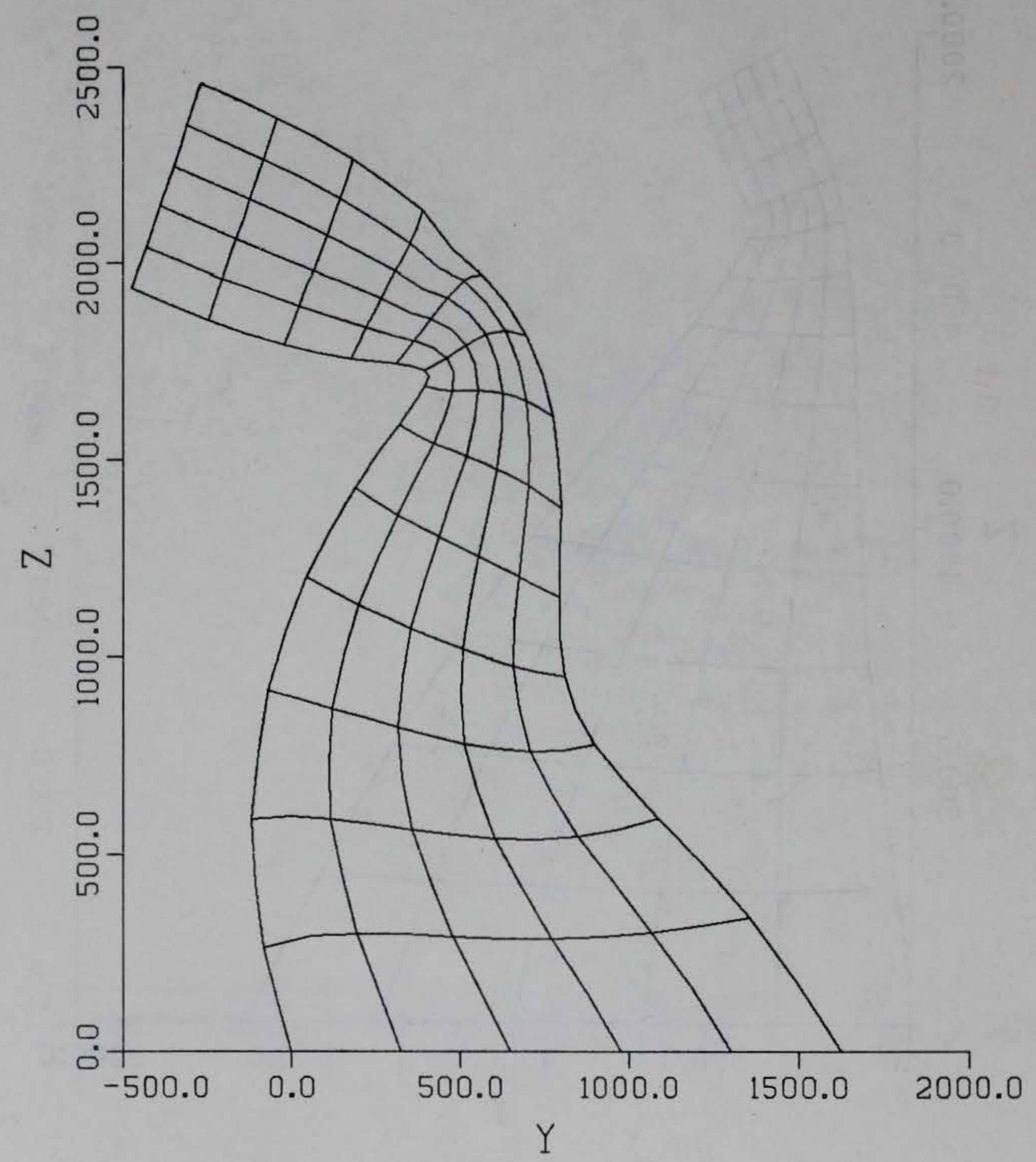

d. Mode 4

Figure 6 . (Sheet 4 of 4 ) 


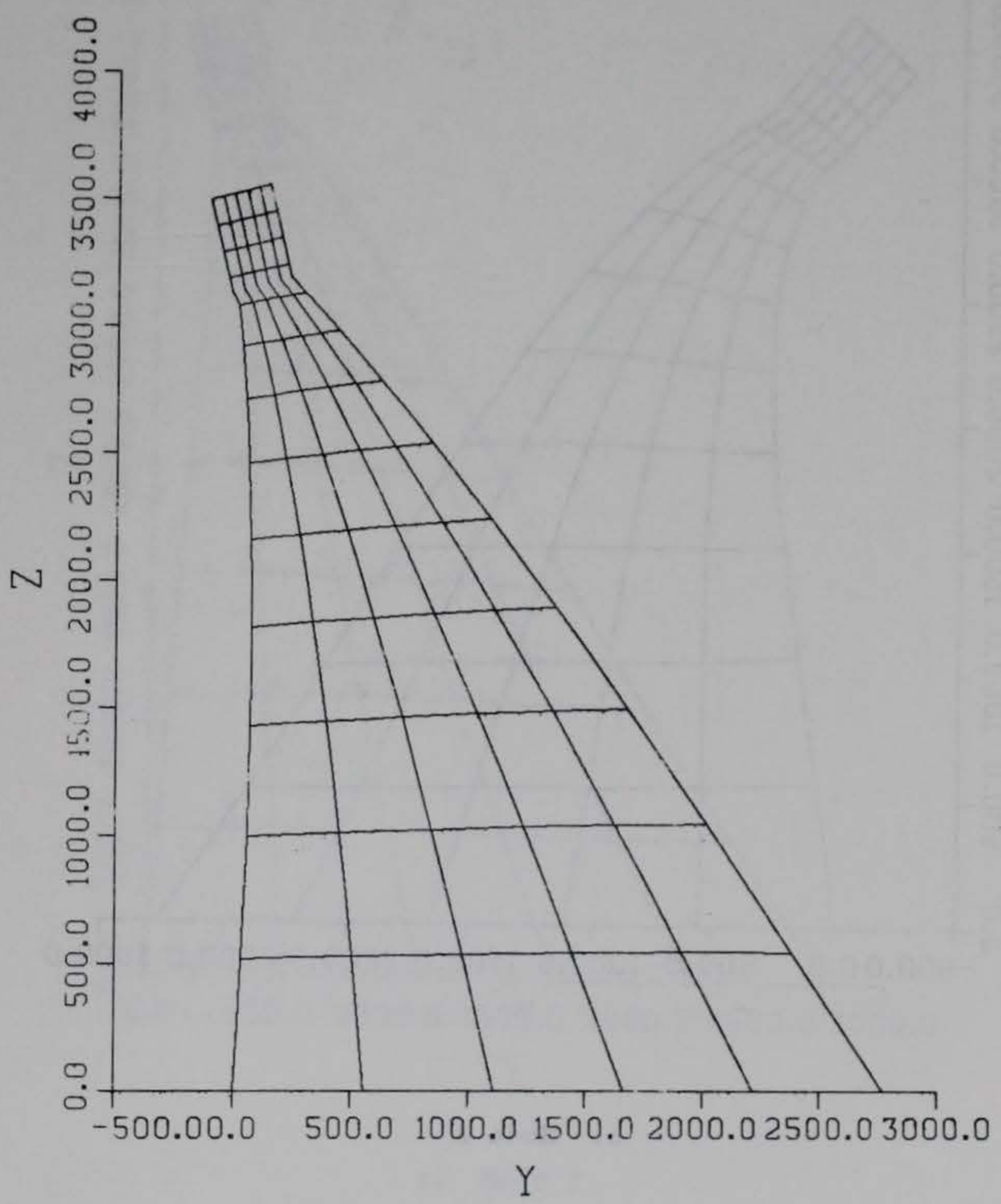

a. Mode 1

Figure 7. Characteristic shapes of Standard Dam (Sheet 1 of 4) 


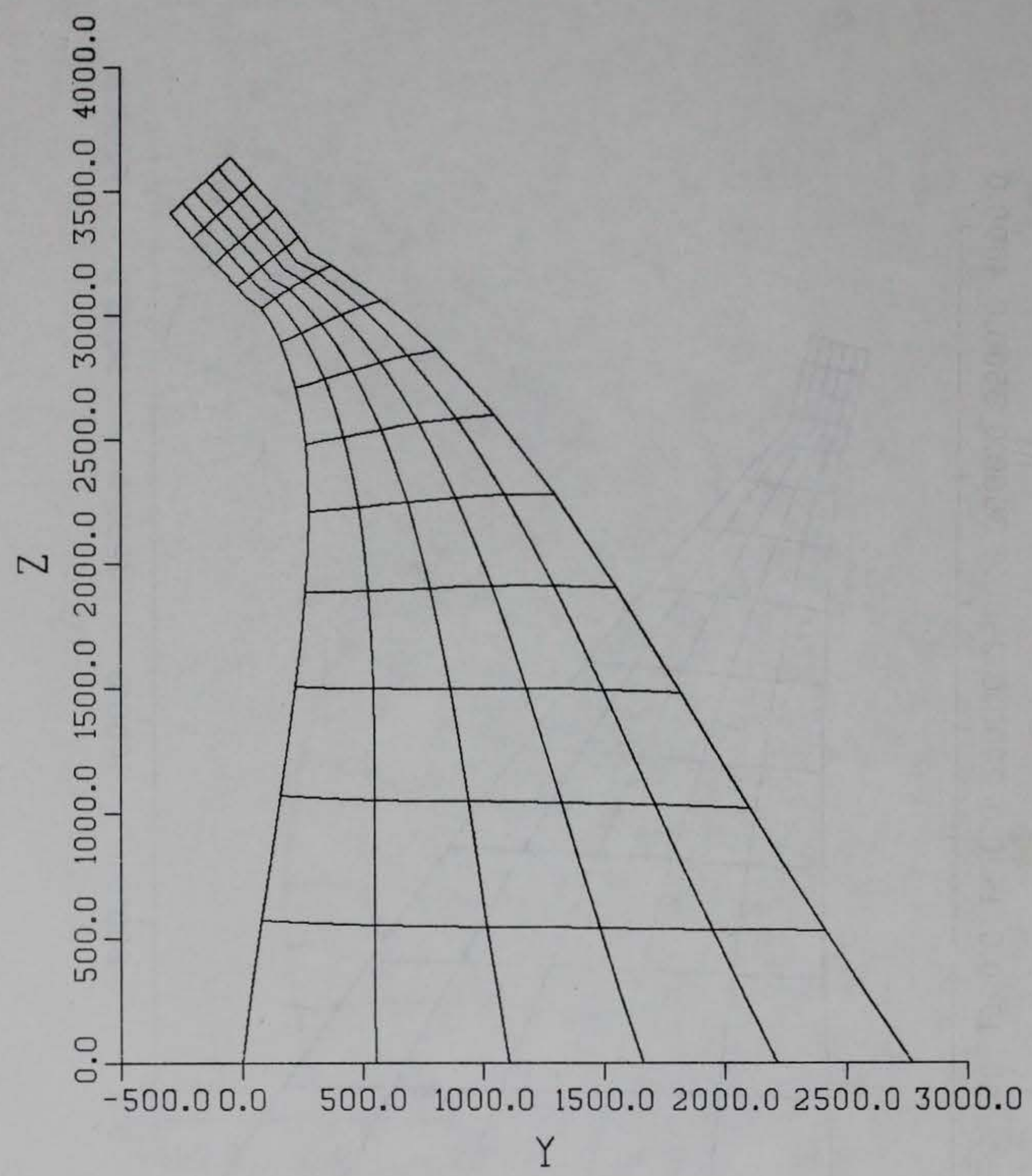

b. Mode 2

Figure 7. (Sheet 2 of 4) 


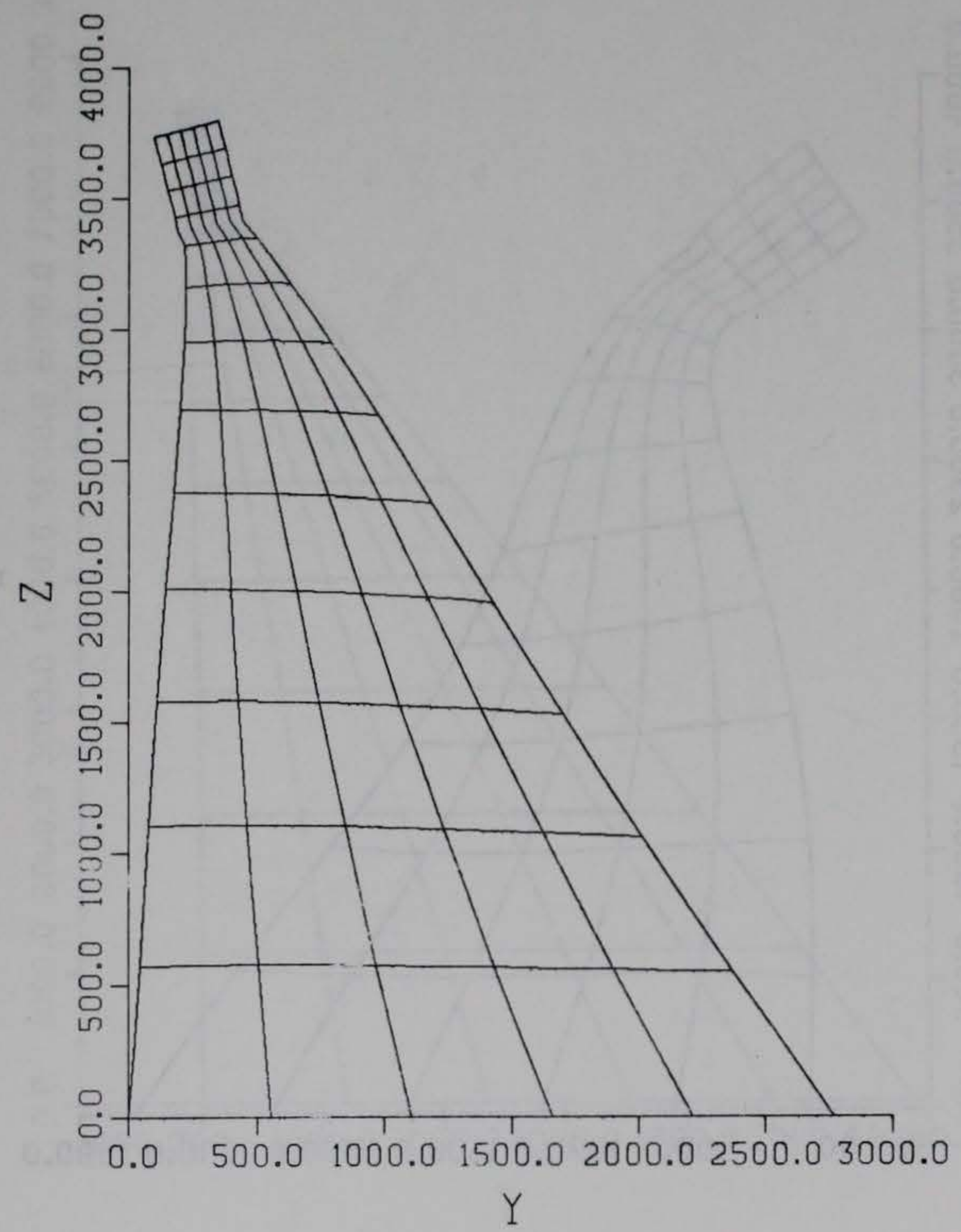

c. Mode 3

Figure 7. (Sheet 3 of 4) 


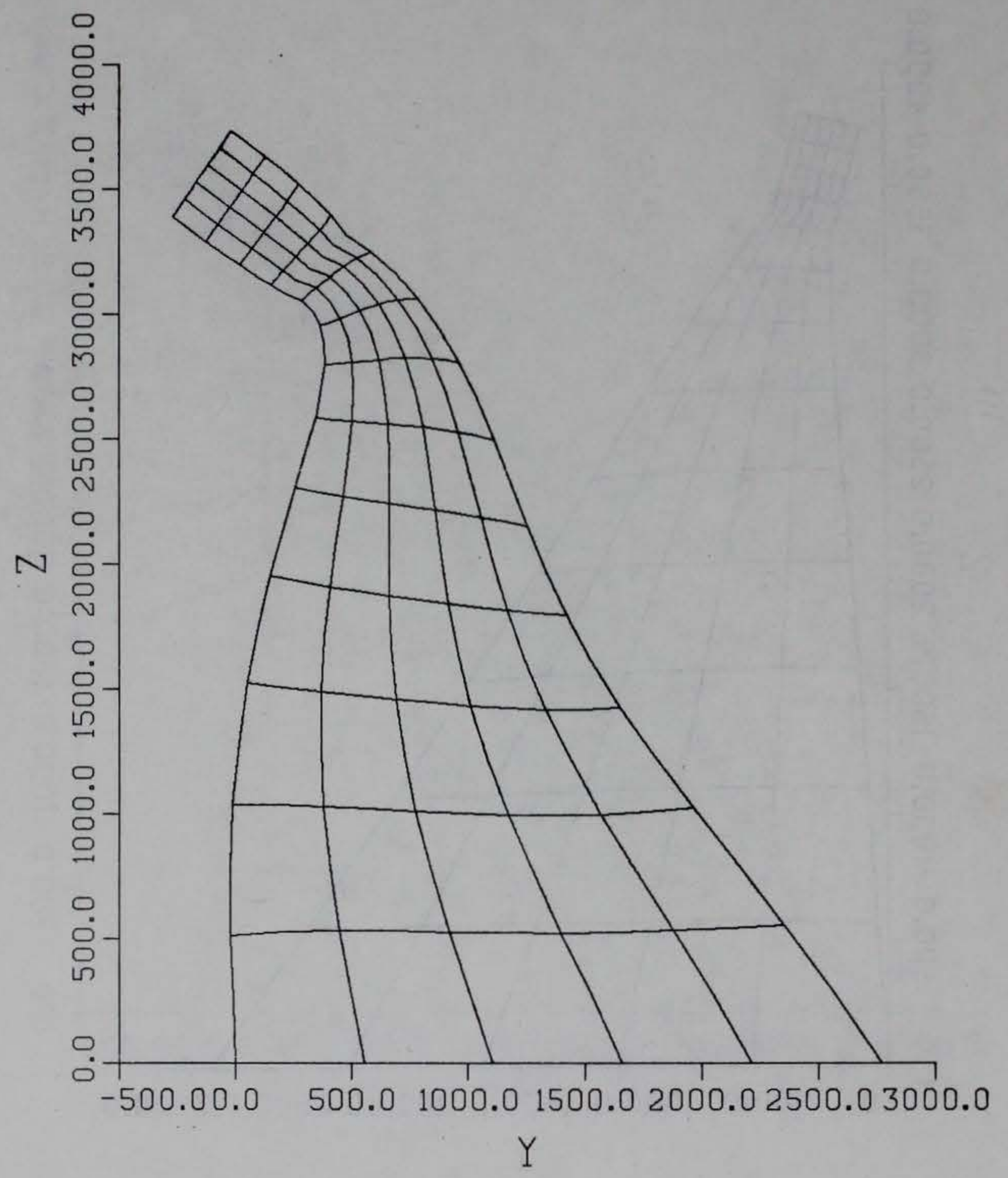

d. Mode 4

Figure 7. (Sheet 4 of 4 ) 


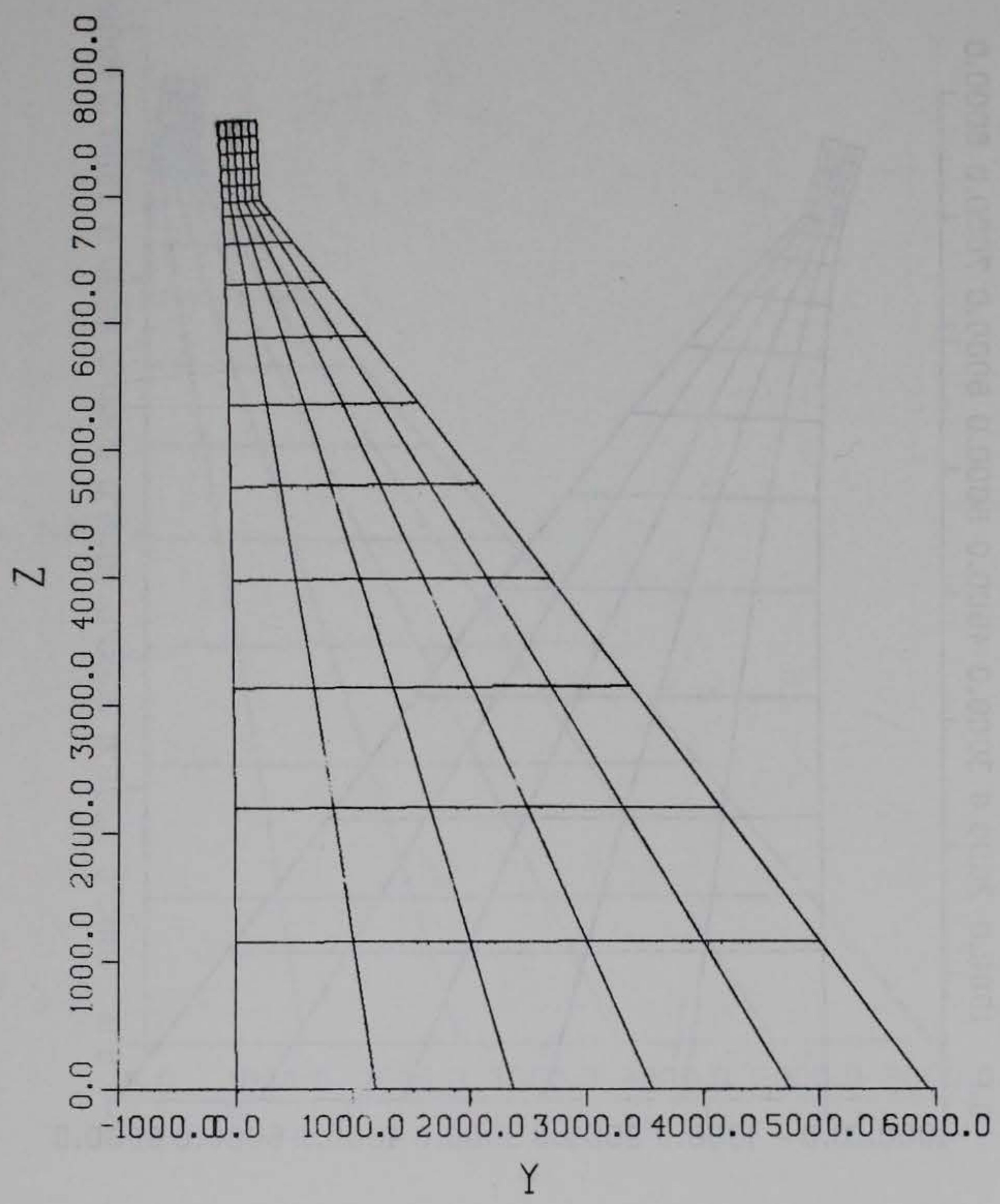

a. Mode 1

Figure 8. Characteristic shapes of Dworshak Dam (Sheet 1 of 4 ) 


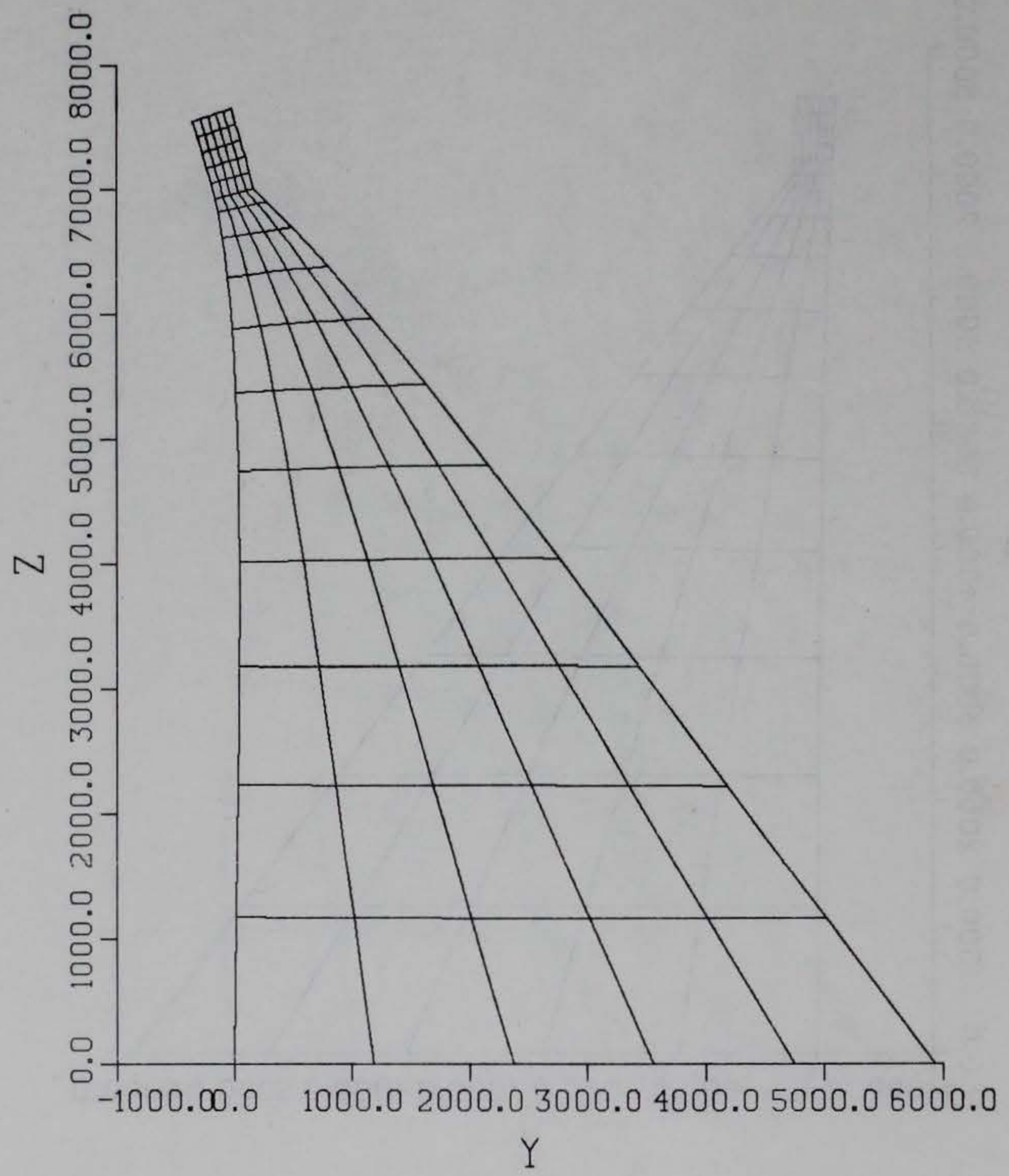

b. Mode 2

Figure 8. (Sheet 2 of 4) 


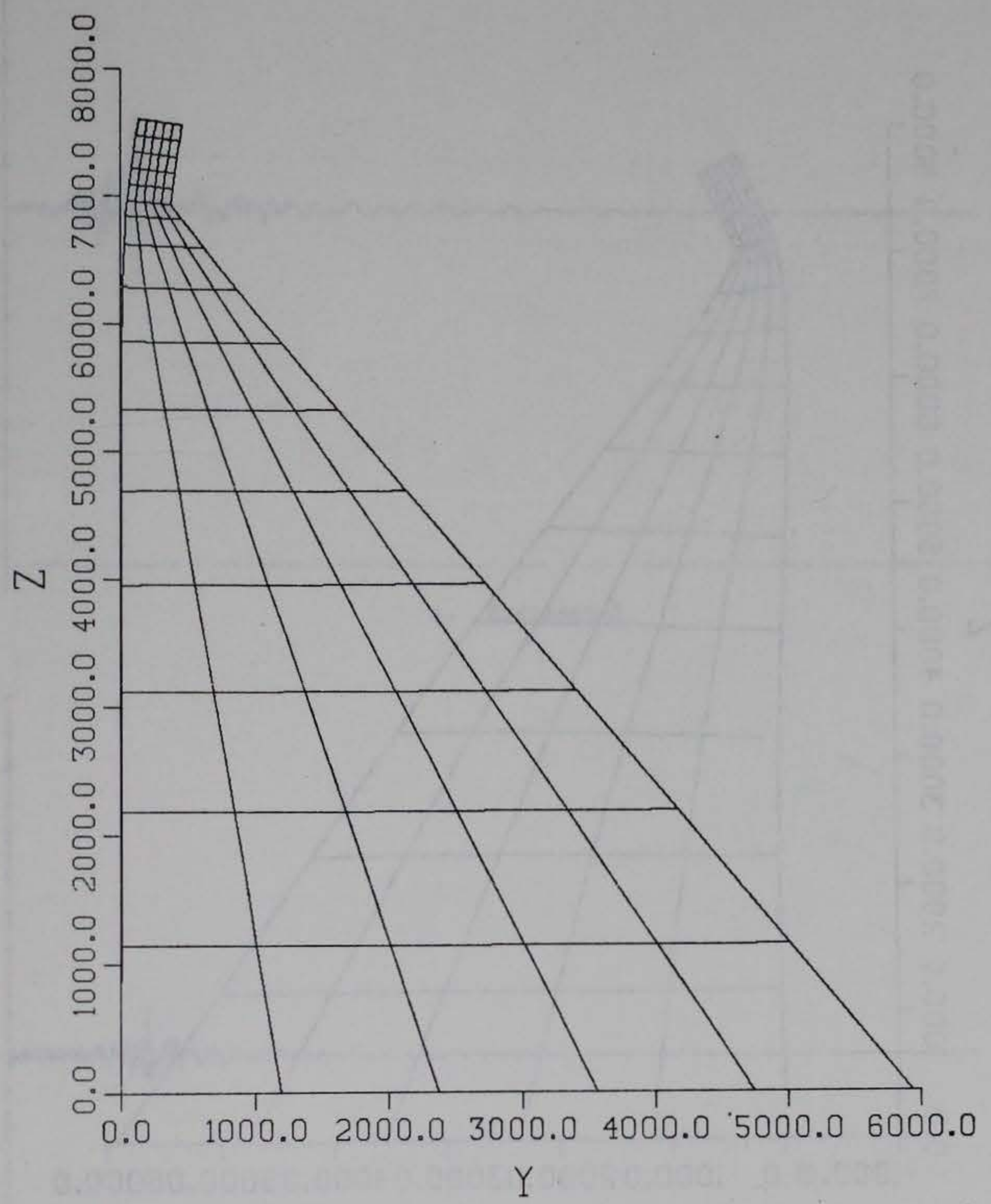

c. Mode 3

Figure 8. (Sheet 3 of 4) 


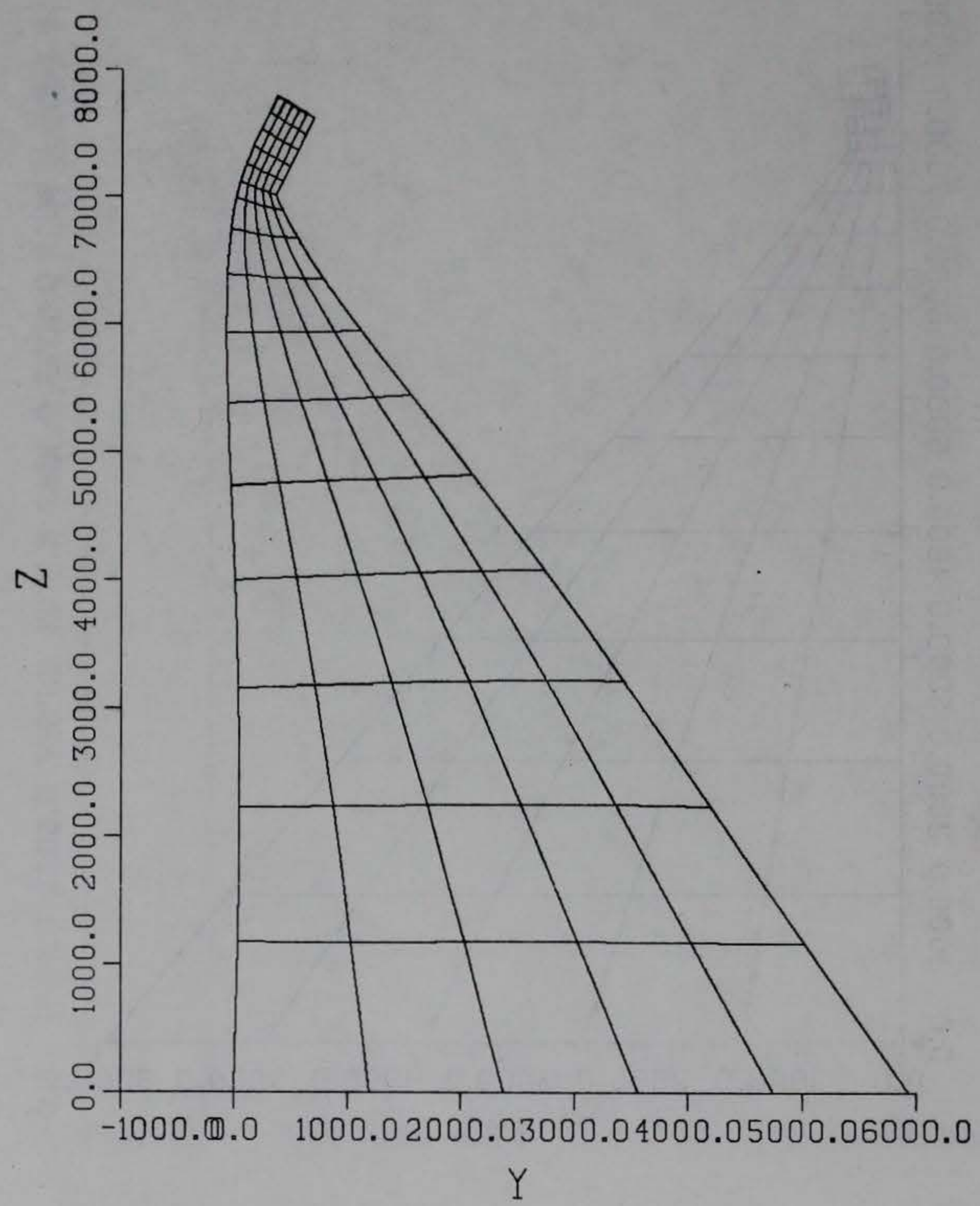

d. Mode 4

Figure 8. (Sheet 4 of 4 ) 


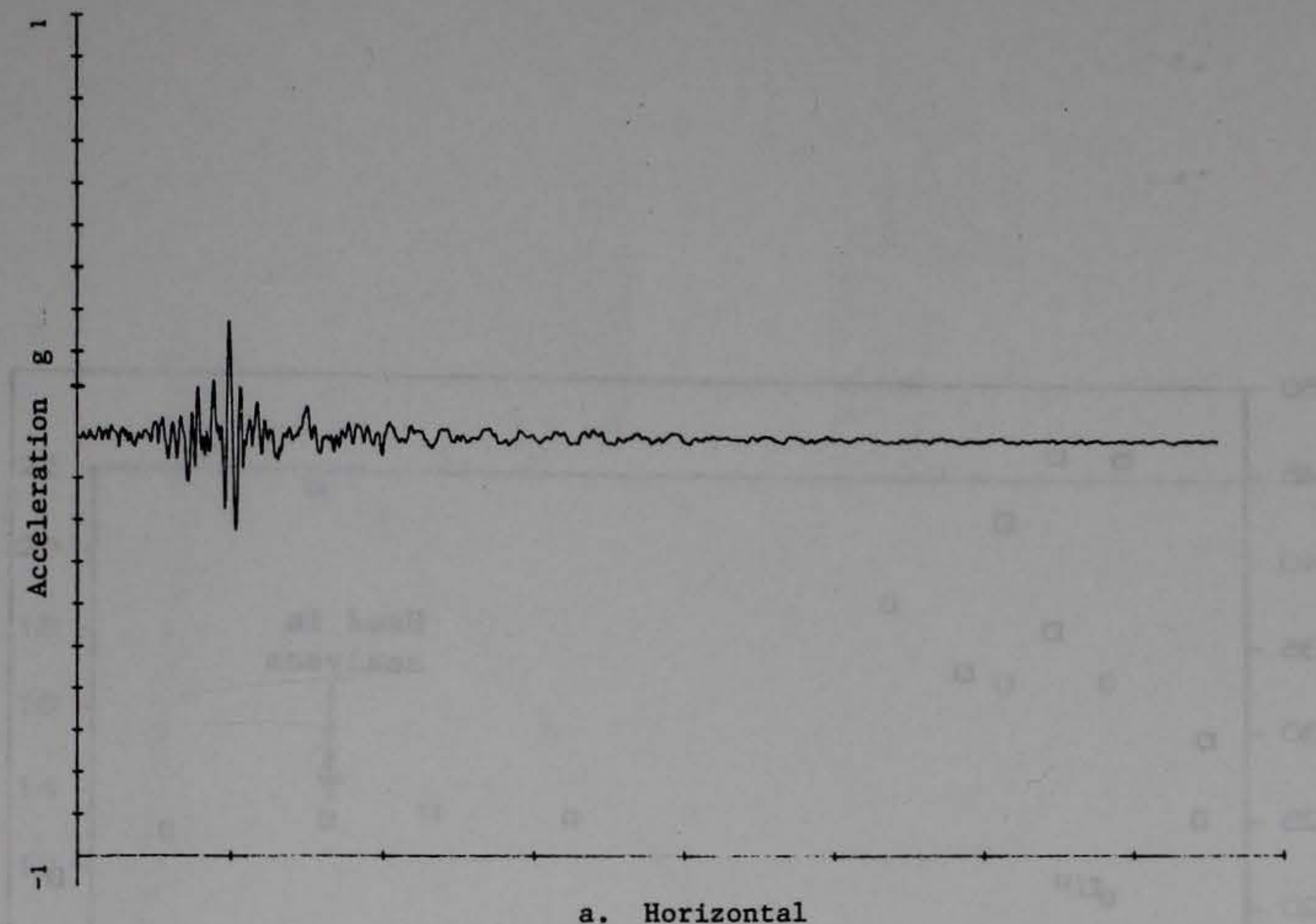

a. Horizontal

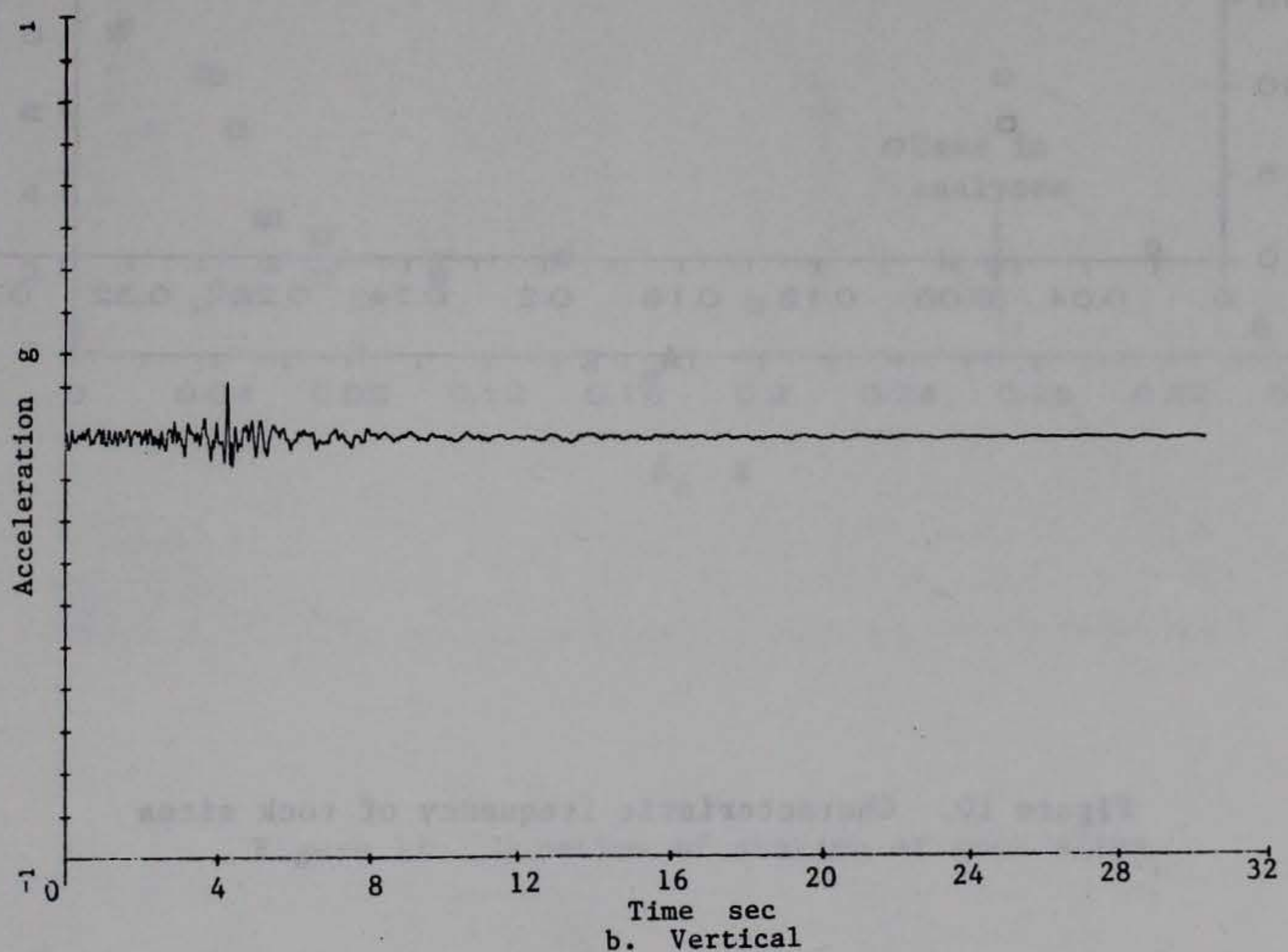

Figure 9. Parkfield earthquake motions used in analyses 


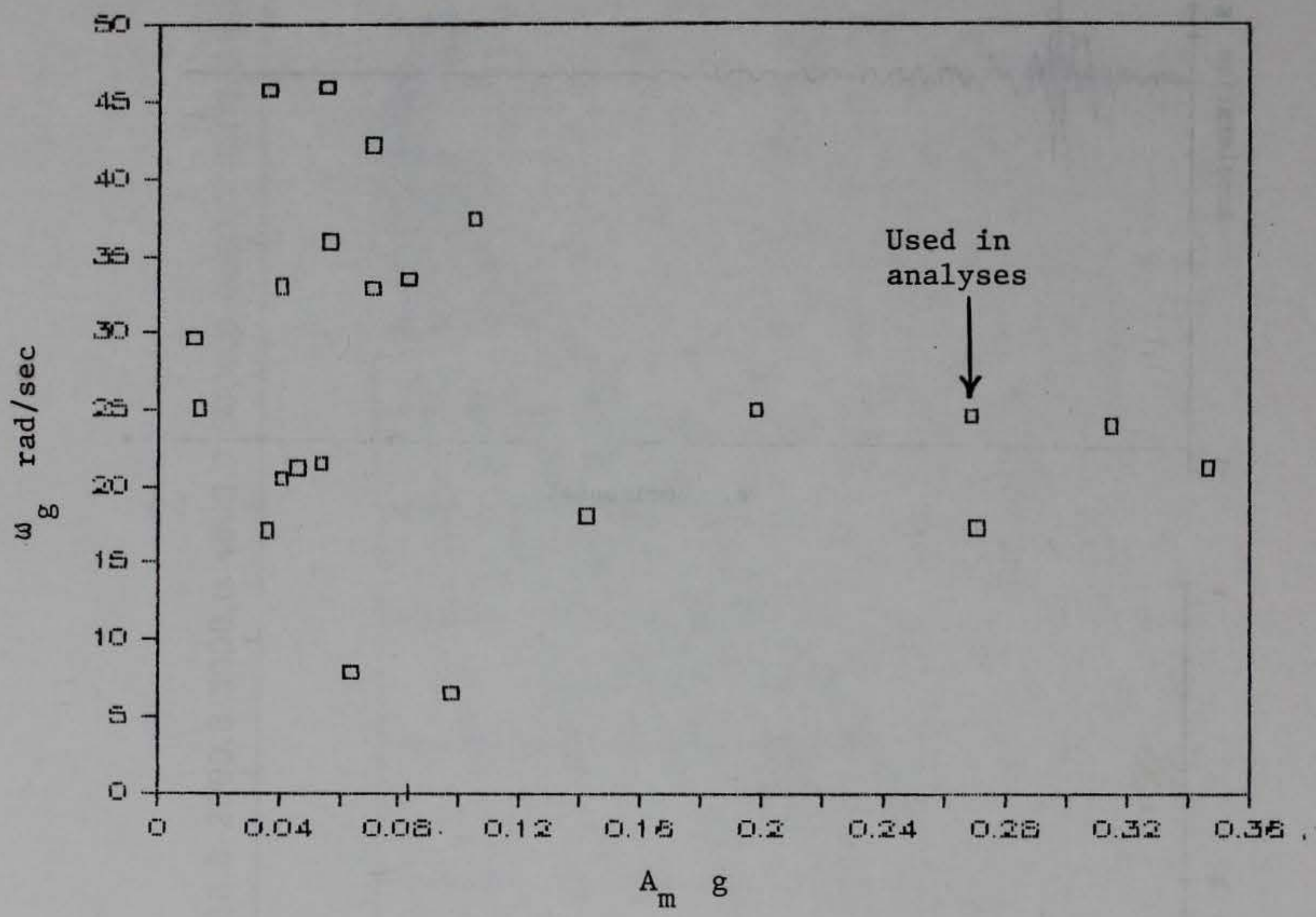

Figure 10. Characteristic frequency of rock sites 


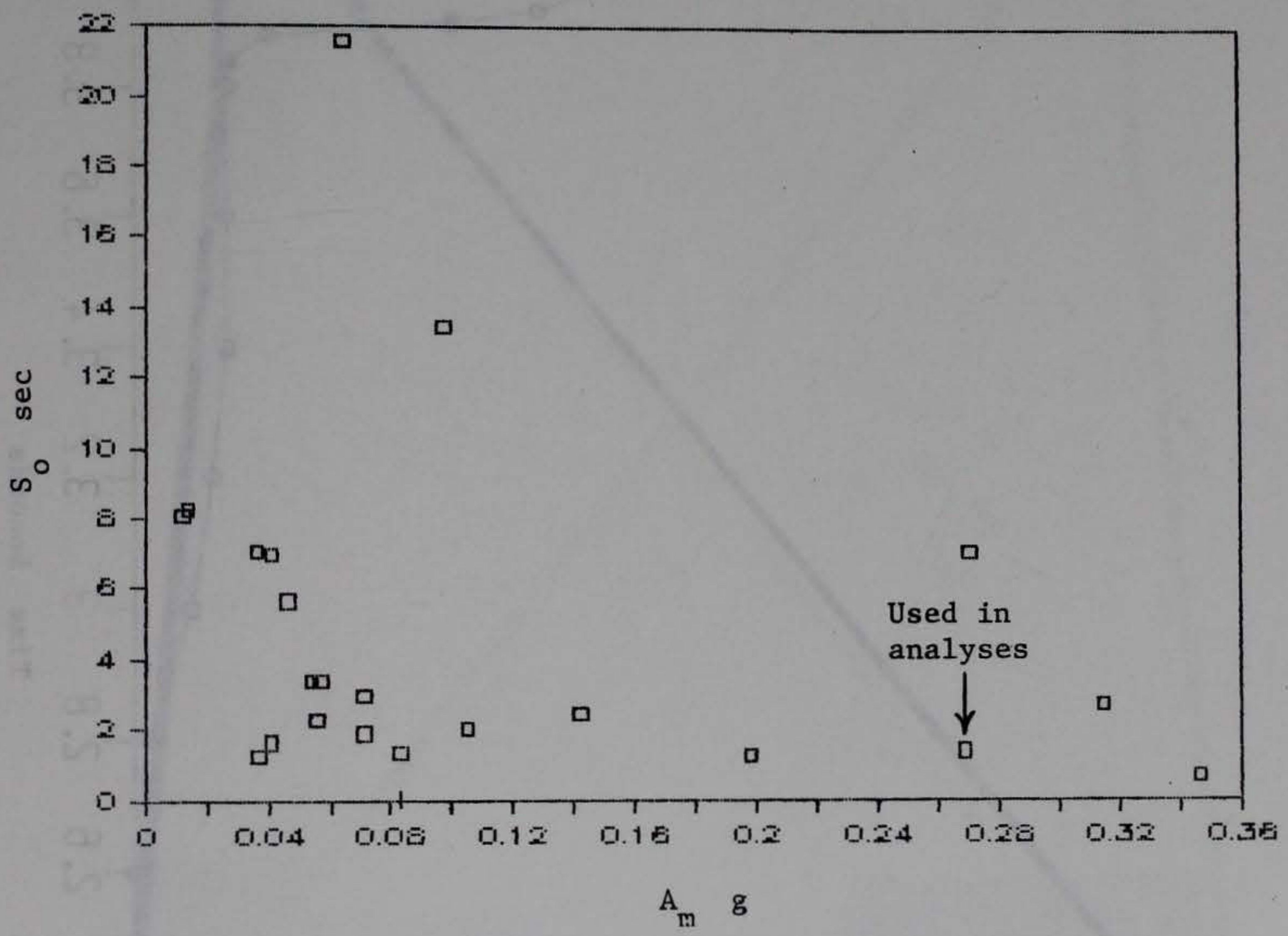

Figure 11. Duration of shaking at rock sites 


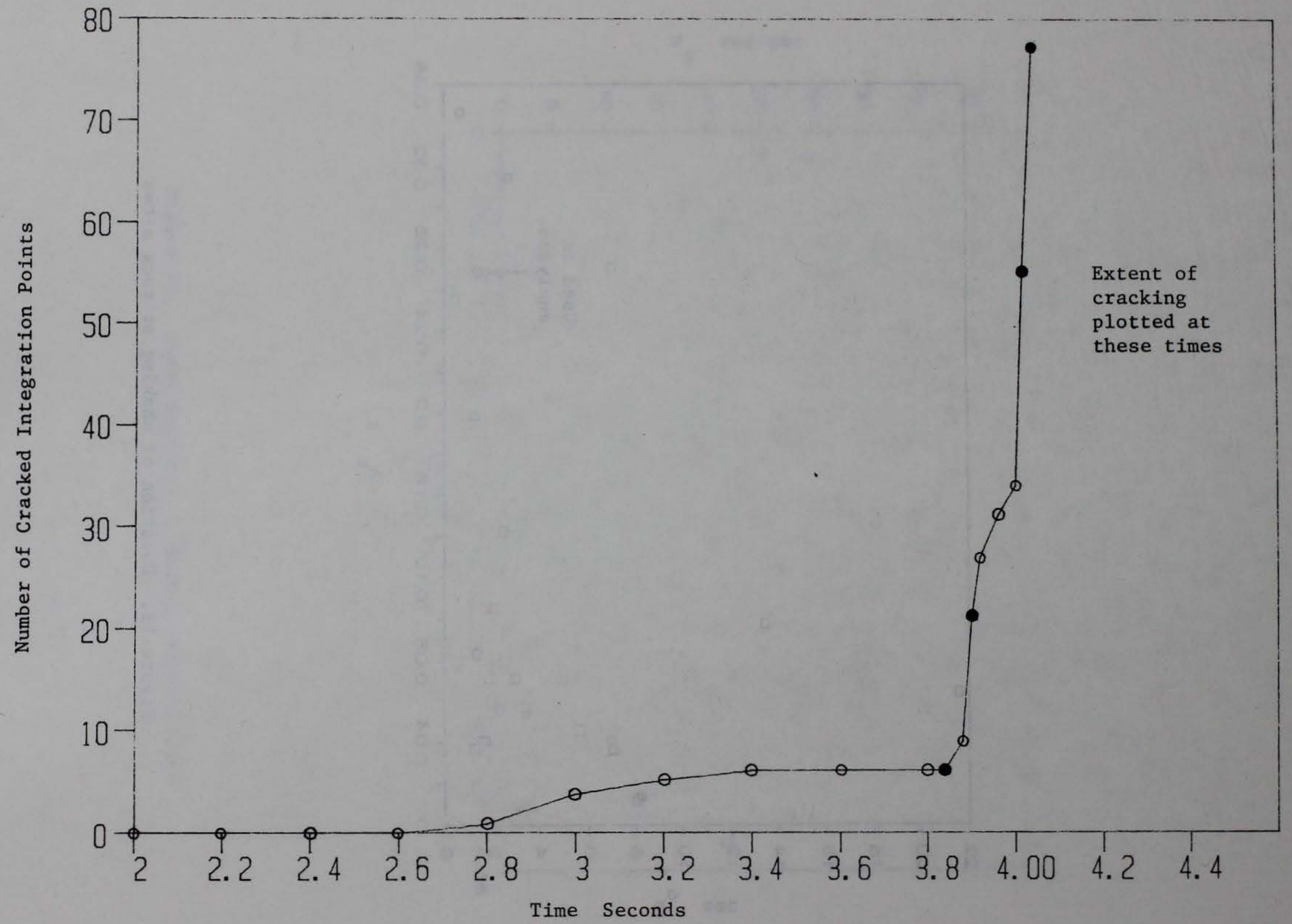

Figure 12. Cracking of Russell Dam with tripled Parkfield loading 


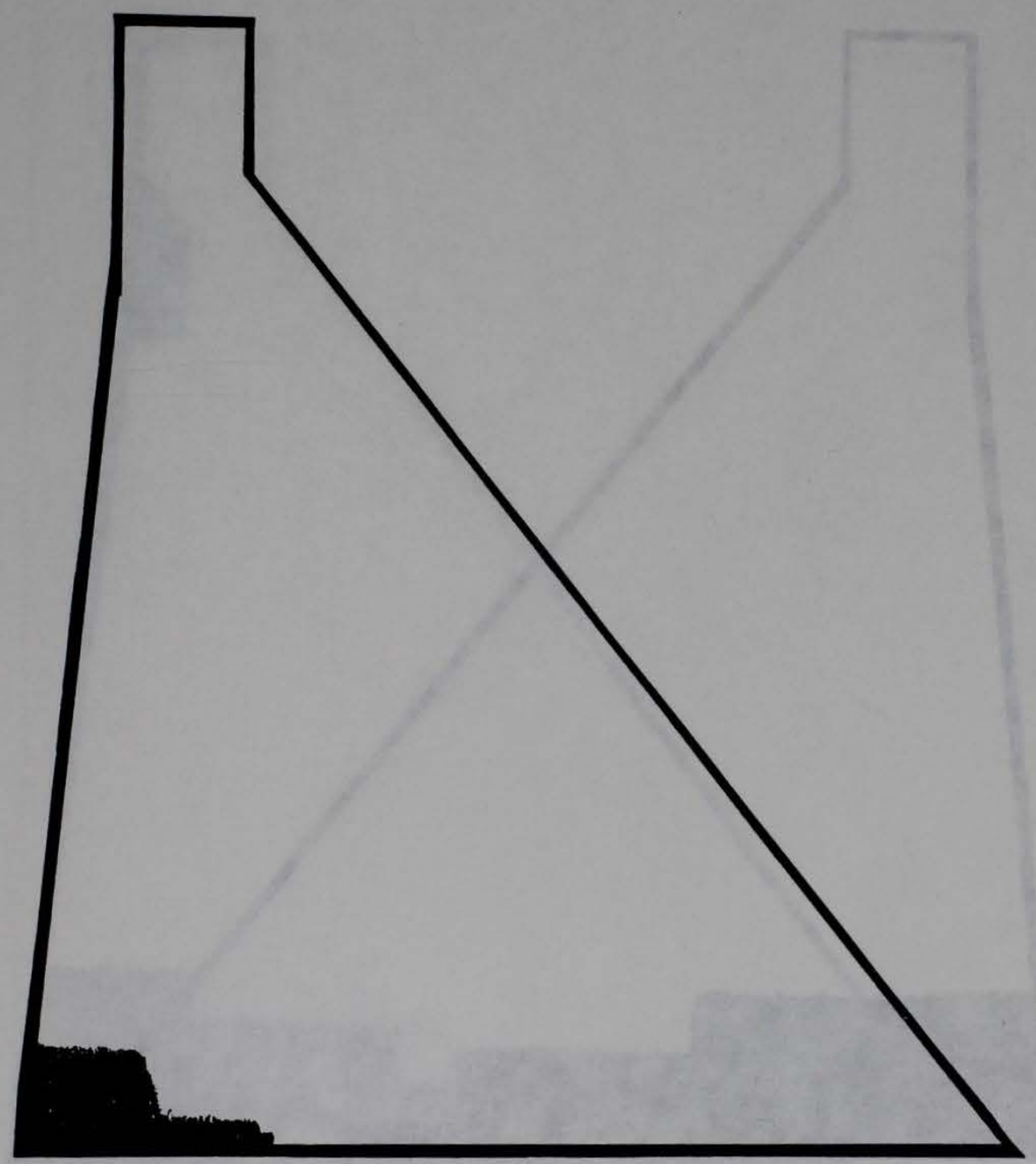

a. $t=3.84 \mathrm{sec}$

Figure 13. Cracked zones of Russell Dam with tripled Parkfield loading (Sheet 1 of 4) 


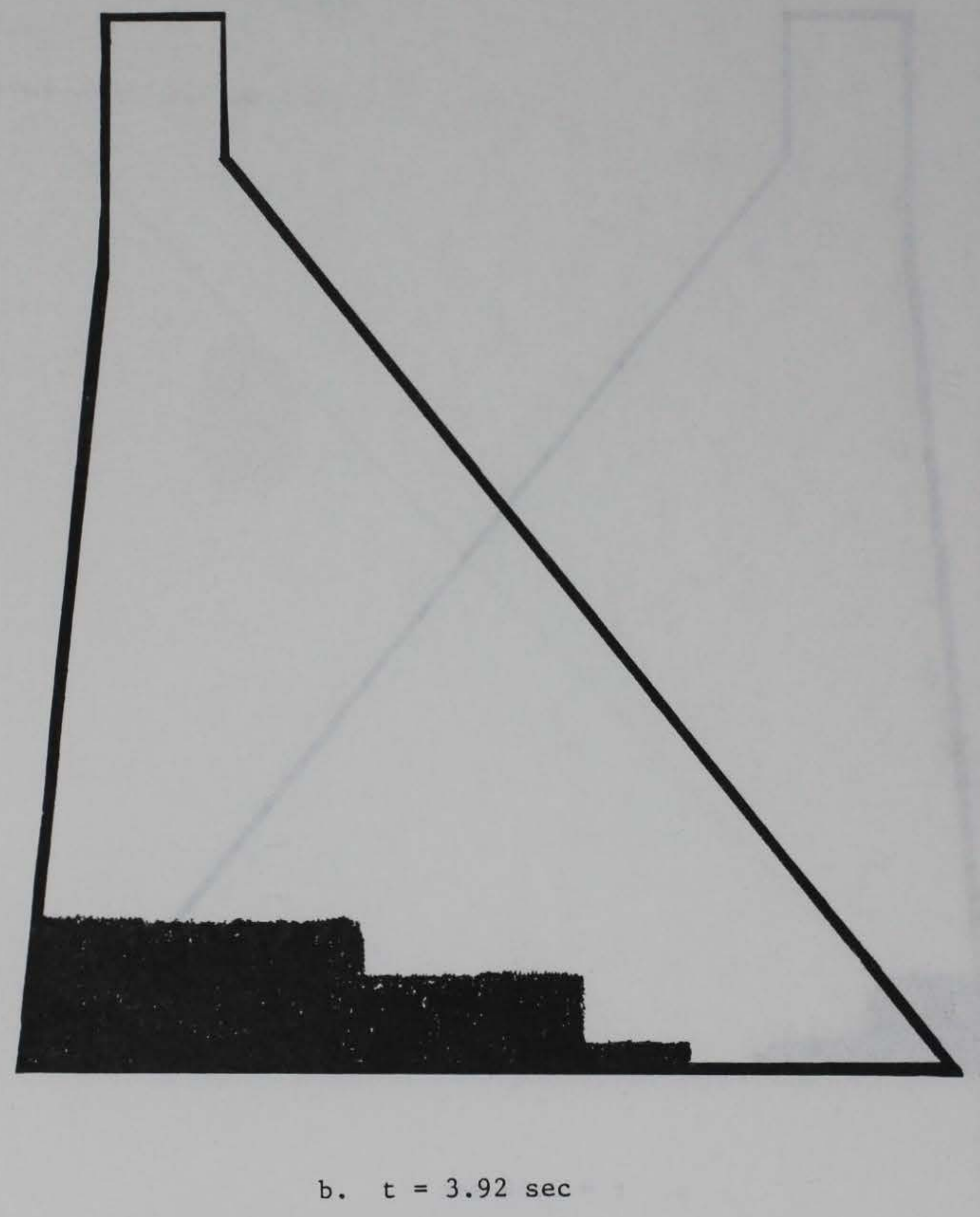

Figure 13. (Sheet 2 of 4 ) 


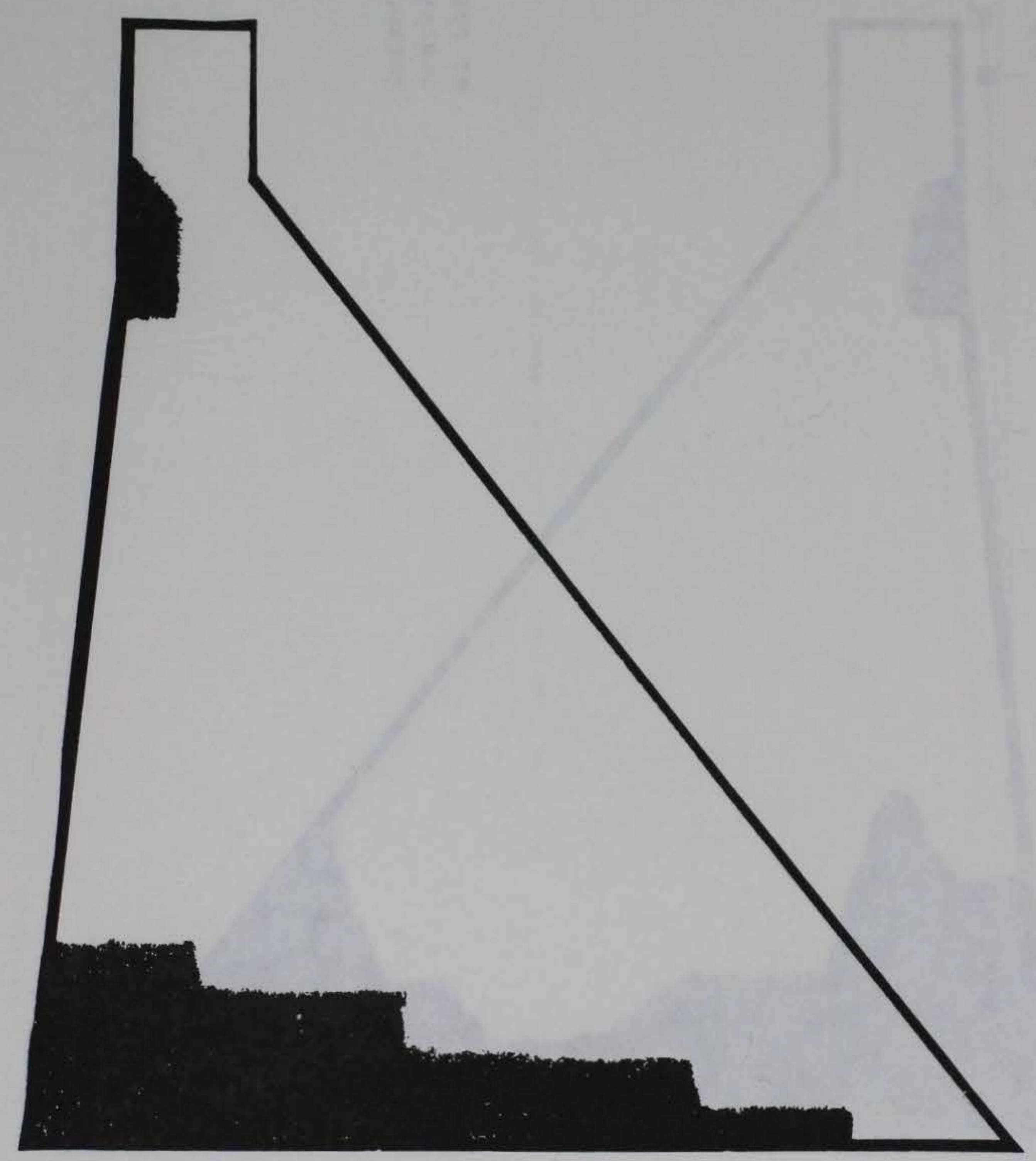

$$
\text { c. } t=4.02 \mathrm{sec}
$$

Figure 13. (Sheet 3 of 4 ) 


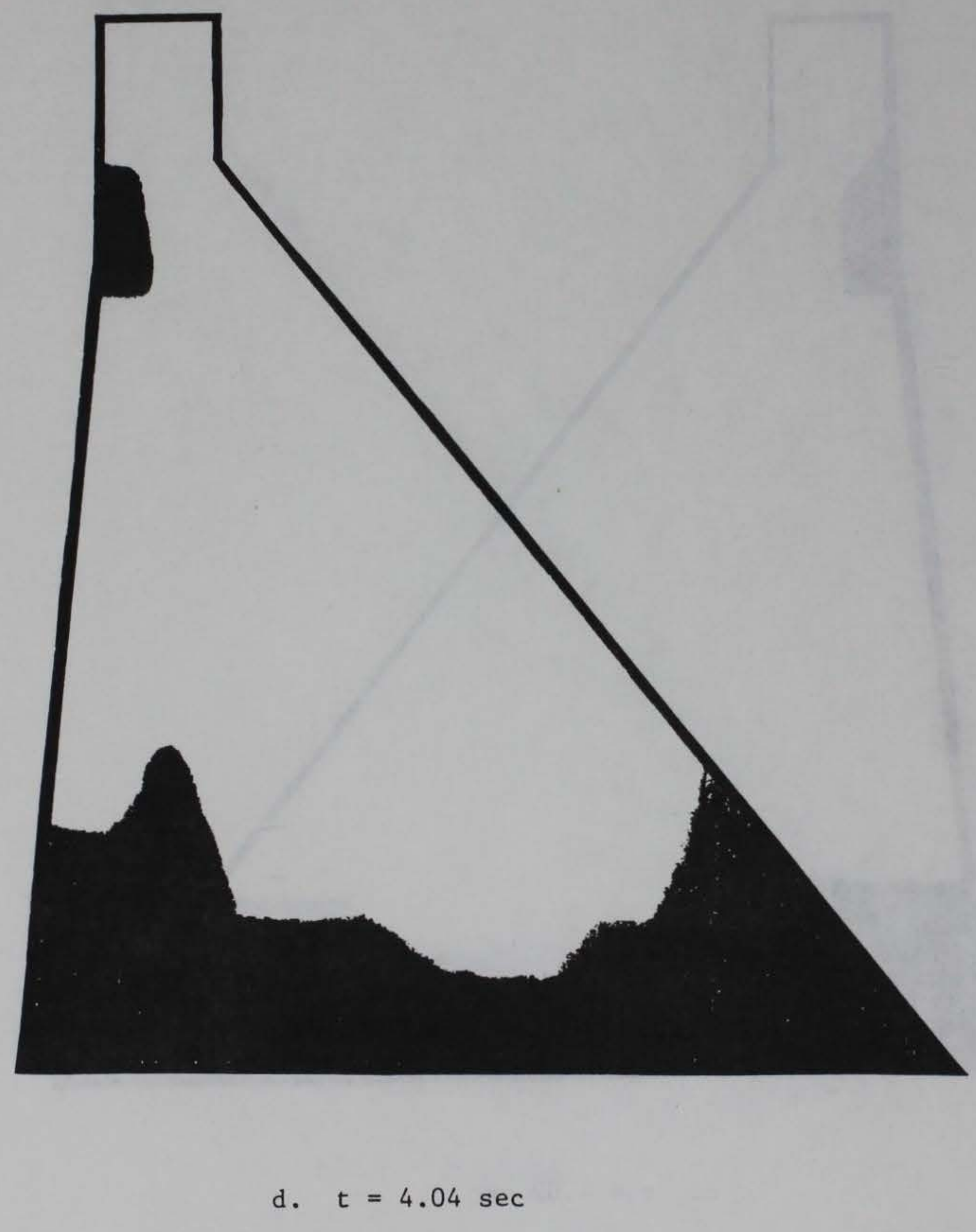

Figure 13. (Sheet 4 of 4 ) 


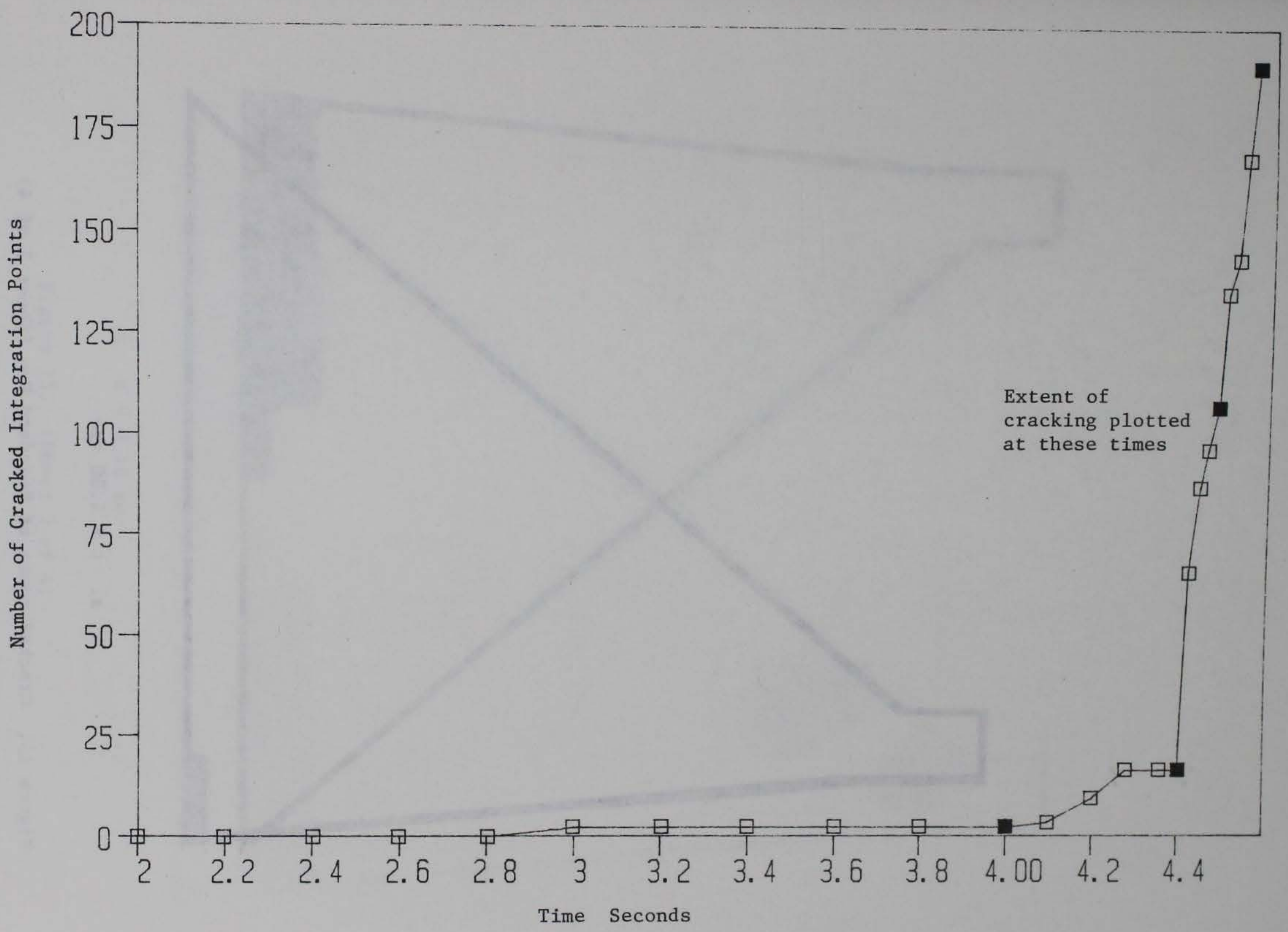

Figure 14. Cracking of Standard Dam 


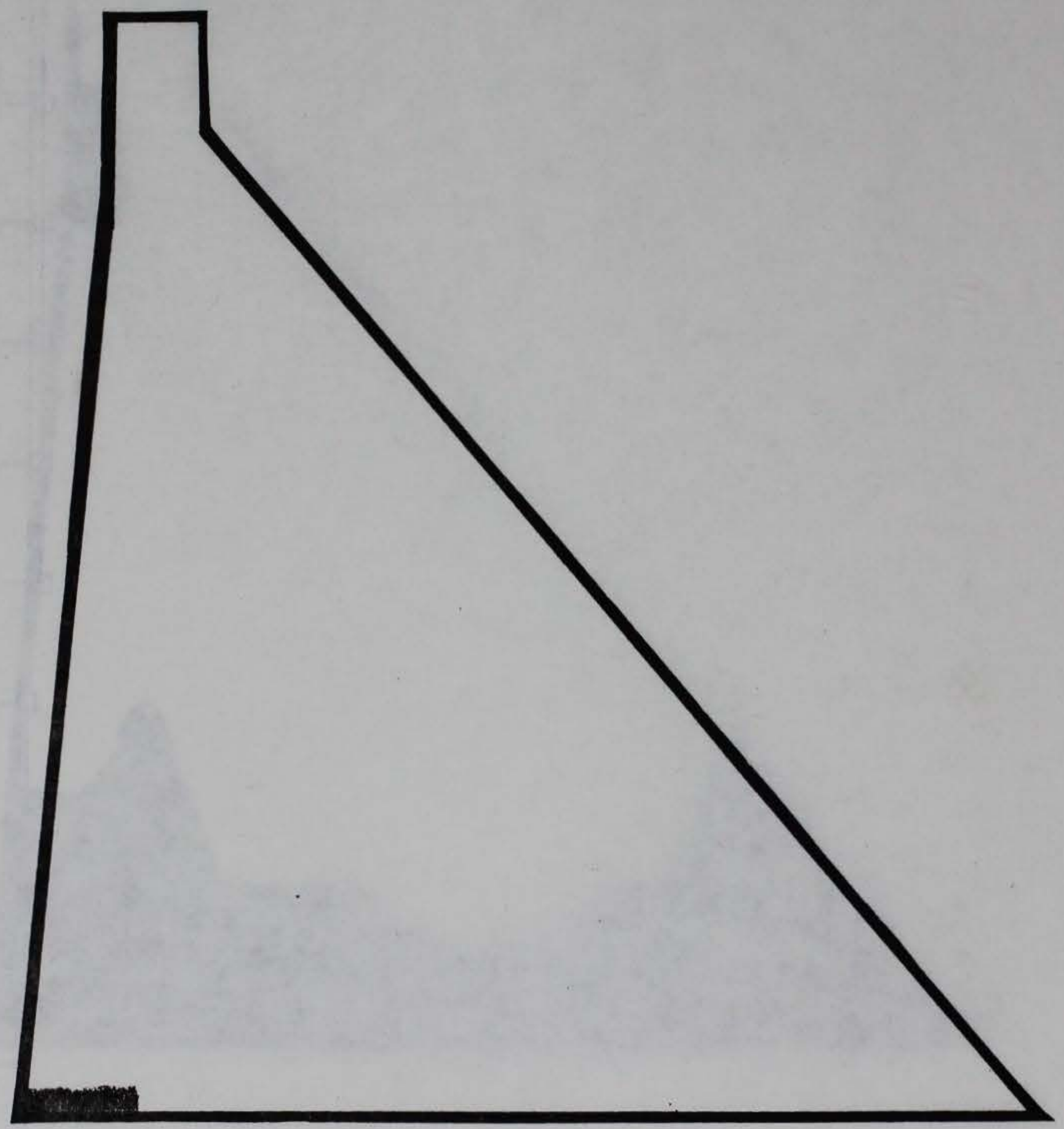

a. $t=4.00 \mathrm{sec}$

Figure 15. Cracked zones of Standard Dam (Sheet 1 of 4) 


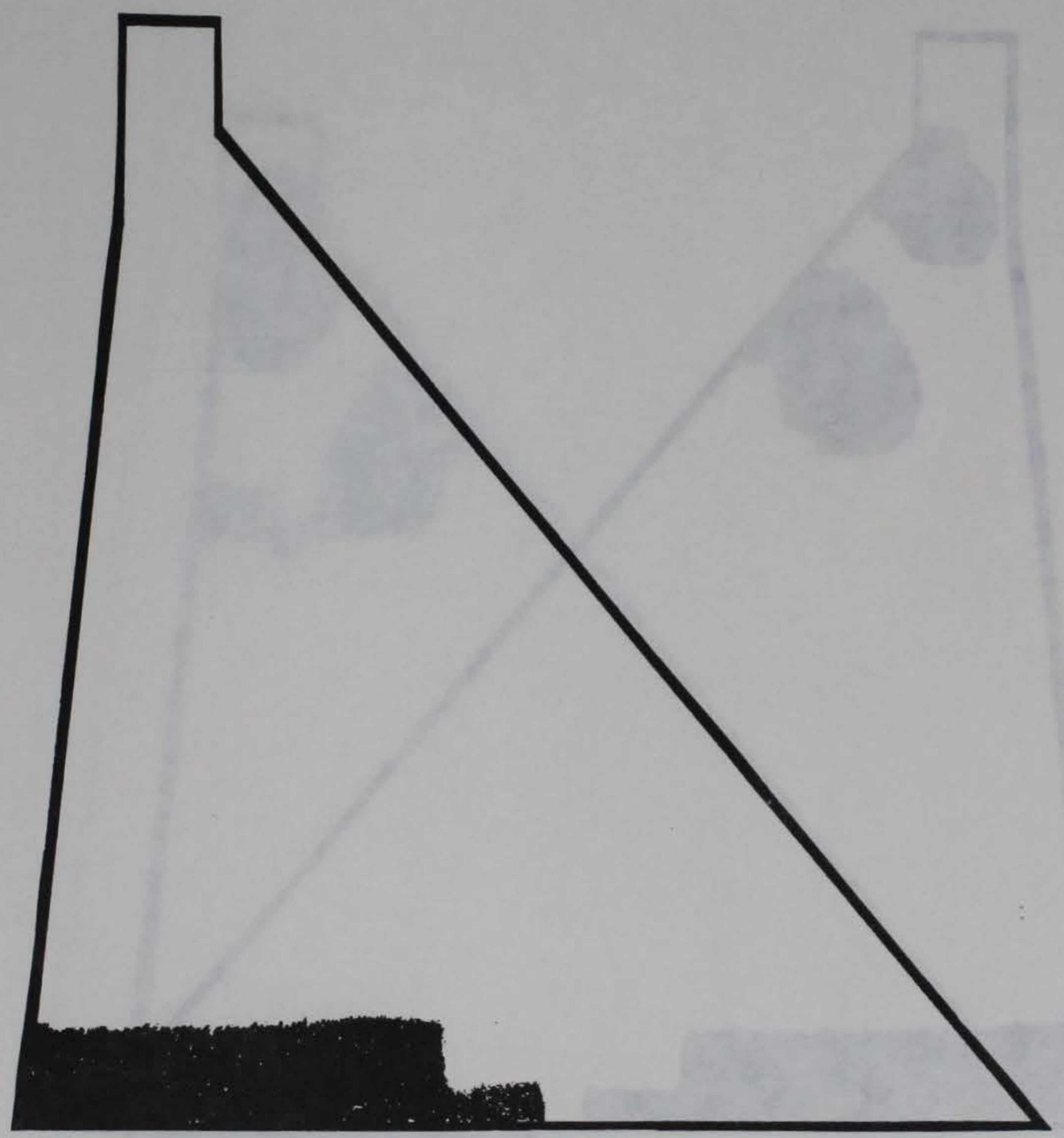

b. $t=4.40 \mathrm{sec}$

Figure 15. (Sheet 2 of 4) 


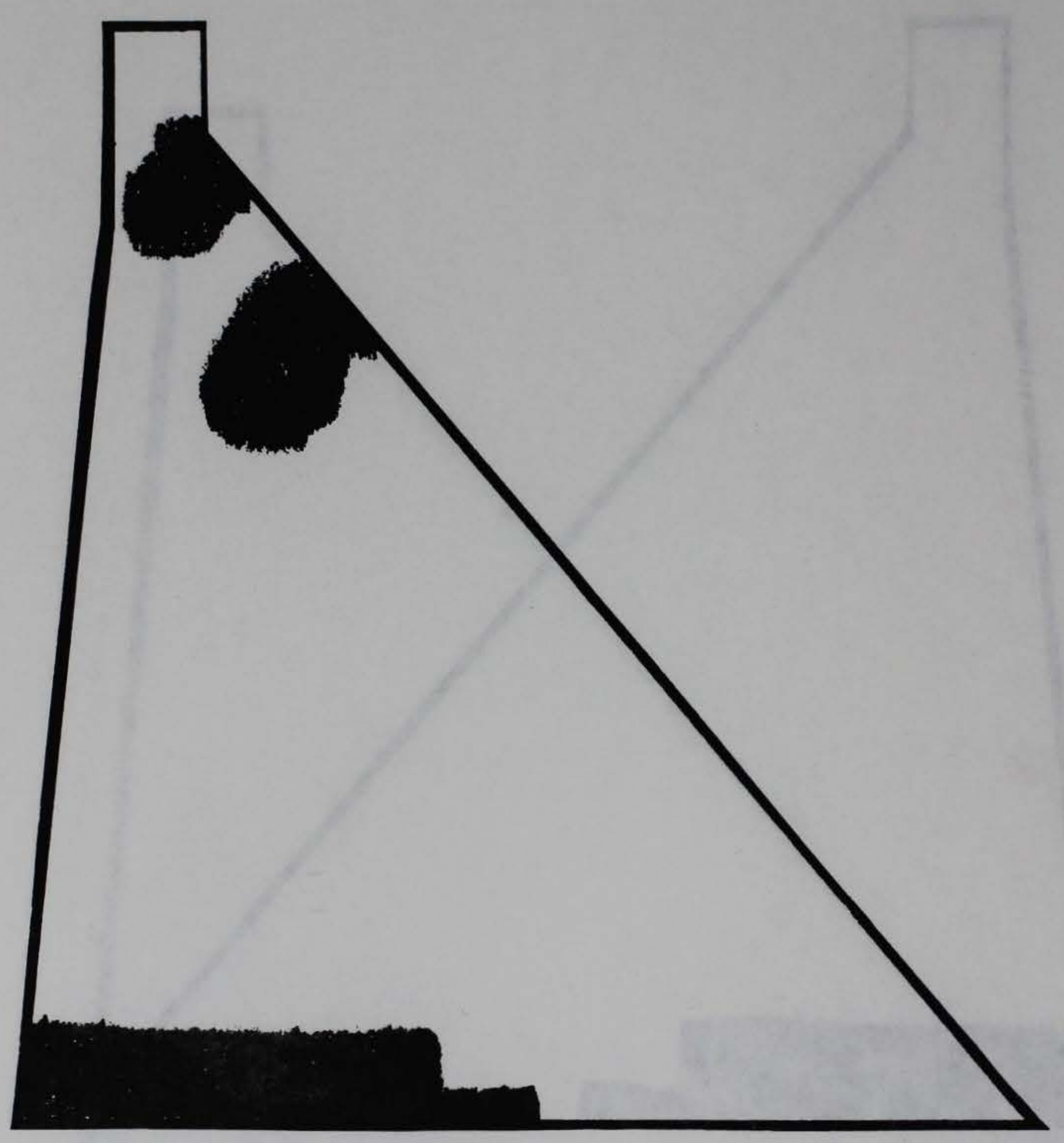

c. $t=4.48 \mathrm{sec}$

Figure 15. (Sheet 3 of 4 ) 


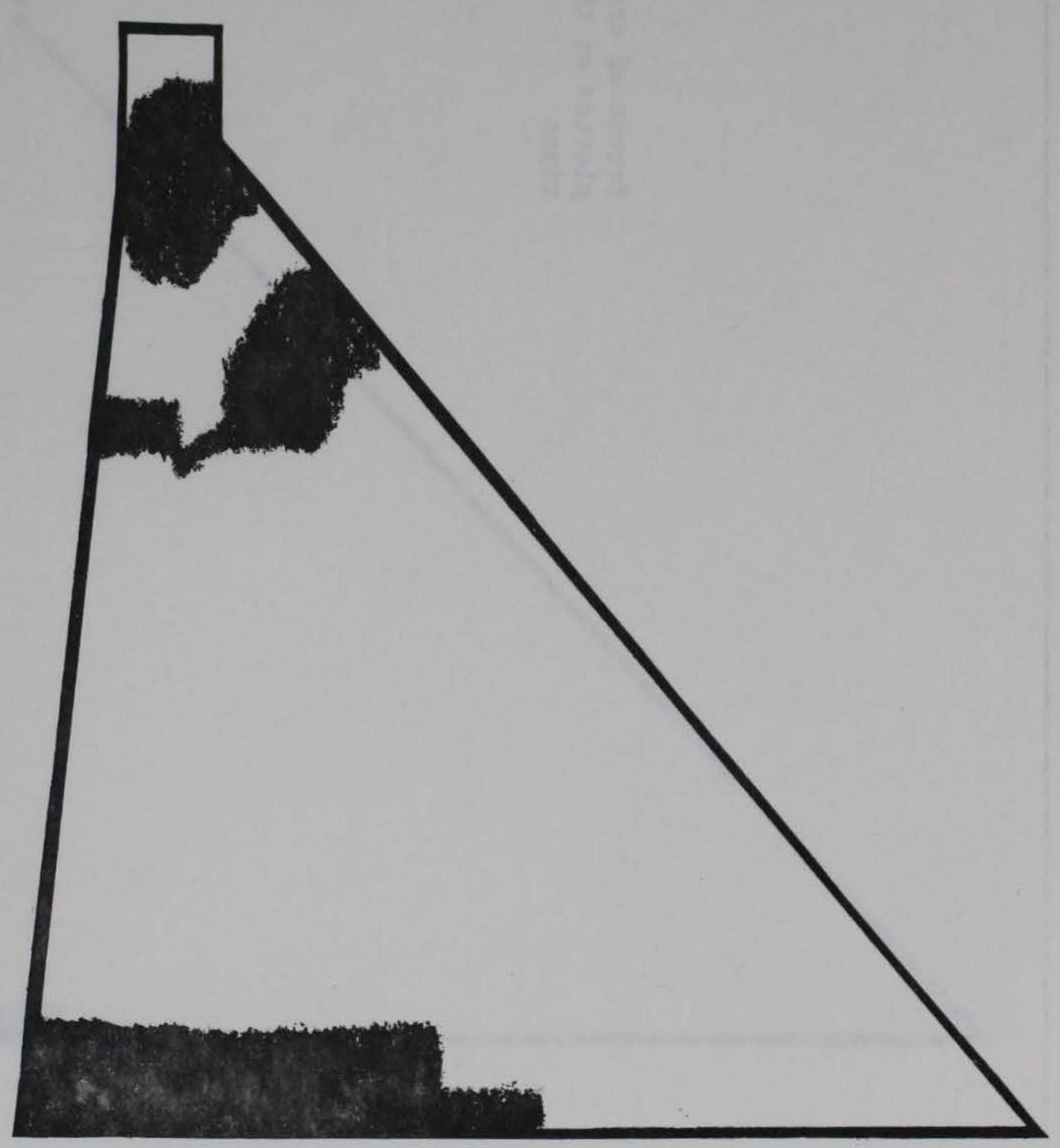

d. $t=4.56 \mathrm{sec}$

Figure 15. (Sheet 4 of 4 ) 


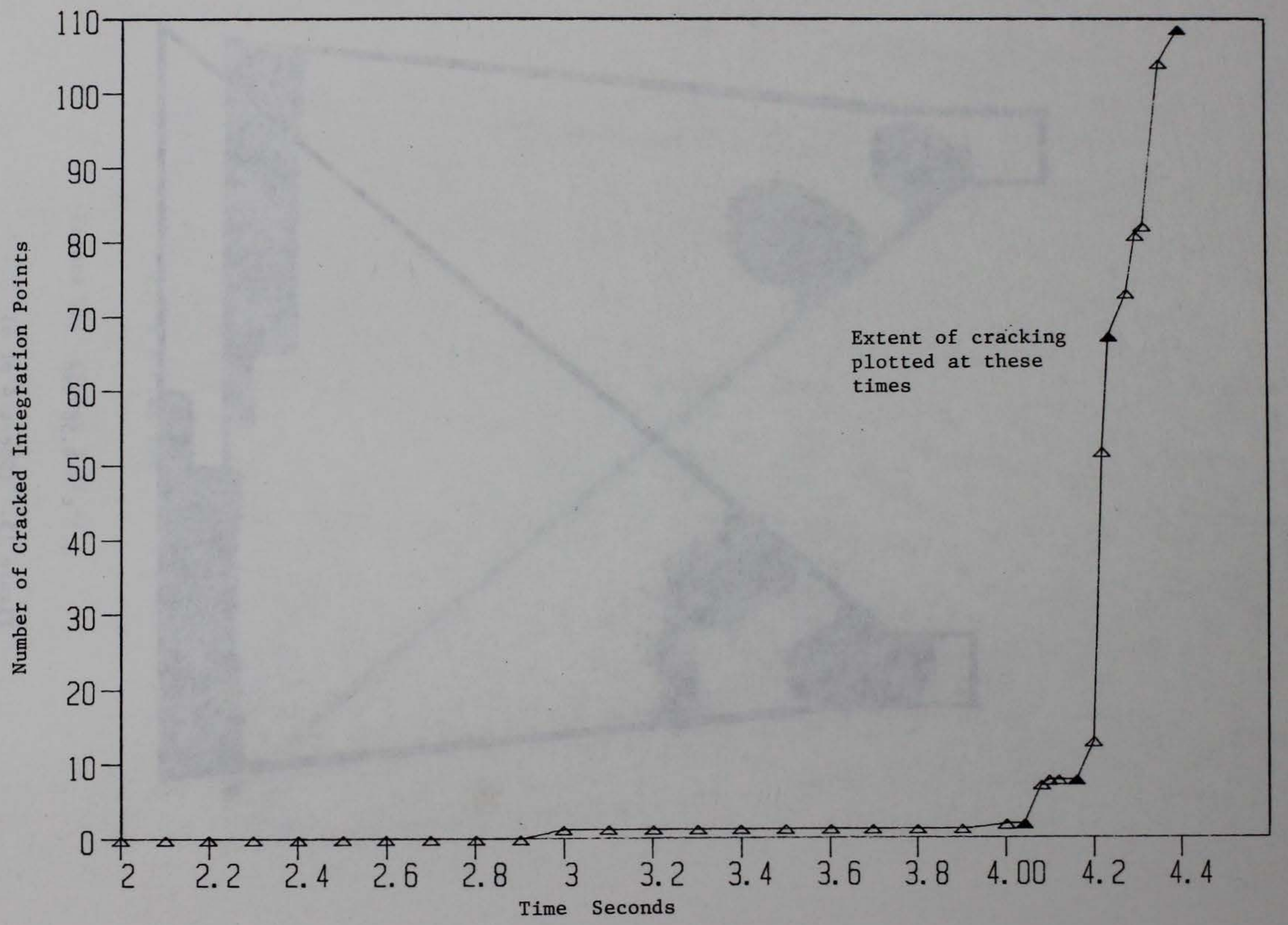

Figure 16. Cracking of Dworshak Dam 


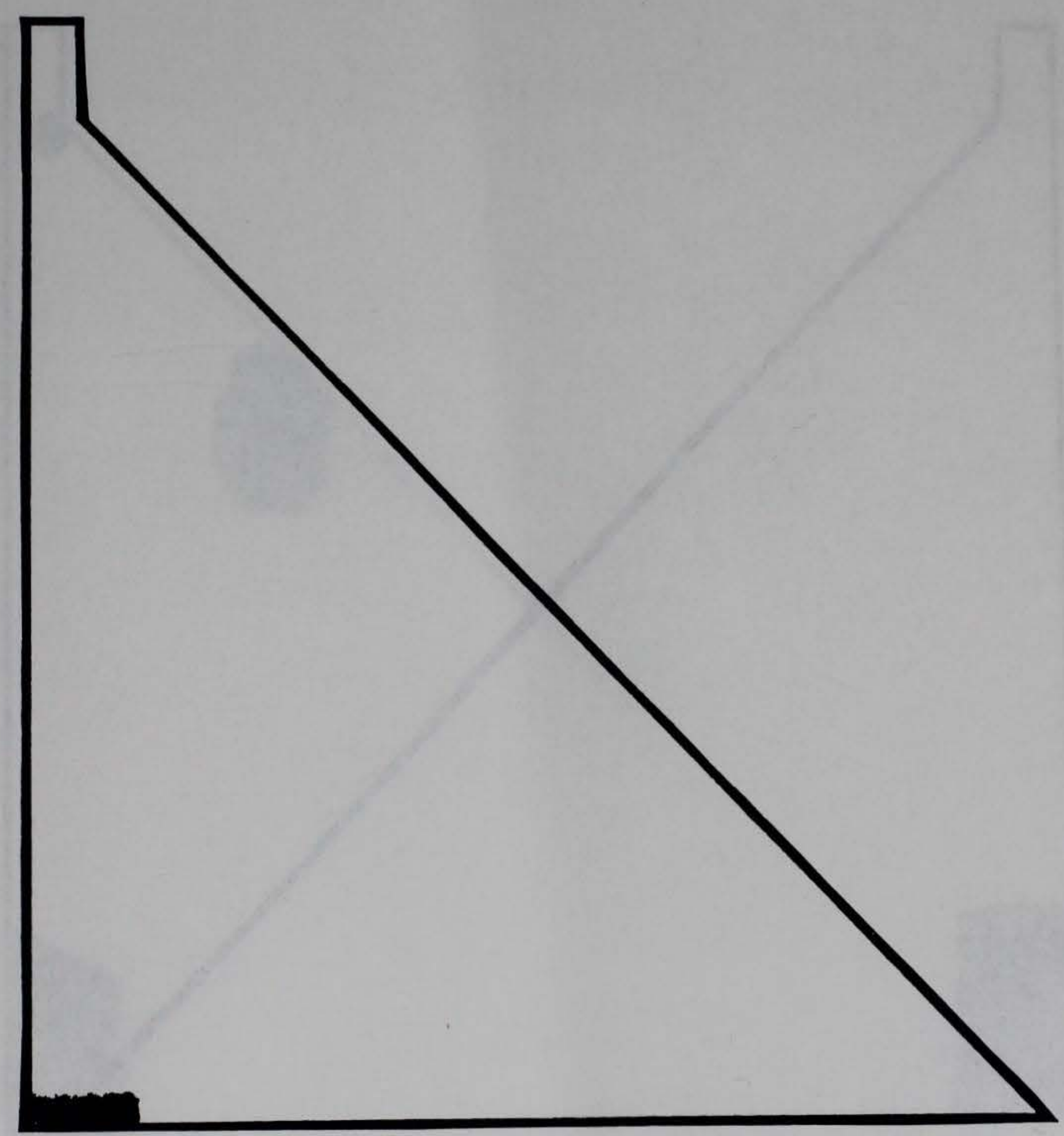

a. $t=4.04 \mathrm{sec}$

Figure 17. Cracked zones of Dworshak Dam (Sheet 1 of 4) 


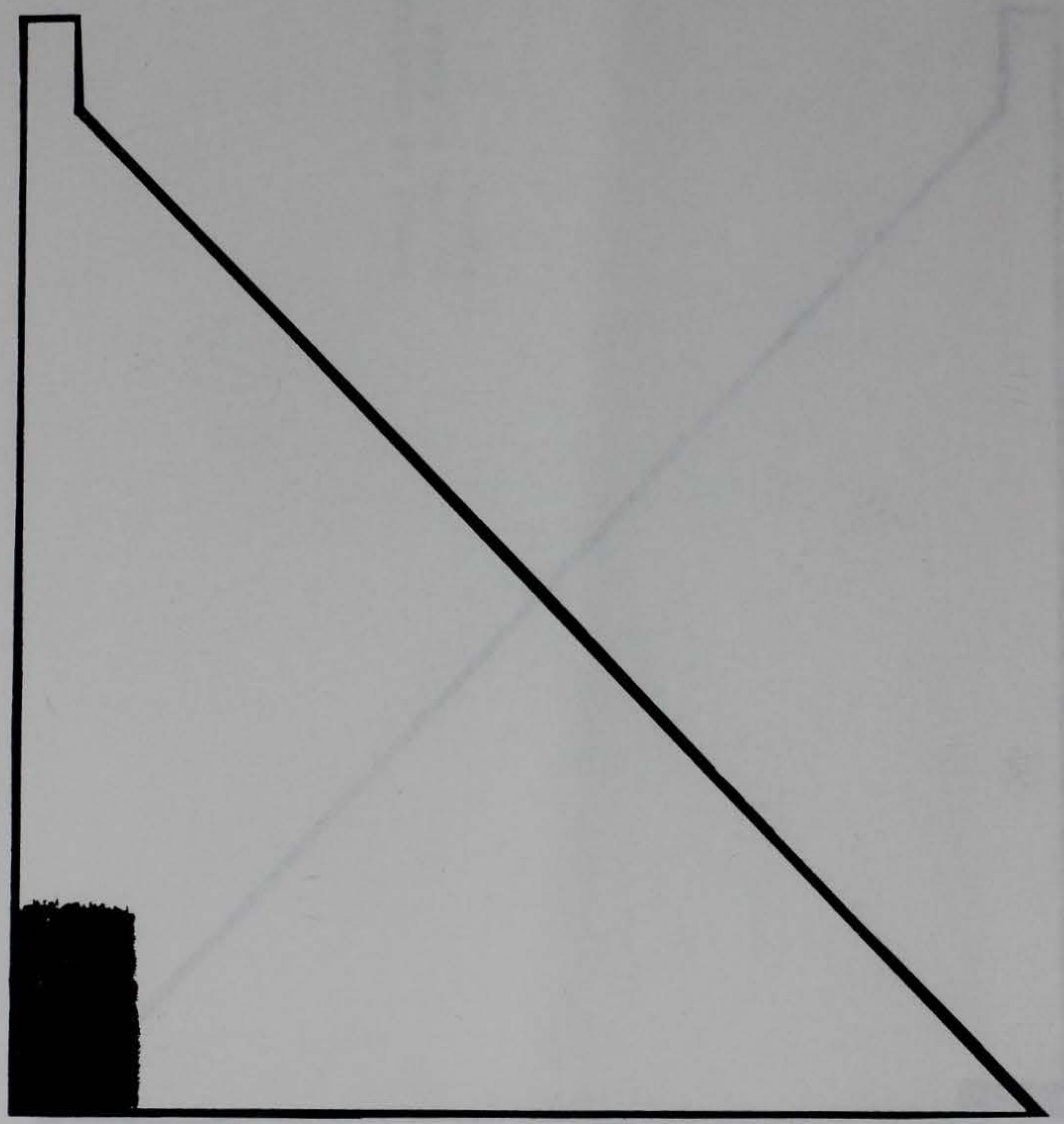

b. $t=4.16 \mathrm{sec}$

Figure 17. (Sheet 2 of 4) 


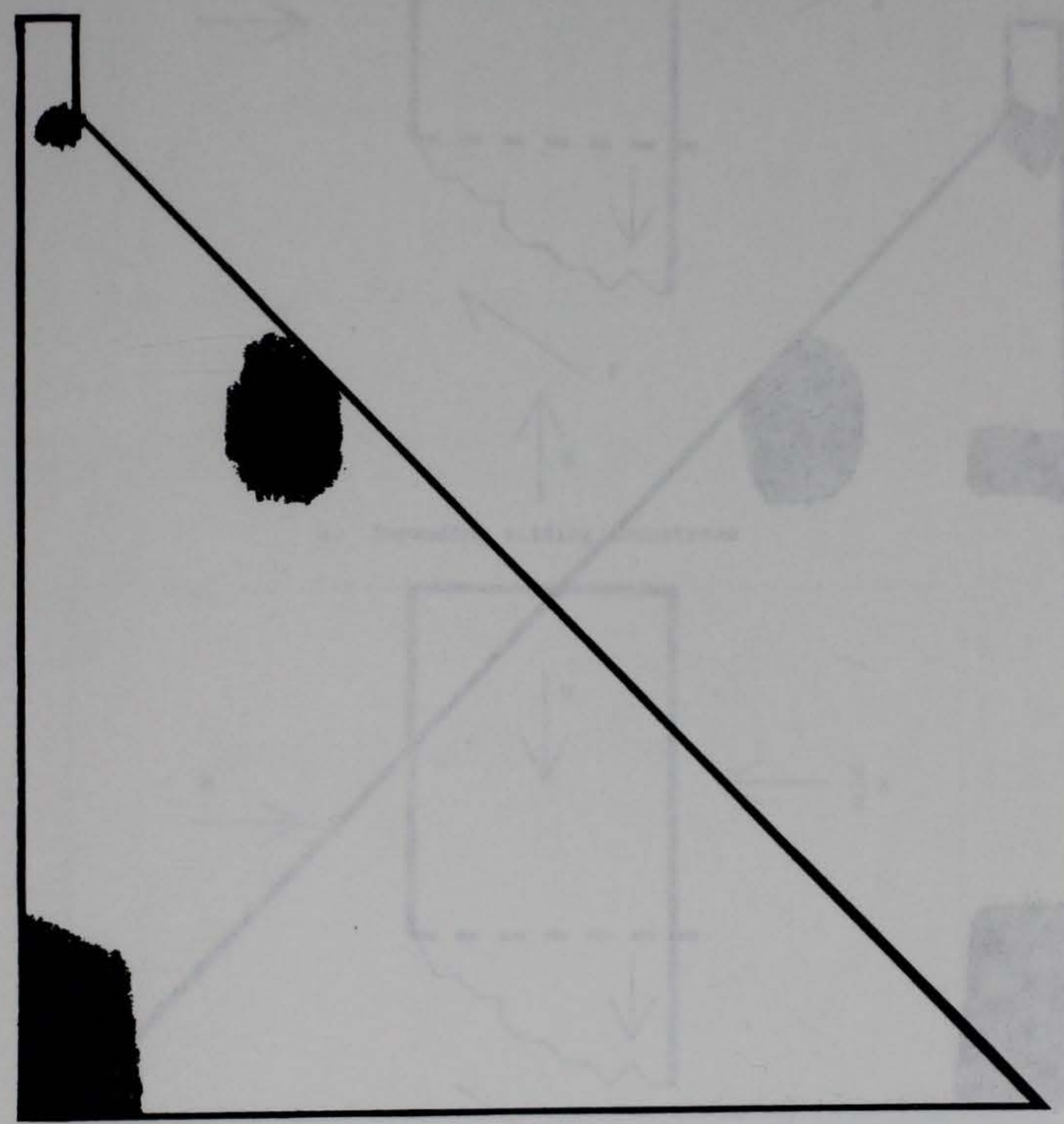

c. $t=4.24 \mathrm{sec}$

Figure 17. (Sheet 3 of 4 ) 


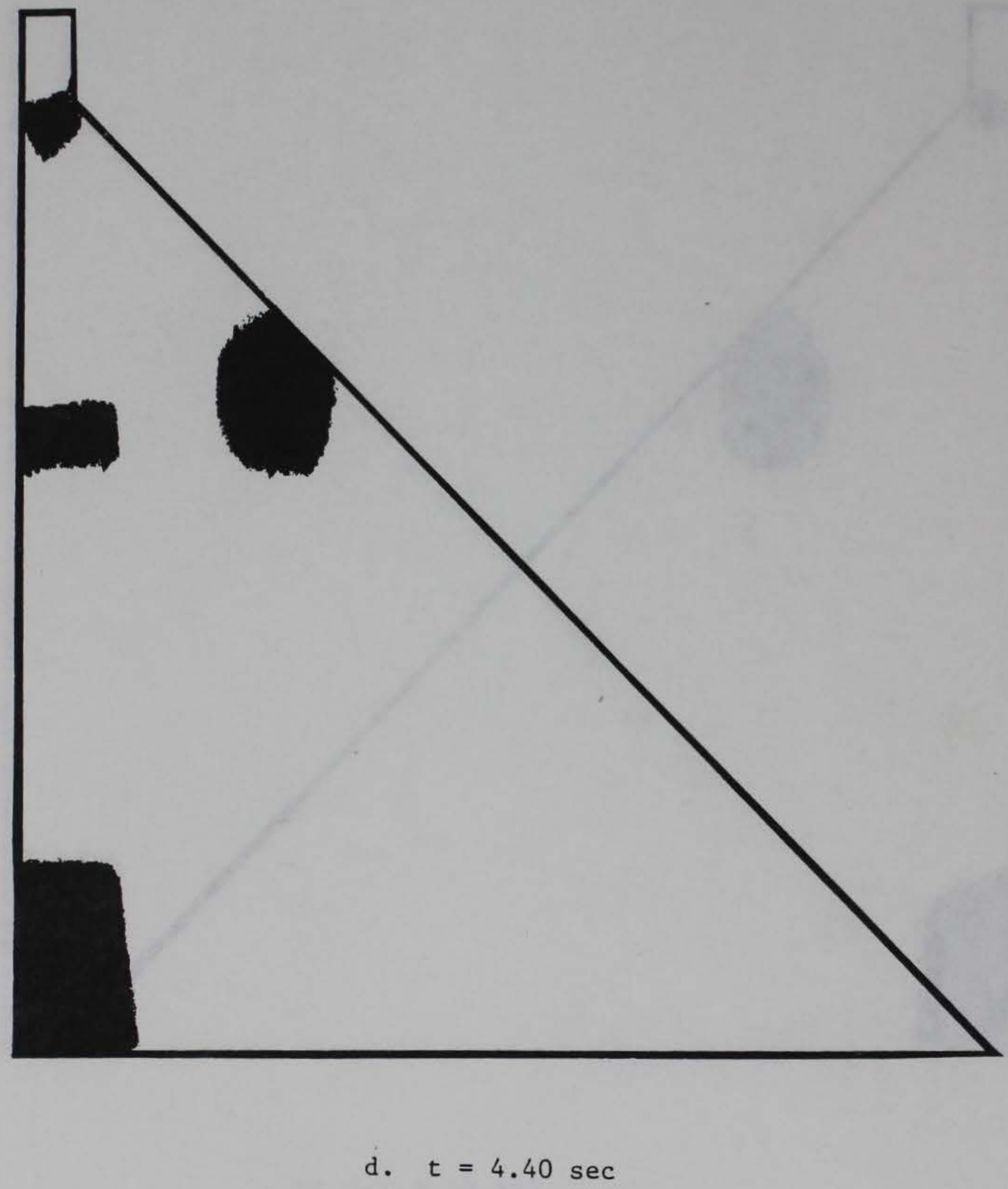

Figure 17. (Sheet 4 of 4 ) 


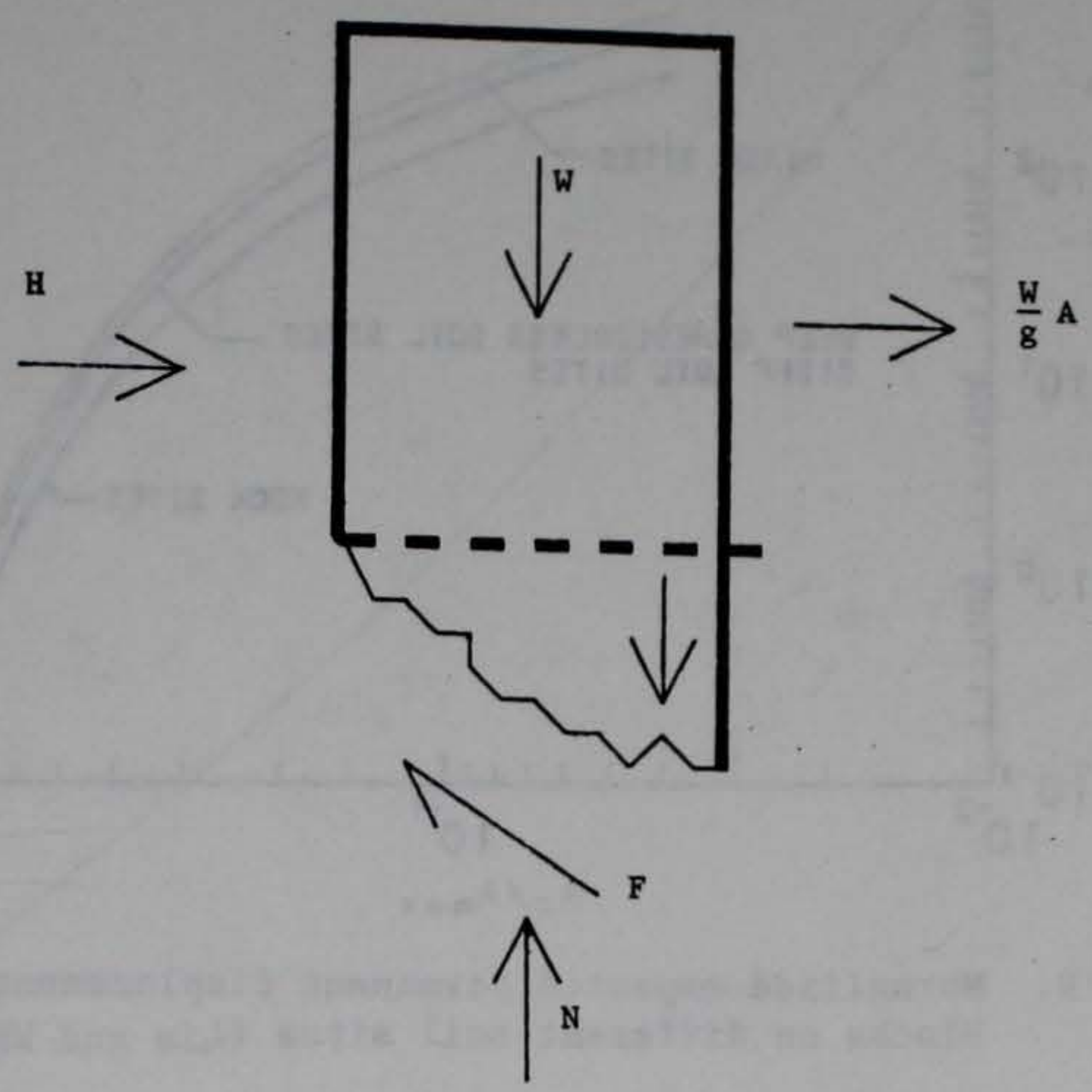

a. Impending sliding downstream

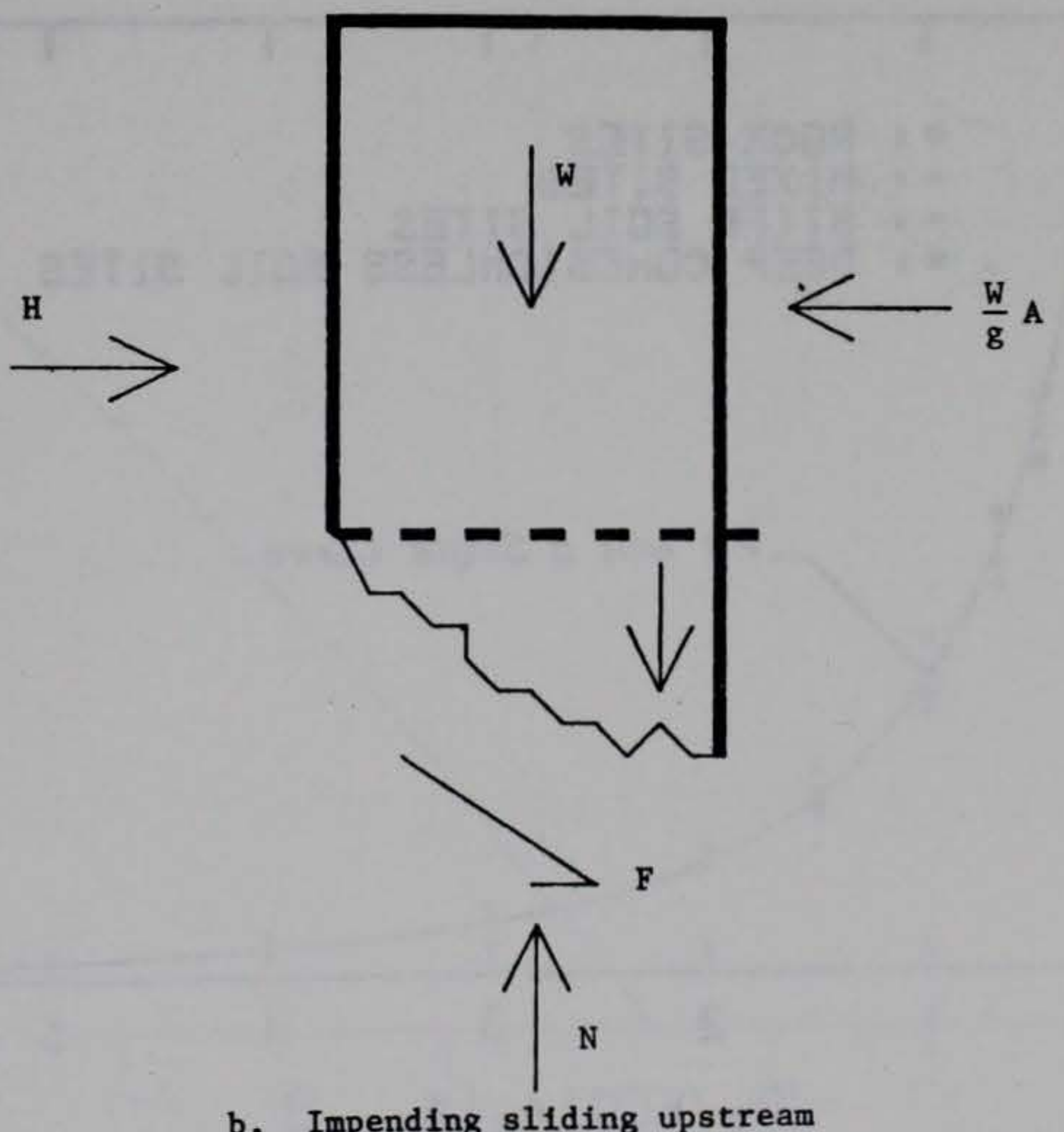

Figure 18. Free body diagram of cracked dam 


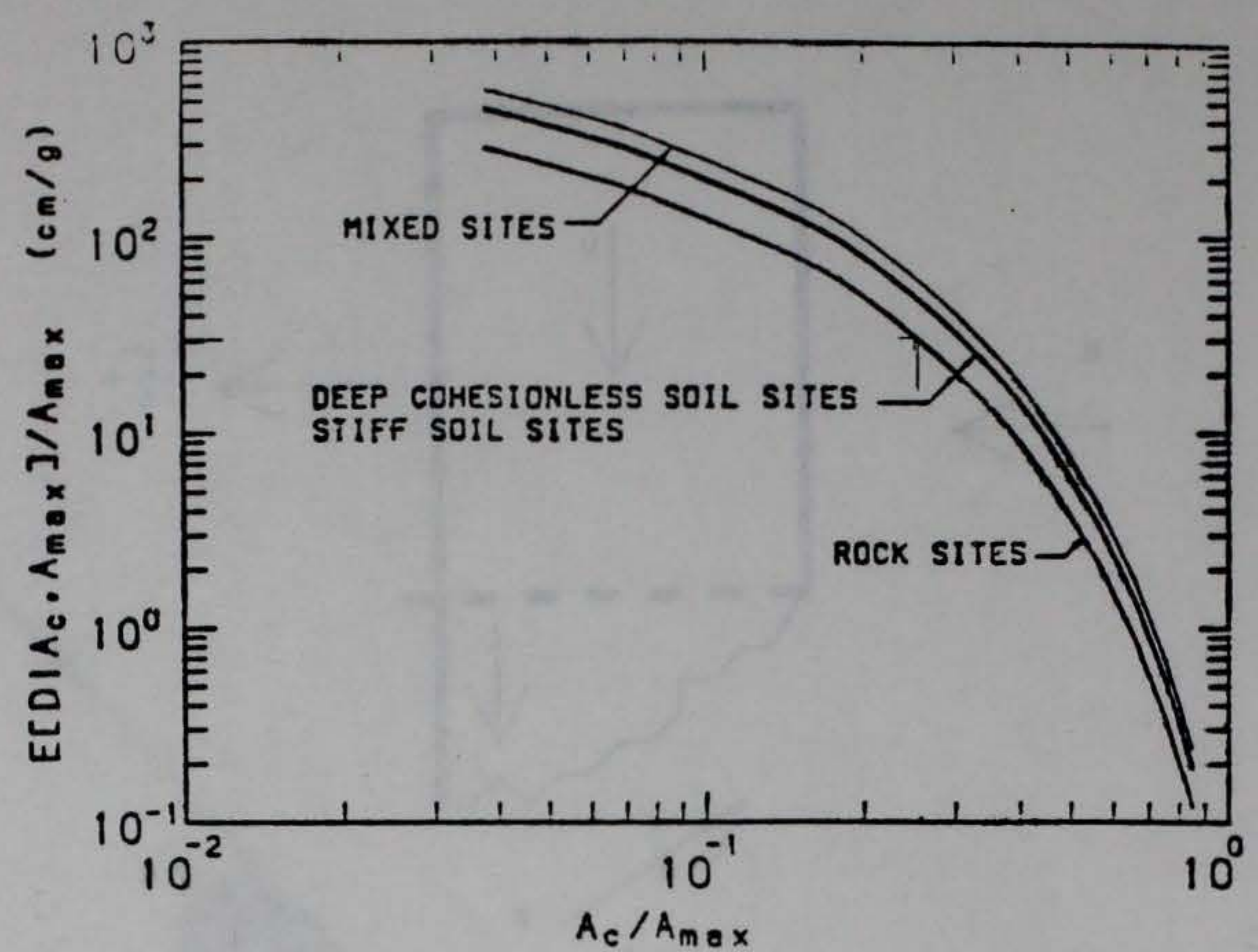

Figure 19. Normalized expected permanent displacements for sliding blocks on different soil sites (Lin and Whitman 1986)

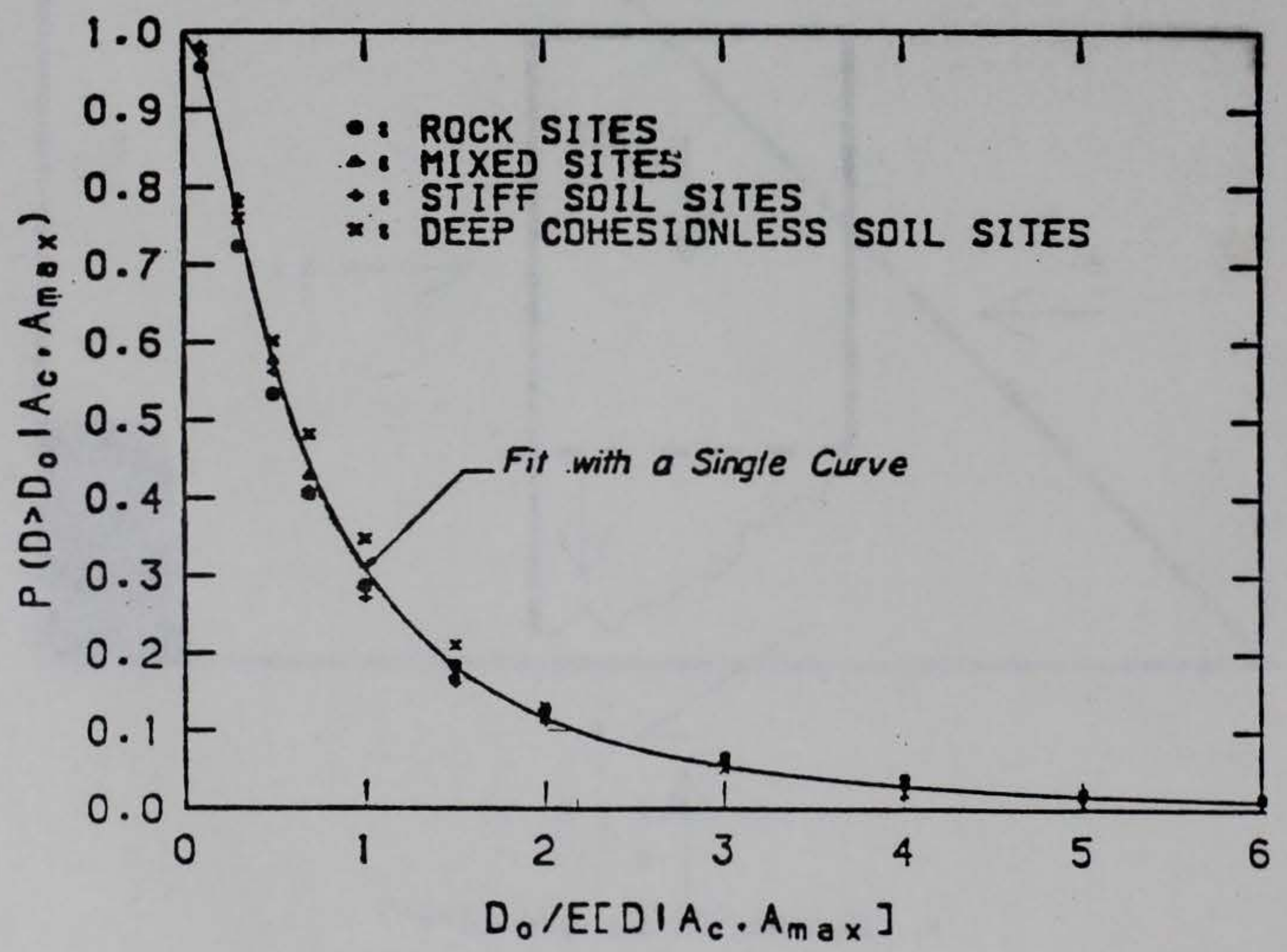

Figure 20. Normalized conditional distributions of permanent displacements for sliding blocks (Lin and Whitman 1986) 


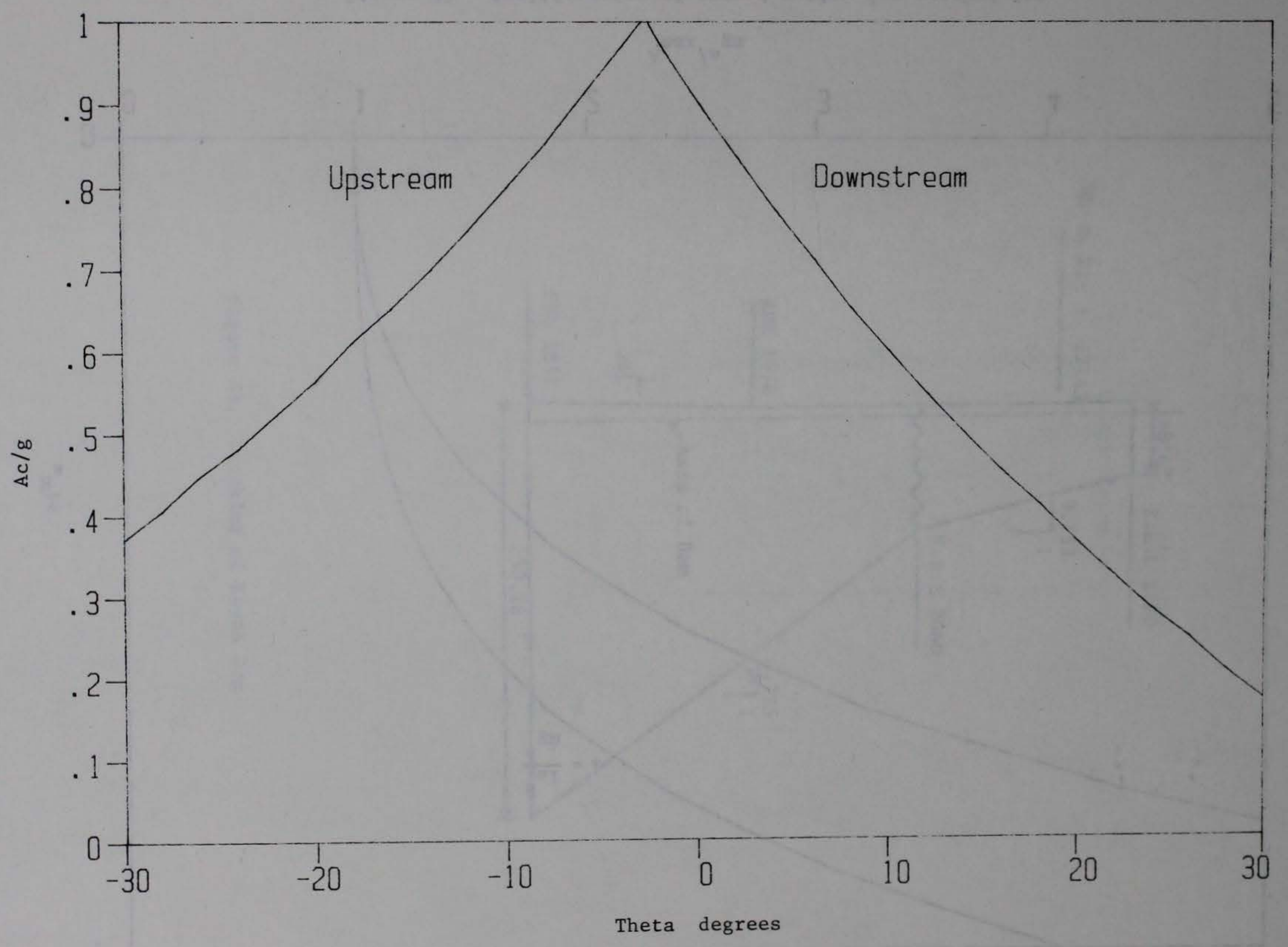

Figure 21. Critical acceleration of cracked dam for $\mu=1.0$ and $H / W=0.1$ 


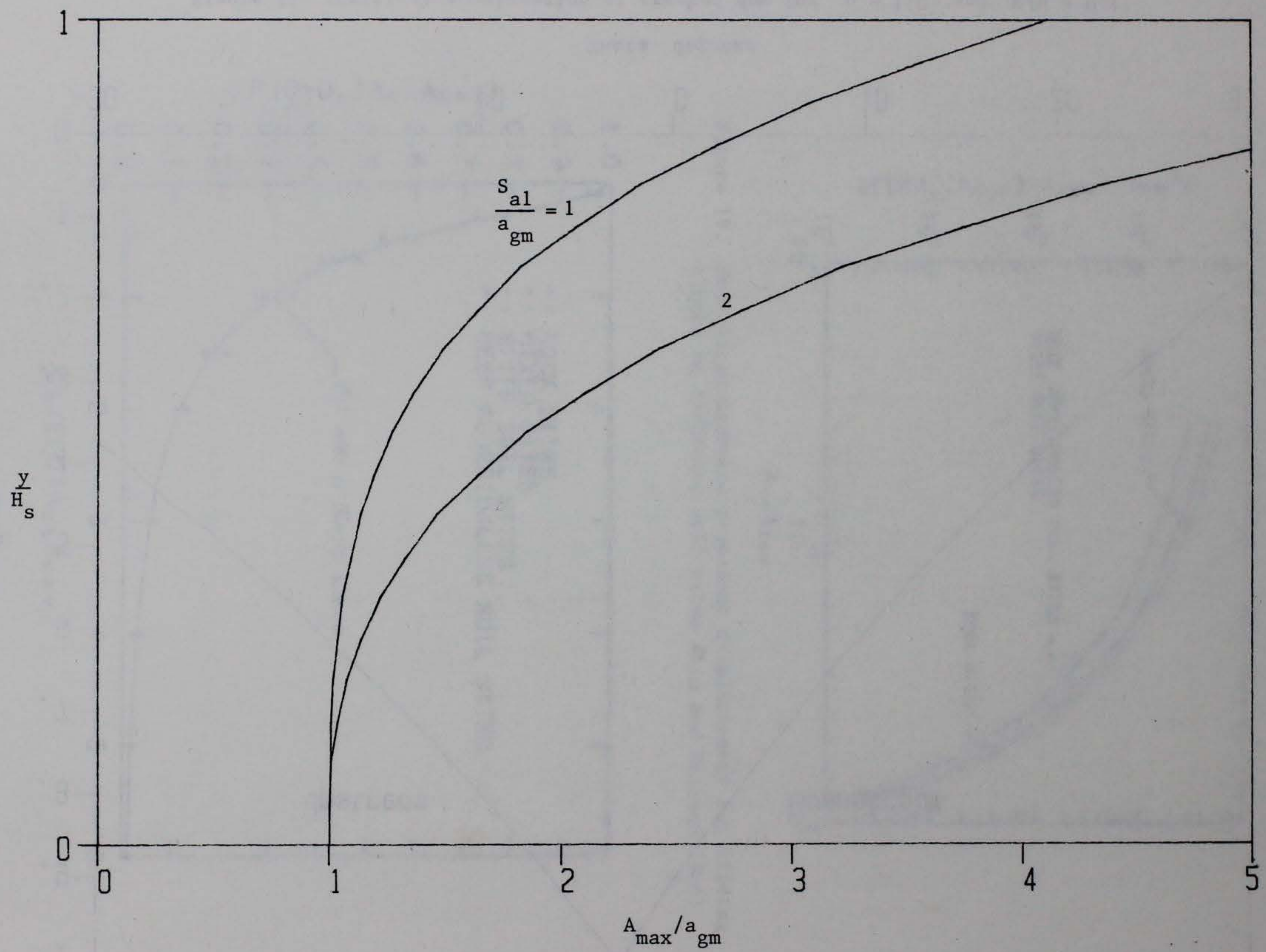

Figure 22. Amplification of ground motion for cracked dam 


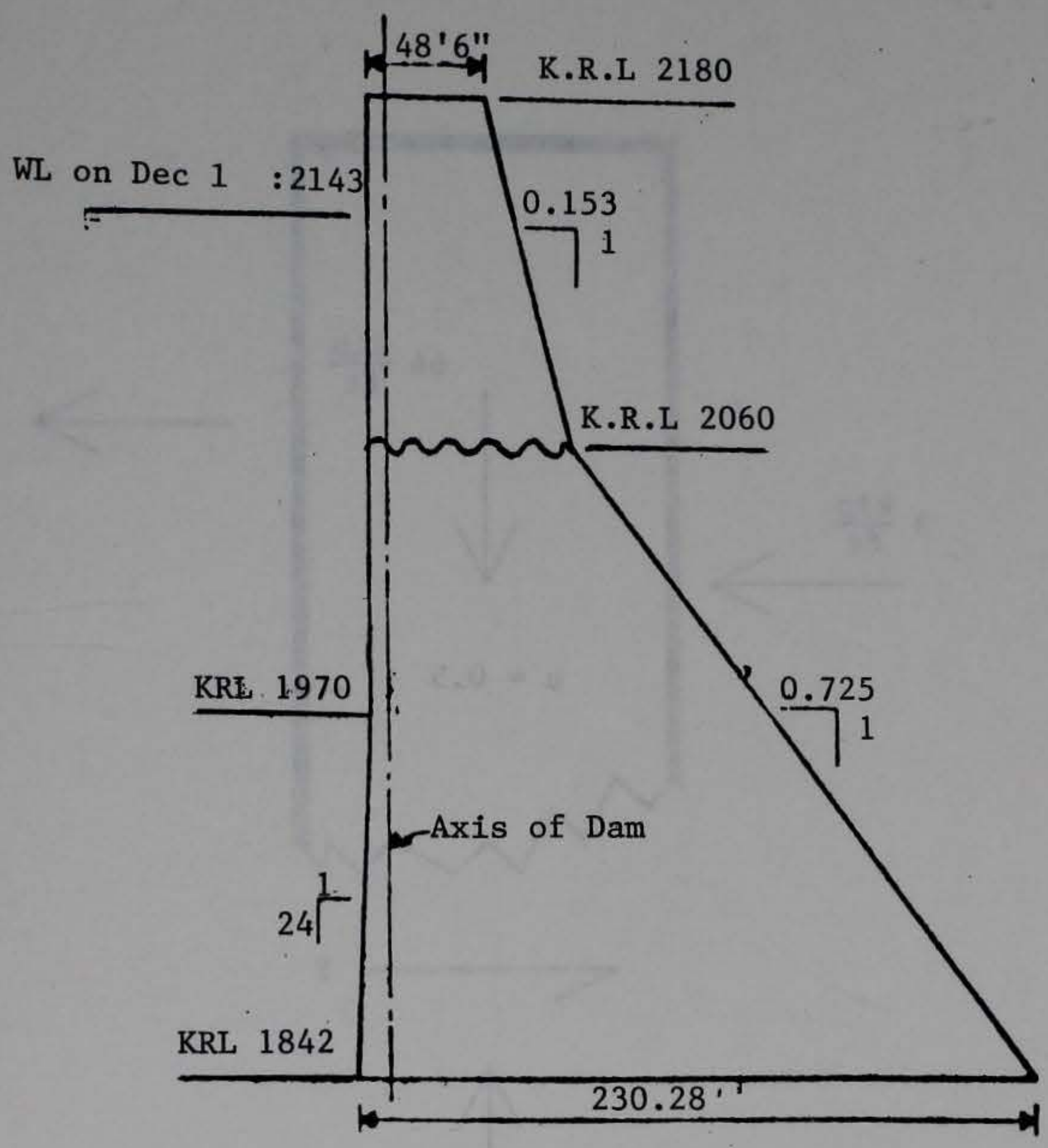

Figure 23. Cracking of Koyna Dam 


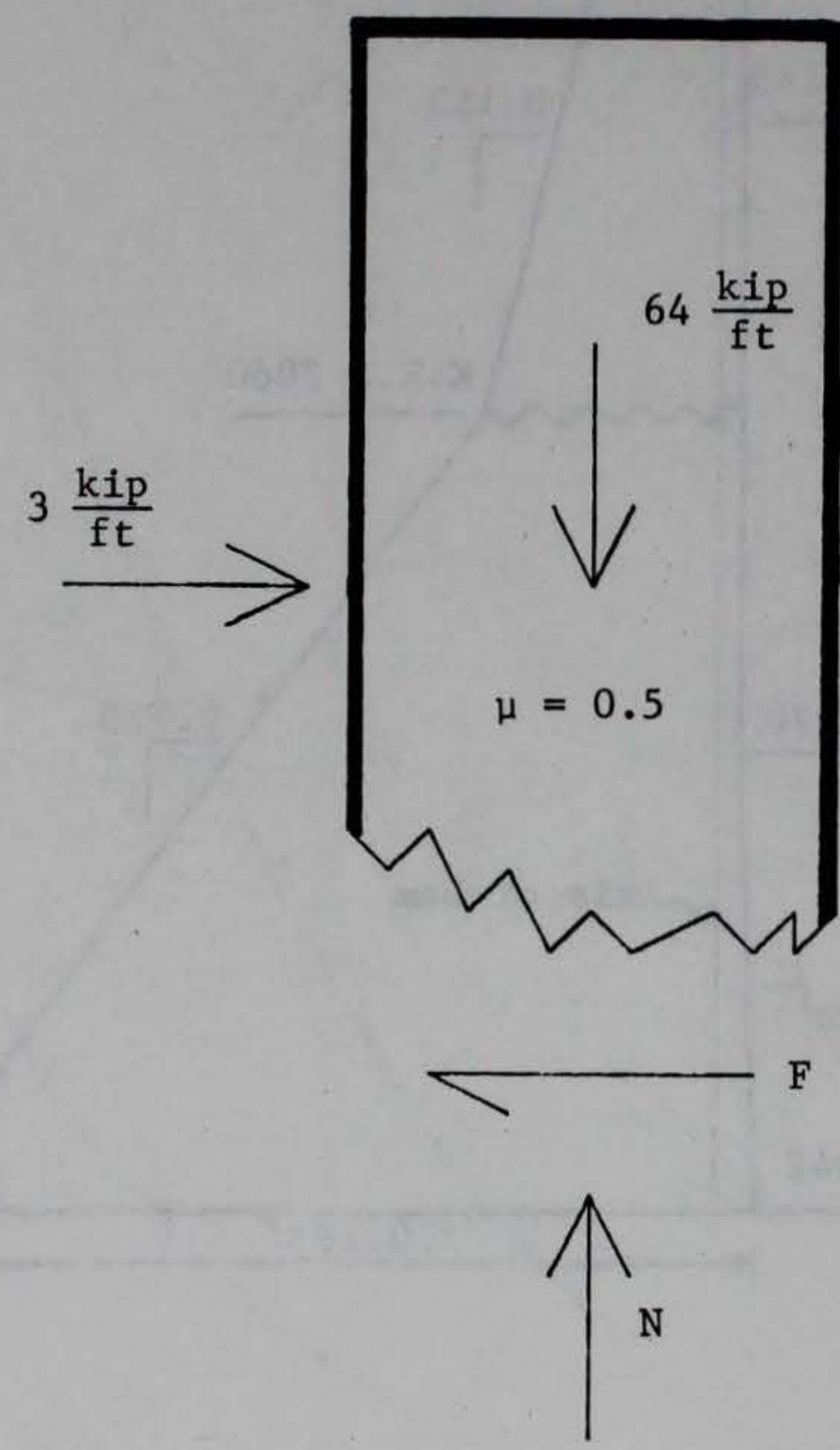

EL185

EL169

Figure 24. Cracking of Russell Dam assumed from linear analysis 